\title{
Modelo de Awareness Basado en Topologías de Interacción para Espacios Virtuales de Trabajo Colaborativo
}

\author{
Edwin Alexander Herrera Saavedra ${ }^{1,2}$ \\ 1. Programa de Maestría en Ingeniería de Sistemas de Información. Universidad Tecnológica Nacional (FRBA). Argentina. \\ 2. Laboratorio de Investigación y Desarrollo de Espacios Virtuales de Trabajo. \\ Grupo de investigación en Sistemas de Información. Universidad Nacional de Lanús. Argentina. \\ edwinalexander13@gmail.com
}

\begin{abstract}
Resumen - En un sistema de trabajo colaborativo un grupo de usuarios puede realizar actividades combinando sus capacidades y trabajo para conseguir un determinado objetivo, para esto los miembros del grupo tienen que estar al tanto sobre el estado, cambios y las acciones que otros miembros del grupo están realizando, este tipo de información se conoce como "Información Awareness". Estos procesos de colaboración han demostrado ser complejos de soportar y desarrollar. Dado esto se han creado varios tipos de awareness tratando de responder como soportar particularidades dentro de los sistemas, pero no existe un modelo general basado en la posibles formas grupales de interacción que sirva como guía en la construcción de awareness. En ese contexto esta investigación propone un modelo de awareness basado en interacciones grupales en los CSCW asociando la información de awareness adecuada para cada topología de interacción. Esto permitirá dar un mejor soporte a la información de tipo awareness en aplicaciones colaborativas.
\end{abstract}

Palabras Clave- Espacios virtuales, Trabajo colaborativo, Awareness, Modelado de interacciones.

\section{INTRODUCCIÓN}

En este apartado se presenta el contexto de la investigación (sección $A$ ), Generalidad de los problemas abiertos identificados (sección $B$ ), se mencionan los objetivos (sección $C)$. El apartado finaliza con la descripción de la estructura general de la investigación (sección $D$ ).

\section{A. Contexto de la investigación}

El área de investigación que estudia el impacto de la tecnología en las interacciones grupales con el fin de facilitar el trabajo en grupo ya sea parcial o íntegramente a través del ordenador y el desarrollo de herramientas colaborativas es el trabajo colaborativo soportado por computadoras (CSCW, Computer Supported Collaborative Work).

En un sistema de trabajo colaborativo un usuario puede realizar actividades en las que intervienen otros usuarios, de tal forma que puedan combinar sus capacidades y trabajo para conseguir un determinado objetivo. Al integrar el soporte del trabajo grupal, los sistemas de trabajo colaborativo adquieren un conjunto de dificultades que se ven reflejadas en su proceso de desarrollo. Una de estas dificultades es un aspecto llamado "conciencia" o en inglés "awareness" que es un concepto de diseño que ayuda a reducir el esfuerzo meta-comunicativa necesaria para desarrollar actividades de colaboración tratando de promover una verdadera colaboración entre los miembros del grupo [1]. Como se vera en este trabajo, la conciencia o Awareness tiene muchas interpretaciones [2] y dependiendo de ellas, un determinado grado de inclusión en el software. En algunos sistemas de trabajo colaborativo, el Awareness es manejado como la "conciencia grupal". En otro tipo de sistemas es manejado como "conciencia situacional". Dependiendo del sistema o de su objetivo se puede relacionar mas hacia un tipo u otro pero no hay una caracterización de todos los tipos de awareness que permita saber cual es el mas indicado para cada caso .

Los procesos interactivos entre humanos soportados por computadora han demostrado ser complejos de soportar y desarrollar [3]. Dado esto se han creado varios tipos de awareness tratando de responder como soportar particularidades dentro de los sistemas, pero no existe un modelo general basado en la posibles formas de interacción de los usuarios que sirva como guía y ofrezca el apoyo sistemático de su desarrollo, de esta forma los ingenieros de software tendrían un modelo base y no tendrían que empezar de cero en cada nuevo sistema, y así disminuir el esfuerzo que esto conlleva y se podría mejorar y sistematizar el desarrollo de apoyo a la información de awareness.

Cabe destacar, que si bien existen distintitas metodologías de construcción de sistemas de trabajo colaborativo, se necesita un análisis previo que sirva de guía para la construcción adecuada de estas situaciones colaborativas que contenga reglas para que no sobre cargue al usuario con información irrelevante.

\section{B. Problemas abiertos}

Dado las numerosas definiciones de tipos de awareness [2] no existe un marco de referencia que ayude a caracterizar cada uno de estas, tampoco existe un modelo general de las posibles interacciones que existen en los sistemas colaborativos que ayude aportar la información de awareness necesaria en virtud de las necesidades de cada modelo. y dado la falta de soporte al awareness en las metodologías de construcción de trabajo colaborativo de hace necesario proponer una forma de análisis que sirva de guía en las posibles situaciones colaborativas a la hora de construir este tipo de sistemas.

\section{Objetivo del trabajo}

Se ha propuesto como objetivo general de este trabajo definir un modelo de awareness basado en interacciones grupales en los CSCW utilizando los lineamientos establecidos en el Modelado de Interacciones en Espacios Virtuales Dedicados a Trabajo Colaborativo propuesto en $[4 ; 5]$ y a partir de este obtener los posibles roles y asociar la información de awareness adecuada para cada rol y topología de interacción. Esto permitirá dar un mejor soporte a la información de tipo awareness en aplicaciones colaborativas. 
Para logar el objetivo general se realizan los siguientes los objetivos específicos que se detallan a continuación:

- Realizar una taxonomía de los diferentes tipos de awareness donde se categorice cada uno de estos.

- Modelar las diferentes interacciones que ocurren en las actividades colaborativas dentro de los CSCW y realizar una generalización de los roles asociados a cada interacción.

- Generar criterios que permitan suministrar la información de awareness necesaria de acuerdo al modelo de interacción grupal.

- Realizar una guía que permita analizar las posibles situaciones colaborativas y así poder asignar un modelo de interacción a dicha situación.

\section{Estructura del trabajo}

El escrito se estructura en siete secciones: Introducción, Estado de la Cuestión, Descripción del Problema, Solución Propuesta, Casos de Validación, Conclusiones y Referencias, los cuales se describen a continuación.

En la sección Introducción (apartado I), se plantea el contexto de esta investigación, se establecen los objetivos, el objetivo general, los objetivos específicos. La sección finaliza describiendo la estructura general de este trabajo.

En la sección Estado de la Cuestión (apartado II), se presentan distintas teorías que son concurrentes con los objetivos de este trabajo. Se presentan varias definiciones del termino awareness en los sistemas de trabajo colaborativo; Se describen varios mecanismos de awareness descritos por diferentes actores; Se describen los diferentes tipos de awareness identificados en los mecanismos anteriormente descritos y Finalmente se describen algunas metodologías de análisis y diseño de sistemas colaborativos.

En la sección Descripción del Problema (apartado III), se desarrolla la problemática que intenta solucionar este trabajo a partir de las dificultades encontradas en las teorías de awareness relevadas, finalizando con las preguntas de investigación que se intentaron responder mediante esta investigación.

En la sección Solución (apartado IV), se desarrolla la solución propuesta para la problemática mencionada en la sección anterior, en la primera parte se propone una taxonomía de mecanismos de awareness. Luego de esto se presentan diferentes modalidades de interacción grupal y a partir de estas modalidades y sus ejemplos específicos se hace una propuesta de generalización de roles, luego se propone el modelo de awareness para las modalidades de interacción grupal y finalmente se realiza una guía de análisis que ayuda a relacionar las modalidades de interacción grupal con las posibles situaciones colaborativas.

En la sección Casos de Validación (apartado V), se presentan tres casos de validación pertenecientes a dominios de conocimiento con diferentes características para implementar el modelo de interacciones de awareness basado en interacciones grupales.

En la sección Conclusiones (apartado VI), se describen las conclusiones obtenidas a partir del desarrollo de esta investigación y se mencionan las aportaciones obtenidas al trabajo colaborativo mediado por computador. Asimismo, se da respuesta a los interrogantes de investigación planteados, finalizando el capítulo con las futuras líneas de investigación a desarrollar a partir de este trabajo.

En la sección Referencias (apartado VII), se enuncian las referencias bibliográficas utilizadas para esta investigación.

\section{ESTADO DE LA CUESTIÓN}

En el contexto de los sistemas de trabajo colaborativo mediado por tecnología, un grupo puede ser visto como un conjunto de individuos que interactúan directamente o por medio de artefactos compartidos y que se perciben a si mismos como un grupo. En gran parte, estas percepciones se logran a través de mecanismos de awareness, diferentes estudios han sido realizados en los sistemas de trabajo colaborativo aportando diferentes perspectivas y teorías. En este apartado se presenta el estado de la cuestión sobre distintas teorías y técnicas que son concurrentes con los objetivos de esta investigación.

A continuación se describe la estructura de este apartado. En la sección $A$ se presentan varias definiciones del termino awareness en los sistemas de trabajo colaborativo. En la sección $B$ se describen varias teorías de awareness. En la sección $C$ se describen varios tipos de awareness. En la sección $D$ se describen algunas metodologías de análisis y diseño de sistemas colaborativos.

\section{A. Definiciones de Awareness}

La RAE (Real Academia Española) proporciona varias definiciones para el término conciencia:

- Conocimiento reflexivo de las cosas.

- Actividad mental a la que solo puede tener acceso el propio sujeto.

Las definiciones de la RAE no son muy fáciles de interpretar y ciertamente no ayudan mucho a comprender lo que es la conciencia y cómo soportarla en los sistemas software. Lo que sí se puede entender a través de estas definiciones es que la conciencia es un proceso o producto mental. El diccionario de Oxford (lengua inglesa) define Awareness como "knowledge or perception of a situation or fact", lo cual, traducido al español significa ("Conocimiento o percepción de una situación o hecho.”).

El término Awareness o conciencia de grupo es más familiar para la comunidad del Groupware, ya sea por su definición más sencilla y genérica o por los trabajos sobre el Awareness en idioma inglés. En este trabajo utilizaremos principalmente el término inglés por estas mismas razones. El término Awareness ha sido definido de diversas formas, por diferentes autores pero siempre de acuerdo a necesidades específicas y en contextos muy determinados.

\section{B. Teorias de Awareness}

La información de tipo awareness ha sido empleada en diversos ámbitos con el objetivo de entregar información valiosa a los actores del sistema en diversas situaciones. A continuación se describen varios mecanismos de awareness que han sido propuestos por diferentes autores, cada uno proponiendo una teoría enfocada a un situación particular.

1) Soporte para Awareness de Espacio de trabajo en la Educación Groupware

En [6] se describe una estructura que enmarca el awareness de espacio de trabajo en un contexto de requerimientos de awareness para aprendizaje colaborativo y presenta una forma de organizar situaciones de colaboración en términos de tareas y separación de vistas, e introduce diferentes tipos de componentes que apoyan el mantenimiento del awareness en espacios de trabajo. Se describe un marco de conocimiento en el aprendizaje colaborativo con el fin de discutir los tipos de awareness que se utilizan en una experiencia de colaboración. Se explora brevemente la participación de awareness para los requisitos del diseñador de planes de estudios, profesor, 
evaluador y el alumno en una actividad de colaboración exitosa. Luego se centra en los tipos de conocimiento de los estudiantes, que incluyen: social, de tarea, de concepto y la awareness de espacio de trabajo.

- Awareness social es la conciencia que los estudiantes tienen acerca de las relaciones sociales dentro de un grupo.

- El awareness de la tarea es la conciencia de cómo una tarea será completada.

- Awareness de los conceptos es la conciencia de cómo una actividad particular es asimilada por los estudiantes.

- El awareness del espacio de trabajo es el conocimiento actualizado sobre las interacciones de los estudiantes dentro del entorno compartido, como: dónde están otros estudiantes trabajando, qué están haciendo, qué está ya completado, etc.

Las preguntas de la Tabla I, se organizan de acuerdo a los tipos de awareness descritos anteriormente.

\section{TABLA I. TIPOS DE AWARENESS}

\begin{tabular}{|l|l|}
\hline Social & $\begin{array}{l}\text { ¿Qué debo esperar de los demás miembros de este grupo? } \\
\text { ¿Cómo interactuar con este grupo? ¿Qué papel voy a tomar } \\
\text { en este grupo? ¿Qué papel va a los demás miembros de la } \\
\text { grupo asuma? }\end{array}$ \\
\hline De Tarea & $\begin{array}{l}\text { ¿Qué sé yo acerca de este tema y la estructura de la tarea? } \\
\text { ¿Qué otras personas sobre este tema y la tarea? ¿Qué } \\
\text { medidas debemos tomar para completar la tarea? ¿Cómo se } \\
\text { evaluará el resultado? ¿Qué herramientas / materiales se } \\
\text { necesitan para completar la tarea? ¿Cuánto tiempo se } \\
\text { requiere? ¿Cuánto tiempo está disponible? }\end{array}$ \\
\hline De Concepto & $\begin{array}{l}\text { ¿Cómo afecta esta tarea se ajusta a lo que ya sé sobre el } \\
\text { concepto? ¿Qué más necesito saber acerca de este tema? } \\
\text { ¿Es necesario revisar ninguna de mis ideas actuales a la luz } \\
\text { de esta nueva información? ¿Puedo crear una hipótesis de mi } \\
\text { conocimiento actual para predecir el resultado de tareas? }\end{array}$ \\
\hline Espacio de & $\begin{array}{l}\text { ¿Cuáles son los otros miembros del grupo que realizan para } \\
\text { completar la tarea? ¿Dónde están? ¿Qué están haciendo? } \\
\text { ¿Qué han hecho ya? ¿Qué van a hacer ahora? ¿Cómo puedo } \\
\text { ayudar a otros estudiantes para completar la proyectar? }\end{array}$ \\
\hline
\end{tabular}

El Awareness de espacio de trabajo también permite a los estudiantes a aprovechar las oportunidades de interacción que hacen que la colaboración de una valiosa forma de aprender. En una situación de aprendizaje de colaboración, las personas pueden aprender en un número de maneras, tales como :

- Identificar y resolver las diferencias entre ideas y teorías en conflicto.

- La enseñanza entre pares, donde asiste o instruye uno de los estudiantes otra cuando sea apropiado.

- La construcción de nuevas prácticas de significados compartidos.

Cada uno de estos mecanismos depende de los alumnos que tienen una clara comprensión de las interacciones de los demás con el espacio de trabajo. Por un alumno modelar sí, deben ser capaces de percibir los detalles de lo que otros están haciendo. Por un alumno a proponer una hipótesis que compiten en un punto en que será inmediatamente relevante, deben saber cuáles son las actividades y las intenciones de los demás son. Enseñanza entre pares es dependiente de manera similar al saber lo que otro estudiante está trabajando en y lo que ya se han tratado, y la creación de conocimiento compartido exige que un grupo entienda lo que el otro está haciendo y lo que ha hecho.

La última parte que los autores proponen, se muestra en la figura 1, donde se organizan situaciones de grupo de una manera que permite examinar los mecanismos específicos y fuentes de información que utilizan las personas para mantener el awareness de espacio de trabajo. Esta organización considera dos dimensiones de la actividad en grupo que implican la distancia entre los alumnos: Vista de separación y separación de tareas. Vista de separación es cómo de cerca los miembros del grupo comparten sus puntos de vista del espacio de trabajo. Estudiantes estarán buscando en el mismo conjunto de objetos o en diferentes objetos en un momento dado. Separación de tareas considera que tan cerca los estudiantes comparten sus actividades. Aunque se supone que van a compartir un objetivo general, los estudiantes pueden completar varias tareas de bajo nivel, como grupo o como individuos. La figura 1 muestra estas dos dimensiones de la actividad del grupo y, para cada área importante dentro del espacio, se enumeran algunas de las preguntas de sensibilización espacio de trabajo que los alumnos puedan necesitar para contestar.

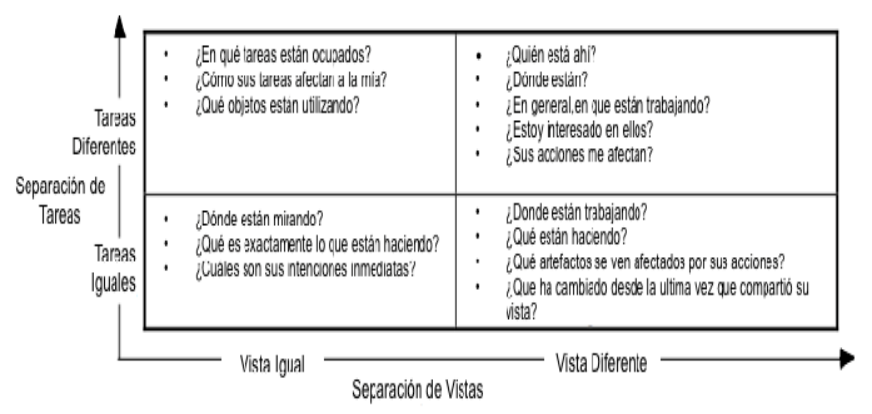

Fig. 1. Vistas y tareas de proximidad en situaciones de colaboración.

Se describen tres tipos de situaciones de aprendizaje colaborativo derivadas de la Figura 1, la mitad inferior: misma tarea y en el mismo punto de vista; misma tarea y diferentes puntos de vista, y la misma tarea con un enfoque mixto entre vistas, donde los estudiantes cambian su atención entre su persona y el trabajo compartido. Dentro de cada situación, se describen los widgets GroupKit y prototipos que apoyan el mantenimiento de la conciencia del espacio de trabajo.

- Misma tarea, mismas situaciones de vista: En algunas situaciones de aprendizaje colaborativo, los estudiantes trabajan en las mismas tareas de bajo nivel, y se centran en un pequeño conjunto de objetos comunes. Estas situaciones implican una interacción estrecha y requieren el conocimiento de la ubicación exacta y las acciones exactas de otros alumnos. Un widget de este tipo es el de múltiples cursores y un scroll-bar multi usuario.

- Misma tarea, diferentes situaciones de vista: Algunas situaciones de aprendizaje implican una acción coordinada que se produce en diferentes áreas del espacio de trabajo. Este tipo de interacción se puede ver cuando los estudiantes crean un póster o collage: los alumnos ya no están tomando decisiones en grupo acerca de cada palabra o figura en el cartel, y pueden ser trabajando en diferentes partes de la página. Sin embargo, un sentido Se necesita del awareness acerca de las actividades de los demás para coordinación de esfuerzo y para la toma de decisiones globales. Un widget para este tipo de vista es relaxed WYSIWIS.

- Misma tarea, situación enfoque mixto: Un tercer tipo de colaboración entre las situaciones de misma y diferente vista. Llaman a este tipo de interacción colaboración enfoque mixto, actividades individuales y compartidas en el espacio de trabajo se entrelazan, y los alumnos cambian periódicamente su atención de ida y vuelta entre las vistas separadas y compartidas del área de trabajo. EL widget para esta vista son los indicadores de actividad. 
2) Soporte de Awareness de Cooperación con los mecanismos de eventos locales: El sistema GroupDesk

En [7] presenta un modelo de distribución de eventos para un entorno de trabajo cooperativo basado en equipos. El modelo propuesto proporciona información sobre las actividades actuales y pasadas de los usuarios que colaboran, basados en la semántica y las relaciones contextuales de los artefactos compartidos y contribuye a aumentar el awareness sobre el actual estado de cosas sin sobrecargar al usuario con información adicional. El sistema implementa un entorno sencillo para la coordinación del trabajo distribuido y permite el apoyo del awareness compartido de los usuarios mediante la aplicación del modelo de eventos y visualización de la información del evento usando la metáfora del escritorio.

Orientación en los procesos de cooperación se basa en los eventos en estos procesos. Los autores utilizan una notación de eventos, que permite una descripción del estado de las situaciones de cooperación y es adecuado para proporcionar información para apoyar cada una de las diferentes modalidades de la conciencia, que se presentan en la tabla II. Awareness síncrono se ocupa de los eventos, que en la actualidad se están produciendo, mientras que el awareness asíncrono considera eventos que han ocurrido en algún momento en el pasado. El apoyo a este último modo necesita ser derivado por una interpretación de resumen de toda una secuencia de eventos, que se han sucedido en ese tiempo. Awareness síncrono debe ser apoyado por un reflejo inmediato de los asuntos en curso en la interfaz gráfica de usuario del sistema.

TABLA II. Modos de Awareness

\begin{tabular}{|l|l|l|}
\hline & Síncrono & Asíncrono \\
\hline Acoplado & $\begin{array}{l}\text { lo que está sucediendo en el } \\
\text { ámbito actual de trabajo? }\end{array}$ & $\begin{array}{l}\text { Lo que ha pasado en el } \\
\text { espacio actual de trabajo } \\
\text { desde el ultimo acceso }\end{array}$ \\
\hline Desacoplado & $\begin{array}{l}\text { ¿Qué sucede en la } \\
\text { actualidad en cualquier otro } \\
\text { lugar de importancia? }\end{array}$ & $\begin{array}{l}\text { Cualquier cosa de interés } \\
\text { que pasó recientemente en } \\
\text { otro lugar? }\end{array}$ \\
\hline
\end{tabular}

El modelo de un ambiente de trabajo se compone por tres entidades :

- Objetos : Las unidades básicas de información en el sistema son objetos. Artefactos de trabajo en el medio ambiente, tales como documentos, herramientas o recursos de trabajo de cualquier tipo, se modelan como objetos respectivos. Lo mismo vale para las entidades más abstractas, que componen el contexto de la organización del trabajo: grupos, departamentos, roles organizacionales y reglas son todos simplemente objetos en el sistema.

- Relaciones : Las relaciones se utilizan para colocar a los actores y artefactos-objetos en un contexto de colaboración. Las relaciones se escriben y se pueden agrupar en tres categorías básicas : las relaciones estructurales, operacionales y semánticos. Relaciones estructurales se utilizan para describir cualquier tipo de relación entre los objetos y el contexto organizacional asociado. Ejemplos de ello son todas las clases de socios de entidades y actores en contextos específicos, como los proyectos y departamentos. Relaciones operativas son siempre las relaciones entre un actor y un objeto. La semántica generales de estas relaciones es el hecho de que el actor correspondiente está actualmente involucrado en algún tipo de actividad relacionada con el objeto de destino. En un entorno de producción de documentos, por ejemplo, expresar el hecho de que un usuario está editando un documento por una relación operativa correspondiente. Relaciones semánticas se utilizan para expresar cualquier similitud semántica entre dos entidades en el sistema. Ellos son altamente dependientes de la naturaleza concreta de trabajo a realizar.

- Eventos : Se distinguen dos tipos básicos de eventos: Modificaciones y actividades. Eventos de modificación se generan por el sistema, cada vez que el estado de un objeto cambia debido a alguna acción de un usuario. Las actividades describen eventos síncronos, relacionados con los usuarios en el sistema. Su creación marca el punto de partida y su supresión el punto final de la acción correspondiente.

Los autores proponen que el usuario no debería registrar en que objetos esta interesado, el sistema debería encargarse de eso. Así que el sistema necesita ofrecer una idea de la situación de trabajo como medio para especificar el interés, de manera que cada vez que el usuario participa en una de estas situaciones, el recibe la información de awareness que necesita.

Las situaciones de trabajo forman una metáfora adecuada para que el usuario especifique su interés en eventos. El interés en los eventos para este tipo de situaciones se define por los contextos de interés, que consisten en un conjunto de tipos de relación, un conjunto de tipos de eventos y una lista de los usuarios interesados que se han suscrito al contexto. Para cualquier clase de objeto dado en el sistema, el usuario puede definir y/o suscribirse a un contexto de interés. La semántica de un contexto de interés es, que el sistema mantiene los eventos del tipo indicado planteada por un objeto de esta clase en los alrededores del objeto. El entorno definen una situación de trabajo y consisten en todos los objetos, que están vinculados al objeto original por las relaciones de los tipos enumerados en la descripción del contexto. Un ejemplo de un contexto de interés para un documento que implica el evento "documento modificado", se muestra en la figura 2.

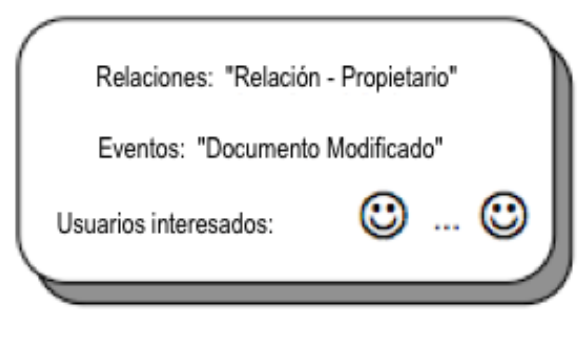

Fig. 2. Contexto de Interés.

cuando un evento es producido por un objeto, En primer lugar, el sistema comprueba si hay contextos coincidentes de interés definidos para la clase de objeto correspondiente, es decir que tienen el tipo de evento recién creado que figuran en su descripción de eventos. Por todos estos contextos, el sistema extrae los tipos de relación y reenvía el evento para todos los objetos en el entorno del objeto original, que están interconectadas por una de las relaciones en esta lista, como se muestra en la figura 3.

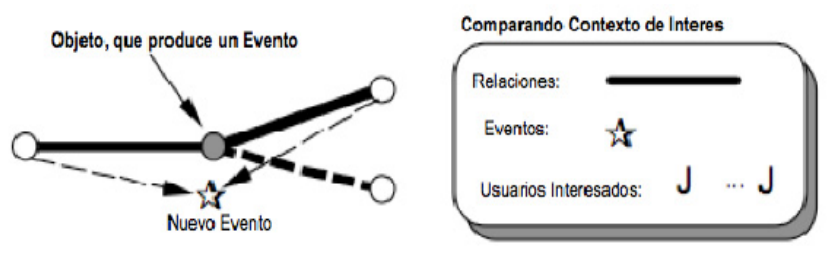

Fig. 3. Distribución de Eventos. 
La implementación de awareness en el sistema groupdesk se realiza utilizando el modelo anterior de la siguiente forma: cada vez que un usuario entra en un espacio de trabajo, el sistema agrega una relación operativa entre el objeto actor y el objeto del área de trabajo. Además se genera un evento de actividad, que describe esta acción. El evento contiene la fecha y una referencia al actor, que ha entrado en el espacio de trabajo. Posteriormente todos los eventos, que han ocurrido en el área de trabajo desde la ultima vez que el usuario ingreso, se reenvían al objeto actor y el usuario puede ver inmediatamente lo que ha cambiado. El sistema envía los eventos de modificación, que han sucedido en el pasado y las actividades actualmente en curso de otros usuarios en el área de trabajo para el nuevo usuario. Los usuarios también pueden solicitar información acerca de las actividades que ya se encuentran terminadas. Esto ayuda a mantener la cantidad de información de eventos mínima y concentrarse en el estado actual de los trabajos.

Las actividades de trabajo genéricos incluyen cualquier tipo de acción que el usuario realiza en un artefacto que no sea de espacios de trabajo. Actualmente se trata de la edición de un documento o abrir una carpeta. En ambos casos, el sistema establece una relación entre el actor y el objeto correspondiente y presenta la información del evento relacionado con el objeto. Entre los tipos de modificaciones, GroupDesk ha implementado actualizaciones de objetos, que se generan cada vez que el contenido de un documento, carpeta o espacio de trabajo cambia, creación, eliminación y el movimiento de objetos. Para cada modificación, el sistema genera un nuevo objeto de evento y la almacena en una lista de eventos específicos objeto.

La visualización de estos es eventos se realiza por medio de diferentes colores en los iconos de los objetos, para las actividades que están sucediendo actualmente por líneas de conexión de color que unen el icono del actor, quien actualmente está llevando a cabo la actividad, con el icono del objeto, que está implicado en la actividad.

3) Un marco descriptivo de Awareness de espacio para Groupware en tiempo real

En [8] se presenta un marco de trabajo orientado a grupos pequeños en áreas de trabajo de tamaño medio, donde es mas probable que los participantes estén interesados en mantener awareness con todos los miembros del grupo, El marco describe tres aspectos de awareness en espacios de trabajo: los elementos que lo componen, los mecanismos utilizados para sus mantenimiento y sus usos en la colaboración. La estructura del marco de trabajo puede ser usada para describir otros tipos de awareness que afectan el trabajo en grupo de forma distribuida. El ciclo de percepción-acción es un modelo general que puede ser usado para explicar como las personas realizan seguimiento de una amplia variedad de información en una situación de colaboración.

Los elementos que awareness del espacio de trabajo responde son quién, dónde, cuándo, cómo y qué. Se refieren a cuestiones como quién está presente y quién es responsable de las acciones, donde la gente está trabajando y donde pueden ver, y las acciones que se están realizando y cuáles son sus intenciones. Otros elementos del espacio de trabajo de awareness considera el conocimiento de la historia y los acontecimientos pasados. Los elementos son un punto de partida para pensar acerca de los requisitos de awareness en situaciones de trabajo particulares, y proporcionan un vocabulario para describir y comparar el soporte de awareness en aplicaciones de trabajo en grupo. El papel del marco del proceso de diseño de trabajo en grupo no es como una guía de diseño prescriptivo, sino más bien como una colección estructurada de conocimiento que puede ayudar al desarrollo iterativo de ayuda de la conciencia. El marco de trabajo se muestra en la figura 4.

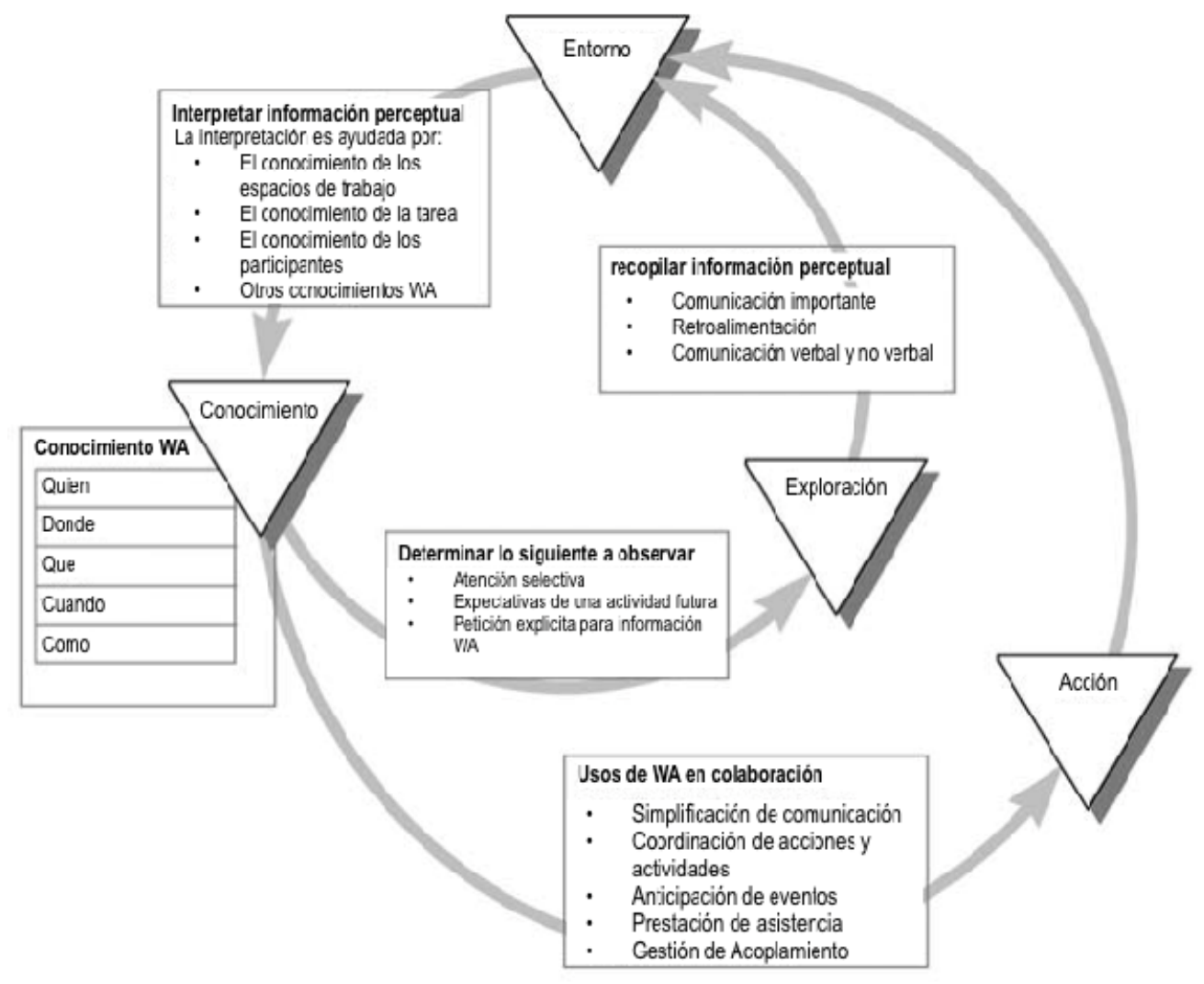

Fig. 4. Marco de Trabajo para Awareness de Espacio de Trabajo. 
Esta parte del marco ofrece a los diseñadores una idea básica de lo que la información de capturar y distribuir en un sistema de trabajo en grupo. El conjunto básico de elementos que responden "quién, qué, dónde, cuándo y cómo". Es decir, cuando trabajamos con otros en un espacio compartido físico, sabemos que estamos trabajando, lo que están haciendo, dónde están trabajando, cuando varios eventos ocurren, y cómo ocurren esos eventos. Las personas no pierden de vista estas cosas en todo tipo de trabajo de colaboración, y estos son los tipos de información que deben ser considerados en primer lugar por los diseñadores.

Dentro de estas categorías básicas, se han identificado elementos específicos de conocimiento que conforman el núcleo de la conciencia del espacio de trabajo.

Figuras 5 y 6 muestran estos elementos y la lista de las preguntas que cada elemento puede contestar. La Figura 5 contiene los elementos que se relacionan con el presente, y en la Figura 6 contiene las relacionadas con el pasado.

\begin{tabular}{cll}
\hline Categoria & Elemento & \multicolumn{1}{c}{ Preguntas Especificas } \\
\hline Quien & $\begin{array}{l}\text { Presencia } \\
\text { Identidad }\end{array}$ & Hay alguien en el espacio de trabajo? \\
& Quien esta participando? Quien es? & Que esta haciendo eso? \\
\multirow{2}{*}{ Que } & Acción & Qué están haciendo? \\
& Intención & Que objetivo es parte de la acción? \\
& Artefacto & Que objeto están trabajando? \\
Donde & Ubicación & Donde están trabajando? \\
& Observación & Donde están observando? \\
& Visión & Donde pueden ver? \\
& Alcance & Donde pueden llegar? \\
\hline
\end{tabular}

Fig. 5. Elementos de Awareness de Espacios de trabajo relacionados con el presente.

\begin{tabular}{lll}
\hline Categoria & Elemento & Preguntas Especificas \\
\hline Como & Historial de acciones & Como ocurrio esa operación? \\
& Historial de artefacto & Como este artefacto, llega a este estado? \\
Cuando & Historial de eventos & Cuando ocurrió este evento? \\
Como (pasado) & Historial de presencia Quien estuvo aquí y cuando? \\
Donde (pasado) & Historial de ubicación Donde ha estado esta persona? \\
Que (pasado) & Historial de acciones & Que ha estado haciendo? \\
\hline
\end{tabular}

Fig. 6. Elementos de Awareness de Espacios de trabajo relacionados con el pasado.

\section{4) Introducción de Awareness de Conocimiento - Compartido}

En [9] se presenta un tipo de awareness llamado SKA (Shared Knowledge Awareness) para aumentar y mantener el conocimiento compartido en un grupo. Este tipo de awareness puede ser proporcionado de forma grafica representado en el indicador de conocimiento compartido (SKI), que estima el conocimiento compartido a través de acciones y mensajes de los miembros del grupo. Los autores citados creen que el SKA puede tener un impacto positivo en las actividades meta cognitivas ayudando en la construcción y mantenimiento de los conocimientos compartidos. El mecanismo que da soporte a este tipo de awareness es construido con un agente inteligente y dos módulos analizadores.

Por lo general, el conocimiento se transmite a través de mensajes entre los miembros del grupo (ver Figura 7) y el conocimiento compartido es el producto de esta interacción.

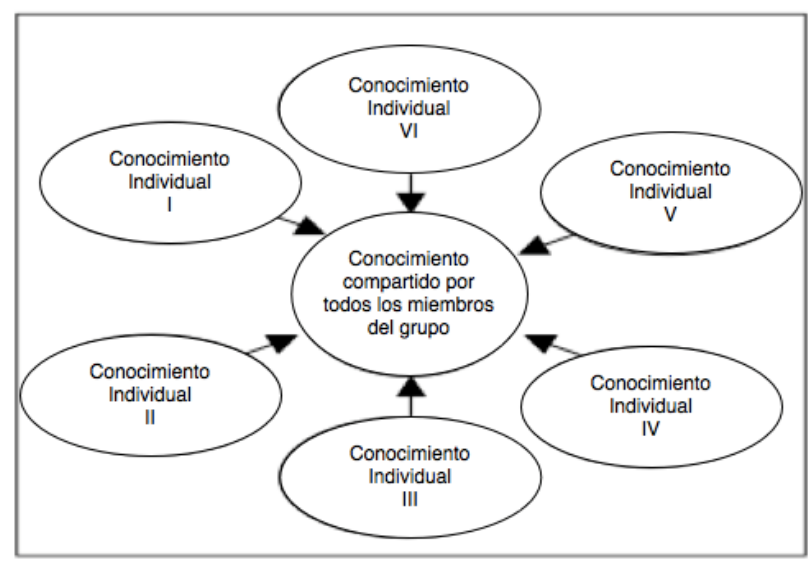

Fig. 7. Construcción de Conocimiento Compartido.

Si un estudiante es consciente del conocimiento propio y el de su compañero de equipo, puede tomar decisiones estratégicas bien fundadas. Estas decisiones estratégicas son del tipo meta cognitivo cuando se explicitan y se comunicarán a los miembros del equipo con el fin de razonar sobre las acciones pasadas o futuras. Tal razonamiento es precisamente lo requiere la negociación que participan cuando los estudiantes quieren llegar a un acuerdo sobre las decisiones. La Figura 8 muestra cómo el awareness (conocimiento compartido, de tarea, de concepto y espacio de trabajo) podrían promover una interdependencia positiva.

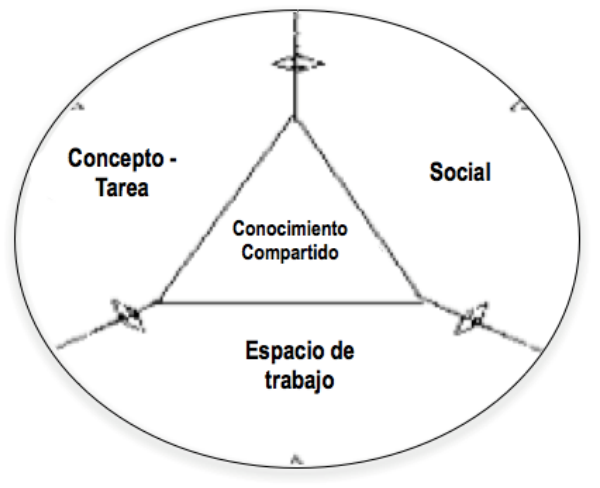

Fig. 8. Awareness en CSCL.

Si la gente es consciente de lo que está sucediendo alrededor de ellos a través de tareas, área de trabajo, conceptual, social y compartir el conocimiento, es posible promover la interacción entre los miembros del grupo. Este aumento en las interacciones podría desencadenar mecanismos de aprendizaje.

La implementación de un mecanismo SKA se realiza analizando dos elementos que representan el conocimiento compartido, las acciones que los miembros del grupo llevan a cabo durante el trabajo colaborativo y los mensajes intercambiados entre ellos. Los mensajes pueden transportar el conocimiento que se comparte entre los miembros del grupo. Las acciones muestran si se entiende el conocimiento transmitido. Sólo el conocimiento que se transmite y se entiende podría convertirse en parte del conocimientocompartido grupo. La propuesta para este mecanismo se muestra en la figura 9. 


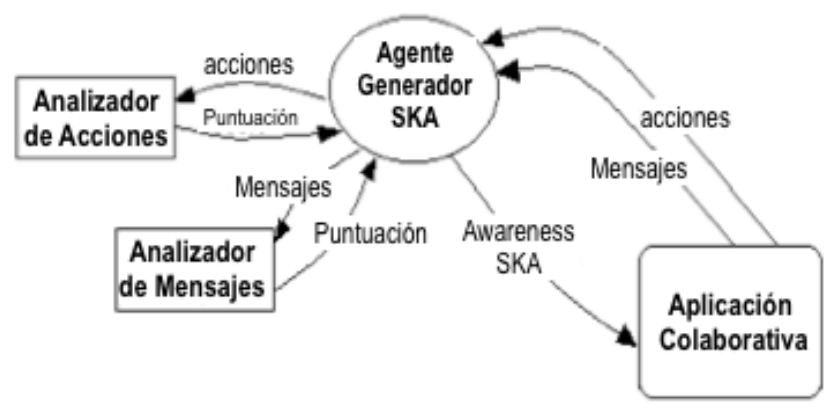

Fig. 9. Mecanismo SKA.

El mecanismo usa Agente Generador SKA. Captura el conocimiento compartido de los mensajes y las acciones a través de un indicador llamado SKI (Indicador de Conocimiento Compartido). Basándose en el valor de este indicador, el agente produce el awareness que se puede mostrar en la interfaz de usuario de la aplicación de colaboración. El agente utiliza dos módulos auxiliares llamados Analizador de acciones y Analizador de mensajes para llevar a cabo estas tareas. El módulo de analizador de acciones se encarga de estudiar las acciones de grupo y clasificarlos en una de estas categorías: éxito, no tiene éxito, o neutral. Entonces, este módulo genera una puntuación basada en las acciones relativamente exitosas (RSA). Este resultado representa el conocimiento compartido utilizado por los estudiantes para llevar a cabo sus acciones. Por otro lado, el módulo de analizador de mensajes debe estudiar los mensajes de grupo. El Analizador de mensajes utiliza las categorías de (coordinación, trabajo, estrategia, social y otros) para generar una puntuación basada en la cantidad relativa de Conocimiento Compartido en Mensajes (RSKM). Este resultado representa el conocimiento compartido que se transmite en los mensajes. Por último, con las dos puntuaciones (RSA y RSKM) es posible calcular el valor de la SKI (Compartido Indicador Conocimiento). El valor de SKI se proporciona como awareness gráfico sobre la interfaz de usuario de la aplicación de colaboración. Si SKI está entre 0 y 0,4 , entonces el conocimiento compartido se considera pobre. La representación gráfica de SKI presente en la interfaz de usuario se muestra en la Figura 10(a). Si SKI está entre 0,41 y 0,6 , entonces el conocimiento compartido se considera justo y el SKA se muestra como en la figura 10(b). Por último, si SKI está entre 0,61 y 1 , entonces el conocimiento compartido se considera alta y el SKA se muestra es la figura $10(c)$.

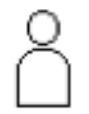

(a)

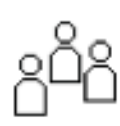

(b)

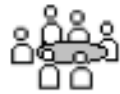

(c)
Fig. 10. Interfaz Grafica SKA.

5) Notificación y Awareness: Sincronizando la Actividad Colaborativa Orientada a las Tareas.

En [10] se sugieren estrategias de diseño para sistemas de notificación que den un mejor apoyo a actividades colaborativas con el Awareness de actividad en el cual se hace hincapié en la importancia de los factores contextuales de la actividad como la planificación y la coordinación. Se ha desarrollado un enfoque alternativo en el cual la gestión de datos de actividades da apoyo en el awareness de actividad, proveyendo líneas de tiempo para la visualización de datos y el acceso a los datos. Los elementos comunes de coordinación (plazos limite, las comunicaciones y las versiones del documento) son omnipresentes en todos los mecanismos de notificación. La colocación de estos elementos en líneas de tiempo proporciona un resumen significativo del progreso del proyecto.

La evaluación de awareness y de las notificaciones en el software de la "Escuela Virtual" en el cual los autores basan su investigación, y el desarrollo del concepto de awareness de actividad como justificación de los cambios de diseño sugieren estrategias más amplias para los sistemas de notificación. En el nivel más general, el enfoque que están persiguiendo tiene dos principios: Primero, están tratando de integrar las notificaciones y el control de los objetos de trabajo en toda la interfaz. Este enfoque contrasta con la estrategia de la colocación de las notificaciones en la periferia de la interfaz. En segundo lugar, están tratando de aprovechar altamente la organización, coordinación de los recursos comunes y la interacción. En este trabajo, se centrado en la construcción de líneas de tiempo.

Han incluido dos tipos de líneas de tiempo activas, cada uno sirviendo como una visualización de datos y un mecanismo de acceso a datos. La línea de tiempo orientado al grupo hace hincapié en la densidad general de la actividad reciente del trabajo con respecto a los grupos y subgrupos; la línea de tiempo orientada a documentos enfatiza patrones más detallados de la actividad a nivel de revisiones y comunicación de documentos específicos. Las líneas de tiempo están activas, y se actualiza cuando los artefactos del proyecto se modifican y los miembros del grupo se comunican.

Las representaciones de línea de tiempo proporcionan una visión integrada del futuro (cuando las cosas se deben hacer), el presente (el estado actual de los artefactos del proyecto de los grupos) y el pasado (lo que se ha completado).

Han desarrollado un enfoque alternativo en el que la gestión genérica de datos apoya incidentalmente el awareness de actividad. Líneas de tiempo en directo proporcionan la visualización de datos y acceso a datos en el contexto de los plazos que destaca ya sea la actividad grupal o patrones de la actividad dentro de un conjunto de documentos. Elementos de coordinación comunes (plazos de entrega, las comunicaciones y las versiones de documentos) son omnipresentes a través de múltiples mecanismos de notificación. Colocación de estos elementos dentro de vistas de línea de tiempo proporciona un resumen significativo del avance del proyecto; es decir, los tiempos de los plazos de entrega, la comunicación y las versiones de los documentos; las posiciones relativas de los objetos en la línea de tiempo con respecto a los otros, y el historial de cambio de los artefactos del proyecto.

6) Modelo de awareness en el CSCL ALLEGRO utilizando la arquitectura blackboard.

En [11] se propone un ambiente multi-agente de enseñanza/aprendizaje (ALLEGRO) en el cual se describen actividades colaborativas, awareness para este ambiente y una arquitectura blackboard. El modelo de awareness propuesto permite promover la concientización, comunicación, colaboración y coordinación en el ambiente de aprendizaje colaborativo mediado por tecnología (Computer Suported Colaborative Learning - CSCL). Este modelo permite a los aprendices tener una percepción de lo que los demás hacen dentro del CSCL con el propósito que evalúen que les sirve para su entorno y actividades de trabajo. Además el awareness del CSCL permite al aprendiz tomar un papel activo en su proceso formativo a través de actividades que le permiten exponer e intercambiar ideas y opiniones con los demás integrantes, convirtiendo de esta forma el aula virtual en un 
foro abierto a la reflexión y al contraste critico de pareceres y opiniones.

La Arquitectura del ambiente de enseñanza/aprendizaje esta conformada por dos tipos de agentes (software y humanos).

Agentes de software: Son agentes informáticos encargados de realizar labores para su dueño dentro de la arquitectura, en este caso tareas de tipo pedagógico, las cuales son su componente cognitivo, así como mostrar un comportamiento determinado. Se presentan seis tipos: tutor, modelo de aprendiz, interfaz, diagnostico, experto, colaborativo.

Agentes Humanos: Estos agentes pueden comunicarse entre sí para buscar una meta común mediante la división de tareas, o para lograr un objetivo compartiéndolas. Para comunicarse con los otros agentes humanos (FC) al mismo tiempo, puede utilizar varios canales como chat, conferencia, videoconferencia, editores multiusuarios $y$ las pizarras compartidas, en este caso esta valiéndose de los servicios de comunicación sincrónica, sin importar el lugar donde se encuentre cada una de las FC. Cuando usa los servicios de comunicación asincrónica puede consultar, publicar y modificar el contenido del tablero con sus aportes, tratando de dar una solución colaborativa a los problemas propuestos. Estos aportes pueden ser debatidos por las demás FC de la sesión de aprendizaje.

También se pueden comunicar directamente con las otras FC sin importar factores como el tiempo y el lugar, a través del correo electrónico, el envío y recepción de archivos y la participación en grupos de interés. Los agentes humanos son : Aprendiz, Asistente de docencia, Docente.

La tarea del awareness es llevada a cabo por el agente colaborativo y los agentes humanos (Figura 11). De acuerdo a la clasificación propuesta por [12] el CSCL de ALLEGRO emplea tres tipos de interacción: cara a cara, sincrónica y asíncrona distribuida. Según su objetivo principal se centra en el individuo, el documento y el proceso; de acuerdo al espectro de trabajo colaborativo, se ubica en los sistemas de alto nivel.
La metodología de awareness utilizada en este sistema empieza cuando selecciona los asistentes de docencia de cada una de las sesiones de aprendizaje, Para cada sesión, se elabora una programación a manera de agenda de trabajo, la cual es construida por el asistente de docencia y el docente. Esta agenda es publicada dentro del tablero (memoria global) para que todos los agentes humanos la puedan visualizar. Cada uno de los problemas se sitúa en un nivel de complejidad diferente y tienen la característica de propiciar la interacción social, la discusión y la colaboración. Los aprendices observan los problemas propuestos para cada una de las sesiones, y de acuerdo con sus conocimientos tratan de darles solución publicando aportes en el tablero. Cuando lo anterior sucede, es decir, cuando se publica un nuevo aporte, el sistema se encarga de enviar un mensaje vía correo electrónico indicando que se ha expuesto una nueva contribución, si el aprendiz no se encuentra conectado. Cuando sí lo está, (en línea) aparece el mensaje en la parte inferior derecha de su pantalla. El objetivo es permitir que los aprendices tengan una percepción de lo que hacen los demás para que incluyan este referente dentro de su propio trabajo.

Los aprendices (FC) se pueden comunicar entre sí utilizando los servicios de comunicación tanto en forma sincrónica como asincrónica.

La función del agente colaboración es la de buscar otros aprendices que están trabajando la misma BUL (sincrónica y/o asincrónicamente) para sugerirle a un aprendiz determinado establecer comunicación con ellos.

El docente observa constantemente los aportes publicados en el tablero dándose cuenta de la calidad de estos y del nivel de avance de los aprendices, brindando mecanismos de awareness a los demás integrantes el grupo. Así mismo, da recomendaciones individuales a cada uno de los aprendices y en grupo.

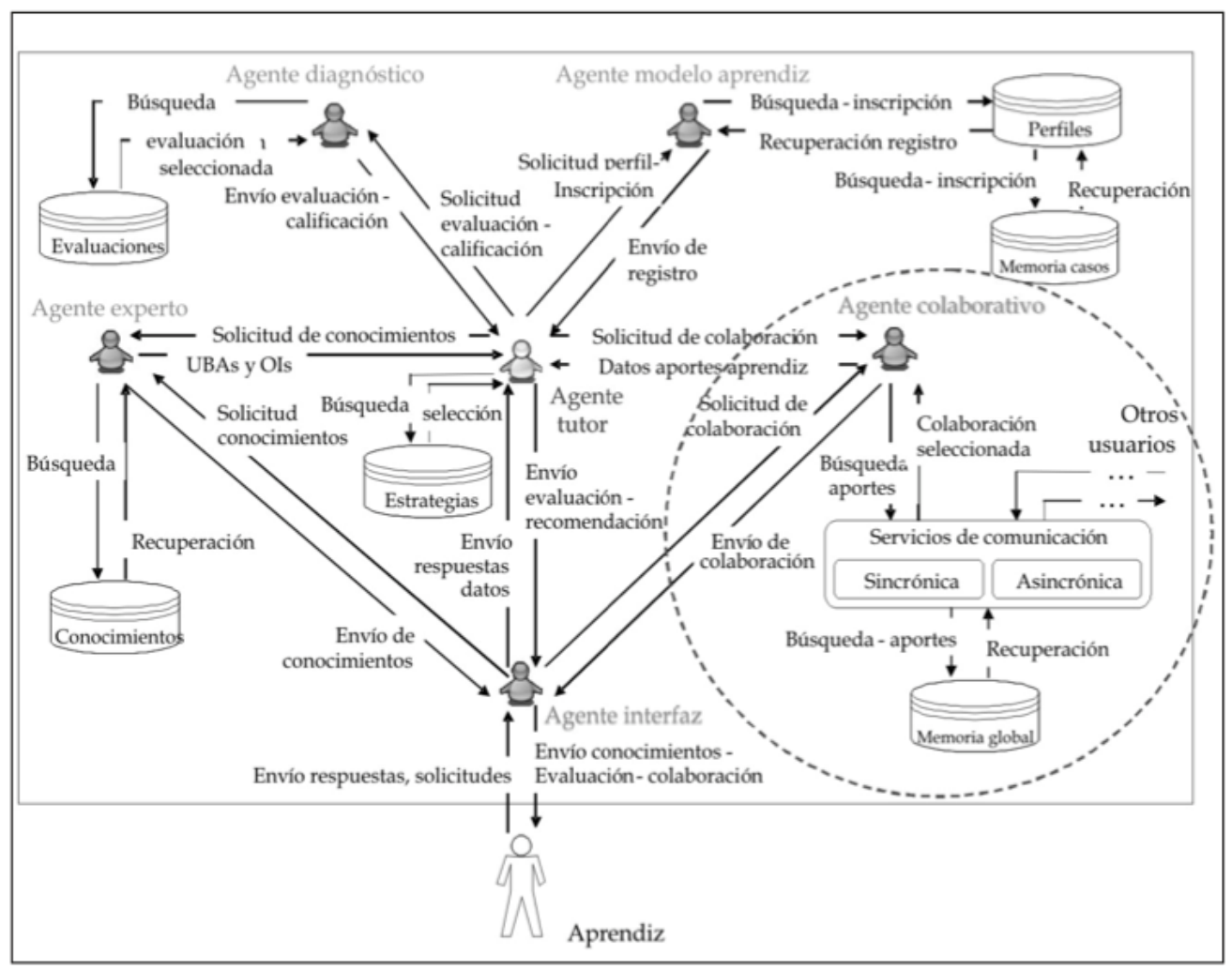

Fig. 11. Implementación del modelo de awareness en el CSCL de la arquitectura multiagente de ALLEGRO 


\section{Tipos de Awareness}

En los estudios descritos en la sección anterior se pueden ver varias definiciones que están ligadas a formas o tipos de Awareness específicos y comúnmente encontrados en la literatura. Estos tipos de Awareness serán presentados y detallados en esta sección, mostramos un análisis de los aspectos más relevantes sobre el Awareness y su relación con los sistemas de trabajo colaborativo.

\section{1) Awareness de Situación}

El Awareness de Situación o Situation Awareness (SA) ha sido descrito ampliamente por Mica R. Endsley en su Teoría del Situation Awareness para sistemas dinámicos y complejos [13]. En este trabajo se analiza todo lo que respecta al Situation Awareness, desde los aspectos más básicos basados en las teorías de la psique humana, hasta su efecto determinante en el proceso de toma de decisiones en entornos dinámicos, complejos y en varios casos, de supervivencia. La principal motivación de este estudio fue el diseño de vehículos militares y la relación existente entre la información actualizada del entorno necesaria para los pilotos y la capacidad de procesarla para cumplir sus objetivos.

Ya que la supervivencia de los pilotos depende de sus capacidades para tomar decisiones de forma rápida y efectiva en entornos cambiantes, la implicación del Situation Awareness como estado de conocimiento para este propósito es innegable.

Podemos decir que el Situation Awareness es el Awareness más genérico de todos los descritos. El Awareness de Situación es la base de todos los tipos de Awareness existentes, ya que el término "Situation" puede utilizarse para describir cualquier cosa, desde la presencia, la localización, hasta los conceptos más abstractos como el contexto, el conocimiento compartido, la creatividad, etc.

El Awareness de Situación es "la percepción de los elementos del entorno en un volumen de tiempo y espacio, la comprensión de su significado y la proyección de su estado en un futuro cercano" [13].

Cada situación de importancia para la toma de decisiones es definida en base a los elementos del entorno, los cuales pueden ser cualquier atributo o característica perceptible del entorno, dependiendo de los objetivos del humano o agente que los percibe y utiliza.

Para la formación del Awareness, la percepción está siempre ligada al tiempo, por lo cual el Awareness representa un estado de conocimiento alimentado por la constante percepción de datos del entorno. Además, a través de procesos de inferencia, deducción o lógica, el observador puede formar una comprensión de los valores de los elementos en su conjunto, aumentando con ello su nivel de conciencia o Awareness. Este nivel de comprensión no va más allá de una sola observación o conjunto de valores percibidos. Es decir, si en una observación se obtiene un conjunto de valores de determinados elementos del entorno, el nivel de comprensión le permite al observador crear nuevo conocimiento a partir de los valores percibidos.

Como ultimo Nivel de conciencia de como Estado de Conciencia encontramos la proyección de los valores de los elementos en un futuro cercano. Esto! Responde a la pregunta $i$ Que Valores tendrán Los Elementos en El Tiempo, X (el Cual no está en el Futuro ) ?.

Este tipo de Awareness fue el primero formalmente descrito mediante un marco teórico completo y generalizado para poder ser aplicado a cualquier situación.
Aunque al principio no se le relacionó con otros tipos de Awareness de importancia, es la base estructural y conceptual de todos ellos. Por tanto, todos los Tipos de Awareness pueden construirse como una especialización del Situation Awareness, aunque [14] afirme que el Activity Awareness se incluye dentro de su definición al Situation Awareness. Esto puede ser si el Activity Awareness no se trata como un tipo de Awareness, sino como un conjunto de componentes cognitivos en los cuales está incluido el Awareness, lo cual parece ser cierto en base a la extensa descripción del Activity Awareness proporcionada por John Carroll.

En la Figura 12 se muestran los componentes del Awareness de Situación divididos en niveles. Primeramente, la percepción de los elementos en la situación actual. Después, la comprensión de la situación, es decir, de los elementos en conjunto. Finalmente la proyección del estado futuro de la situación, la cual estará representada por los elementos percibidos.

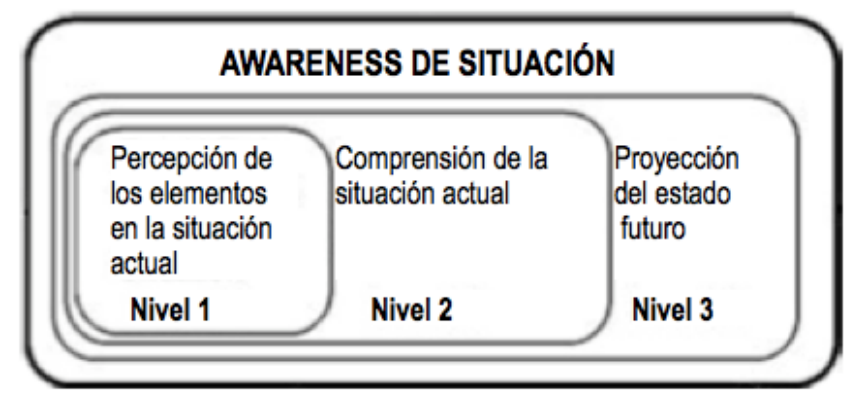

Fig. 12. Componentes del Awareness de Situación. Percepción Comprensión y Proyección.

La descripción del Awareness de Situación muestra varios aspectos clave en lo que respecta al Awareness: Percepción, Comprensión y Proyección.

La percepción implica el uso de los medios sensoriales del que requiere el Awareness, como puede ser un ser humano que usa sus sentidos o un robot que utiliza sus sensores para percibir el mundo que lo rodea. El Awareness empieza y vive por la percepción, es decir, por la percepción constante. Si una persona tapa sus ojos al caminar, no podrá ver el camino, por lo tanto pierde conciencia de su entorno exterior captado por la vista. La comprensión implica un proceso inteligente. Se refiere a la creación de nuevo conocimiento a partir del ya existente. Por ejemplo, si uno va en el coche y detecta ruidos raros en el motor, se sabe que la situación no está bien. Lo que percibe el conductor no le da esa información directamente, sino que la utiliza y la procesa con todo su conocimiento previo, lo cual le brinda información de más alto nivel y probablemente le permita tomar mejores decisiones.

La proyección del estado de la situación es la capacidad de aproximar los valores de los elementos que definen la situación en un futuro. Esta capacidad depende de varios factores como la experiencia y las técnicas utilizadas para calcular dichos valores. Por ejemplo, para calcular las predicciones del estado del tiempo (clima) se utilizan superordenadores y gran cantidad de información real y antigua. Sin embargo, para calcular el tiempo de llegada a un lugar a velocidad constante, una fórmula física básica es suficiente.

El proceso de toma de decisiones: En la Figura 13 se muestra el diagrama del proceso de ejecución de tareas en entornos dinámicos empezando con el análisis del estado actual del entorno hasta la ejecución de la propia tarea. En este proceso interviene el Situation Awareness previo a la toma de decisiones. ¿A qué se debe esto? A que la decisión depende del estado actual del entorno. 




Fig. 13. Diagrama del Awareness de Situación y de su papel en el proceso de toma de decisiones para la ejecución de tareas, además de los factores que intervienen en su adquisición .

Como se muestra en la Figura 13, una serie de factores afectan al proceso de toma de decisiones y a la propia adquisición del Awareness de Situación. Están los factores humanos, los factores del sistema y los factores de la tarea a desarrollar.

Factores humanos: el ciclo de ejecución/Awareness alimenta constantemente el conocimiento que se tiene del entorno $\mathrm{y}$ varios patrones del comportamiento pueden detectarse. Esto es lo que comúnmente se llama experiencia.

La experiencia permite relacionar los distintos elementos que componen "la situación" de interés y generar nuevo conocimiento a partir de ellas, así como aproximar los valores de dichos elementos en un futuro cercano. Sin embargo, la experiencia no sustituye al conocimiento actualizado de la situación, es decir, el Situation Awareness. Los dos aspectos son complementarios y aunque la experiencia puede ser muy buena, la situación puede tomar rutas inesperadas y requerir decisiones diferentes a las tomadas comúnmente.

El problema de basarse demasiado en la experiencia y dejar de lado el Awareness de la Situación se conoce como Automatización.

La automatización está fuertemente asociada a la memoria a largo plazo, en la cual se guarda el conocimiento y los patrones de comportamiento del entorno. La memoria a corto plazo, por otra parte, es también llamada memoria de trabajo y permite guardar y manipular temporalmente la información captada por los sentidos. La capacidad de la memoria de trabajo puede elevarse a través del entrenamiento, no obstante, está condicionada por el estrés y la sobrecarga cognitiva derivadas de la complejidad y dinamismo del entorno.
Factores del sistema: un sistema informático o electrónico puede servir de intermediario entre el usuario o agente que utilizan Awareness de Situación y el propio entorno en el que se van a ejecutar las acciones. Esto puede ser un sistema computacional o el panel de control de un vehículo o nave.

El diseño de esos sistemas es un área de gran importancia para incrementar y mejorar el Situation Awareness, a la vez que se busca reducir la carga cognitiva y la complejidad del entorno a través de mejores mecanismos de abstracción y transmisión de información [15].

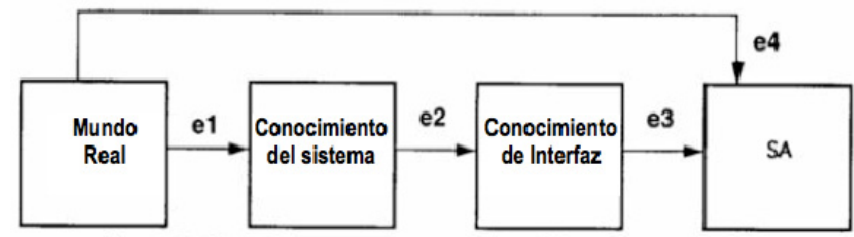

Fig. 14. Flujo de información de Awareness de Situación: Mundo Real $\rightarrow$ Conocimiento del Sistema $\rightarrow$ Conocimiento de la Interfaz $\rightarrow$ Awareness de la Situación.

En la Figura 14 se muestra un diagrama de las entradas de información que recibe un individuo para obtener un determinado Awareness de Situación cuando se utiliza un sistema intermediario entre el entorno y él mismo. La información va desde el mundo real, pasando por el sistema y por la interfaz de usuario hasta llegar al usuario. Esta serie de pasos representa el camino en el cual la información del mundo real puede perderse, malinterpretarse o unirse a otra que resulte innecesaria, por lo cual el diseño del sistema y de las interfaces 
de usuario forma otro eslabón en lo que es el soporte del Awareness de Situación.

Factores de la tarea: la tarea ofrece sus propias dificultades al Situation Awareness, como son la complejidad inherente de cada tarea, los objetivos que se busca conseguir y las precondiciones y predisposiciones unidas a la ejecución de la tarea.

Entornos de uso y su papel en la colaboración: la investigación sobre el Awareness de Situación está orientada principalmente a los entornos altamente dinámicos y complejos, como son los entornos bélicos y de gestión de emergencias. Además de ello, el SA forma parte del proceso de toma y decisiones y ejecución de tareas, por lo tanto, también es aplicable al estudio de robots, vehículos o maquinaria con capacidades autónomas [16].

En los entornos colaborativos el Awareness de Situación es prácticamente desconocido, ya que otros investigadores han definido y documentado tipos de Awareness más específicos a entornos Groupware y CSCL, como veremos más adelante. Esto no significa que el Awareness de Situación no pueda utilizarse en los entornos colaborativos para enriquecer la experiencia del usuario o complementar las funcionalidades requeridas por el sistema. En la Figura 15 se muestra una representación del Awareness de Situación en un equipo de trabajo.



Fig. 15. Awareness de Situación de un equipo de trabajo.

En los entornos colaborativos el Situation Awareness es prácticamente desconocido, ya que otros investigadores han definido y documentado tipos de Awareness más específicos a entornos Groupware y CSCL, como veremos más adelante. Esto no significa que el Situation Awareness no pueda utilizarse en los entornos colaborativos para enriquecer la experiencia del usuario o complementar las funcionalidades requeridas por el sistema. En la Figura 15 se muestra una representación del Awareness de Situación en un equipo de trabajo.

El Situation Awareness que todos los miembros del equipo deben tener se representa por la conjunción del Awareness de Situación de cada uno de ellos. A su vez, el Situation Awareness global se representa por la suma del SA de todos. El SA grupal o común en todos los observadores permite desarrollar tareas colaborativas en las que cada ejecutor requiere tener el mismo Awareness de Situación que todos los demás sobre determinados aspectos. El SA global permite desarrollar tareas colaborativas en las que todos los individuos no tienen un SA común, requiriendo que los propios individuos mantengan canales de comunicación para transmitirse la información necesaria durante la toma de decisiones $y$ ejecución de tareas. Por otra parte, este tipo de interacción es base social del crecimiento humano y ciertamente permite atacar problemas más complejos y dinámicos.

Para el soporte del Awareness de Situación existe el Diseño basado en el Situation Awareness descrito en [17], el cual da guías para detectar y definir los elementos del entorno que definen las situaciones de interés a cada tarea del sistema.

Debido a que las necesidades de los sistemas pueden cambiar según su propósito, el Situation Awareness requerido también varía. En determinados sistemas como [18] y [19] se utilizan ontologías para definir los elementos del entorno que representan la situación de interés.

El soporte del SA varía con los objetivos del sistema y depende de las necesidades específicas encontradas. A partir de estas ideas podemos entender mejor los tipos de Awareness encontrados en la literatura del Groupware y de los CSCL, como el Workspace Awareness que se describe a continuación.

\section{2) Awareness de Espacio de Trabajo}

Para la comunidad de Interacción Persona-Ordenador (IPO) el Workspace Awareness es uno de los Awareness más conocidos. Reconocido como necesario para cualquier sistema Groupware, Gutwin define el Workspace Awareness o Awareness del Espacio de Trabajo compartido como "el conocimiento actual de las interacciones de otras personas con el espacio de trabajo compartido" [3].

El Workspace Awareness se refiere al Awareness creado durante la interacción de varios individuos en un espacio de trabajo compartido, limitándose a los eventos ocurridos en dicho espacio, ya sea asíncronos o síncronos.


Fig. 16. Tareas del dominio y de colaboración

El Workspace Awareness nace del estudio de la colaboración en los entornos informáticos. Un clásico en esta área es el trabajo de Paul Dourish sobre Awareness y Coordinación en espacios de trabajo compartidos [20], el cual analiza el concepto de Awareness en varios sistemas colaborativos, describiendo el Awareness como "el entendimiento de las actividades de los otros, lo cual provee un contexto para nuestras propias actividades" [20]. Esta definición es más acorde al Awareness de Actividad, descrito mas adelante. Sin embargo, los puntos remarcados y analizados concuerdan mejor con el Workspace Awareness.

La Figura 16 muestra una metáfora de lo que representa el espacio de trabajo y las tareas del dominio a través de un sistema informático. Se puede distinguir el trabajo individual y el trabajo colaborativo a través de tareas de colaboración. Una forma sencilla de verlo es una mesa en la que puede trabajar una sola persona o varias, de tal forma que el trabajo hecho en esa mesa sirva para cumplir los objetivos del sistema.

Gutwin reconoce el Workspace Awareness como un caso especial [8] del Situation Awareness, el cual busca responder a las preguntas who, what, where, when, how, referentes a las tareas colaborativas que se llevan a cabo en un espacio virtual compartido. En este caso, los elementos del entorno que definen la situación son descritos en la Figura 5.

Como puede observarse, los elementos que componen al Workspace Awareness pertenecen a varias entidades que 
intervienen en el proceso del trabajo colaborativo, como pueden ser los propios participantes, sus acciones, su localización, sus capacidades, etc. Esto sitúa al Workspace Awareness como un conjunto de Awareness de distintas situaciones, cada una de ellas importante para distintas decisiones y tareas.

El soporte del Workspace Awareness puede ser parcial en sus diferentes aspectos, pero normalmente se requerirá su soporte en cierta medida.

El conocimiento que representa el Awareness de Espacio de Trabajo permite una colaboración efectiva, tal y como se muestra en la Figura 4. Ayuda a simplificar la comunicación, la coordinación de las acciones y actividades, a anticipar eventos, a proveer asistencia y a administrar el grupo de trabajo. De esta forma podemos observar que el soporte del Workspace Awareness es necesario para el trabajo colaborativo y su soporte agrega una serie de requisitos al desarrollo del sistema, ya que los mecanismos para obtener y proveer la información que alimenta al Workspace Awareness deben diseñarse e implementarse con los mismos estándares de calidad que cualquier otra parte del sistema.

Como afirma [8], cualquier sistema que soporte tareas colaborativas a través de un espacio de trabajo compartido debe también soportar el Workspace Awareness adecuado a la situación y al entorno de trabajo proporcionado por el sistema.

Uno de los estudios clásicos del Awareness referente a la información de Awareness que se proporciona a los usuarios de distintos sistemas colaborativos es el previamente mencionado trabajo de Paul Dourish [20]. Otro trabajo clásico es el del proyecto Portholes [21], un sistema colaborativo basado en la compartición de video e imágenes y pensado para construir el sentido de comunidad a distancia. Se demostró que se podía crear la sensación de Awareness a distancia, es decir, a través de un sistema informático.

El Awareness de Espacio de Trabajo, al igual que el Awareness de Situación está afectado por diversos factores externos e internos del sistema. Además, el aspecto colaborativo de estos sistemas incrementa la complejidad y la dificultad de identificar, modelar e implementar la información y los mecanismos necesarios para el correcto soporte de este tipo de Awareness.

En lo que respecta a la comunicación, en el Workspace Awareness se reconocen dos formas de comunicación según el tiempo: síncrona y asíncrona. Cada una de ellas requiere distintos mecanismos de Awareness debido a que la forma de interacción es distinta.

El tamaño y la jerarquía de los grupos de trabajo también afectan a los mecanismos de Awareness implementados. Por ejemplo, es distinto trabajar con grupos pequeños como en los sistemas tradicionales que trabajar con grupos de trabajo de decenas o cientos de personas, como pueden ser las redes sociales colaborativas (Facebook, Google+, etc.) o juegos en línea (World of Warcraft, Starcraft, etc').

Las interfaces de usuario juegan un papel clave en el soporte de cualquier tipo de Awareness. En el caso del Workspace Awareness, las interfaces deben modificarse para transmitir los aspectos inherentes a la colaboración, además de permitir una continua actualización de sus datos y ayudar a disminuir la carga cognitiva generada por los mecanismos de Awareness.

Por si esto fuera poco, cada usuario es distinto y lo que para uno funciona, para el otro no. Por tanto, se han desarrollado mecanismos de adaptación y personalización para afrontar estos problemas, aunque ciertamente el enlace entre Awareness y la toma de decisiones seguirá estando presente.
El Workspace Awareness cuenta con un excelente marco de trabajo teórico desarrollado por Gutwin [8], el cual funciona como guía para el soporte de este tipo de Awareness. Con la experiencia y el análisis de distintas aplicaciones se vio la necesidad de interfaces de usuario adaptadas a los requerimientos de las tareas colaborativas. En este ámbito se desarrolló Groupkit [22], un kit para el desarrollo de sistemas Groupware el cual incluía mecanismos para el soporte del Workspace Awareness. Este kit principalmente enfocado a las interfaces de usuario colaborativas fue uno de los precursores de los posteriores kits de desarrollo para sistemas colaborativos en lo que respecta a ideas base e interfaces de usuario.

[23] actualiza las ideas de Roseman y desarrolla MAUI, el cual incluye mejoras a las ideas plasmadas en Groupkit y las aplica a las nuevas plataformas tecnológicas. Sigue conservando soporte para las interfaces de usuario descritas por [8], como son el telepuntero, la vista de radar, las barras de movimiento multiusuario, entre otras.

En lo que respecta al desarrollo de Groupware basado en el paradigma del espacio de trabajo compartido, recientemente [24] presentó un nuevo enfoque para diseñar este tipo de sistemas planteando el 'Community Based Groupware', el cual permite la colaboración informal y oportunista, la cual raramente es soportada en el paradigma tradicional. Este enfoque pretende mejorar la adopción de los sistemas Groupware, ya que se reconoce la colaboración informal como una parte esencial de los grupos de trabajo co-localizados.

El enfoque provee soporte para tres aspectos en particular: Awareness de los otros y de su trabajo individual, una manera sencilla y ligera de iniciar la interacción, y la habilidad de comenzar una colaboración estrecha y conjunta cuando se requiera.

En el soporte del Workspace Awareness destaca la falta de herramientas y técnicas para incluirlo en el desarrollo dirigido por modelos. Esta situación es ciertamente comprensible, ya que la naturaleza dinámica de los entornos de aplicación del Workspace Awareness y las distintas formas de modelar el dominio y el contexto han dificultado el desarrollo de estas técnicas.

\section{3) Awareness de Concepto}

Awareness de Concepto es el awareness de cómo una actividad particular o un pedazo de conocimiento cabe en el conocimiento ya existente de un usuario. Este tipo de awareness permite a las personas revisar las ideas que tienen a la luz de la nueva información dada y les ayuda a saber si necesitan conocer mas acerca de esta nueva información, también permite revisar si la tarea que se esta realizando se ajusta a lo que ya se conoce sobre el concepto.

\section{4) Awareness de Tareas}

Awareness de tareas es el conocimiento de cómo se completará la tarea, también se considera que el awareness orientado a tareas se centra en actividades realizadas para lograr una tarea compartida específica. Este tipo de conciencia puede ser promovida por un sistema de notificaciones $\mathrm{o}$ información sobre el estado de un determinado documento o un espacio de trabajo compartido. Permite a los usuarios coordinar sus actividades en el objeto compartido. Esto puede ocurrir ya sea de una manera síncrona o asíncrona. Las notificaciones que contribuyen al awareness orientado a las tareas, incorporan información sobre quien hace o hizo que acciones sobre alguna tarea compartida o un objeto relacionado a la tarea. Para el awareness orientado a las tareas el contexto compartido es establecido por un objeto que es parte de un proceso de cooperación. 


\section{5) Awareness de Social}

Social Awareness (quien esta alrededor?) Es una concepción débil del awareness con respecto a la cooperación. Es el awareness del contexto social del trabajo, no de las actividades en curso y los artefactos de un esfuerzo de cooperación conjunta. Los primeros trabajos sobre el awareness se centró en la comprensión de la gente sobre el actual contexto social en colaboraciones remotas: quien está aquí, con quien puedo trabajar? Algunas organizaciones exploraron el uso de enlaces de vídeo abiertos entre oficinas remotas $[21 ; 25]$. Otros trabajos han explorado las representaciones para mantener el awareness social en colaboraciones remotas. Un chat en grupo muestra los participantes en una sala de chat, así como la visualización de sus contribuciones en el tiempo [26]. Del mismo modo, el sistema Babble [27] incluye una representación social, muestra el nivel de la contribución a una discusión. Otros investigadores han explorado el uso de iconos o otras representaciones visuales simples para transmitir información sobre la situación de los individuos en un sitio remoto [28;29; 30]. Estos sistemas de notificación proporcionan información acerca de los cambios en el entorno social, como una interacción progresa, los usuarios son informados de la llegada colaboradores, la disponibilidad para la interacción, la participación y la salida. Los estudios sobre el awareness social hacen hincapié en que es sólo una faceta del problema del awareness, es necesario pero no suficiente para establecer una base común eficaz durante períodos más largos y en diversas actividades [31].

\section{6) Awareness de Acción}

Awareness de Acción (lo que está pasando?) Se refiere al estado de los objetos orientados a la tarea y las contribuciones de los colaboradores: en el tiempo, el tipo o la frecuencia con la que los colaboradores interactúan con un recurso compartido; ubicación y la orientación de la actividad actual de los colaboradores. Está orientada hacia la dependencia de productos en lugar de la dependencia proceso.

TABLA III. INFORMACIÓN EN LA QUE SE ENFOCA EL AWARENESS SOCIAL, ACCIÓN Y DE ACTIVIDAD

\begin{tabular}{|l|l|}
\hline Enfoque de Awareness & $\begin{array}{l}\text { Información necesaria para el enfoque de } \\
\text { awareness }\end{array}$ \\
\hline $\begin{array}{l}\text { Social : "Quien esta } \\
\text { alrededor" }\end{array}$ & $\begin{array}{l}\text { Presencia de los colaboradores; características de } \\
\text { un colaborador en línea que transmiten estado de } \\
\text { motivación 0 actitud; tiempo, la frecuencia 0 la } \\
\text { intensidad de la actividad o comunicación individual } \\
\text { o de grupo }\end{array}$ \\
\hline $\begin{array}{l}\text { Acción: "Que esta } \\
\text { pasando" }\end{array}$ & $\begin{array}{l}\text { El tiempo, el tipo o frecuencia de las interacciones } \\
\text { de colaboradores con un recurso compartido; } \\
\text { ubicación y la orientación de la actividad actual } \\
\text { colaboradores }\end{array}$ \\
\hline $\begin{array}{l}\text { Actividad: "Como van las } \\
\text { cosas" }\end{array}$ & $\begin{array}{l}\text { Creación o cambios en los planes compartidos, } \\
\text { evaluaciones, o justificación; asignación o } \\
\text { modificación de los roles del proyecto; dependencias } \\
\text { de tareas basadas en roles, de tiempo, recursos, etc; } \\
\text { manejo de excepciones }\end{array}$ \\
\hline
\end{tabular}

En muchas situaciones de colaboración a distancia, los miembros del equipo acceden y manipulan los recursos compartidos (por ejemplo, documentos, imágenes, bases de datos). En estos casos, no es suficiente saber quién está alrededor, y si están disponibles para la interacción. Los usuarios necesitan sistemas de notificación que les mantenga informados sobre lo que sucede a los objetos que les interesan, qué acciones se están tomando sobre estos objetos para investigar o modificarlos, y quien está llevando a cabo este tipo de acciones (Tabla. III). La información relevante puede ser un evento discreto (por ejemplo, la selección de un documento), o puede ser una serie de acontecimientos (por ejemplo, extraer y presentar el resumen de una serie de cambios en un documento compartido, [32]).

Una cuestión importante para el awareness de acción es el intercambio entre la cantidad de la información proporcionada, y la capacidad de los usuarios para comprenderla y utilizarla [33]. Saber qué acciones los colaboradores han llevado acabo ayuda a los usuarios a hacer un seguimiento del estado de los objetos relevantes para la tarea, y ha monitorear las contribuciones de colaboradores. Sin embargo, es el individuo el que proporciona un marco interpretativo de esta información, para determinar si la información es relevante o la forma en que se relaciona con los objetivos de la tarea actual. $\mathrm{Al}$ igual que con el awareness social, este requisito adicional a menudo resulta en interacciones del usuario, donde el mantenimiento del awareness se gestiona como una tarea independiente, es decir una tarea de coordinación que se impone sobre la verdadera tarea de crear un documento compartido, alcanzar un consenso sobre una visión compartida y así sucesivamente.

\section{7) Awareness de Actividad}

El Awareness de Actividad está ligado al trabajo colaborativo y en cierto nivel forma parte del Workspace Awareness. Se refiere al Awareness generado de las actividades y tareas que se desarrollan en entornos colaborativos. El workspace Awareness trata esa información de forma más centrada al conocimiento actualizado de lo que se está haciendo y quién lo está haciendo. Este enfoque es extendido en trabajos posteriores de otros autores, de tal forma que también se incluyen otros aspectos relacionados a las actividades colaborativas.

El Awareness de Actividad como tal ha sido estudiado en mayor profundidad en [14], el cual analiza el Awareness de Actividad a través de visiones diferentes, las cuales son la Base común, las Prácticas de la comunidad, el Capital social y el Desarrollo humano. La base común se refiere al conocimiento compartido que se va formando a través de la colaboración, como es la historia de las actividades realizadas, las personas que las desarrollaron, los recursos implicados, las herramientas utilizadas y los resultados obtenidos. Es un concepto similar al Awareness de Situación grupal, que se refiere al conocimiento que todos los miembros del equipo poseen y comparten.

Las prácticas comunitarias se refieren a las prácticas y comportamientos que son compartidos y comprendidos por todos los integrantes del grupo, como son los protocolos de comunicación, las formas de expresión, vocabulario, vestuario, entre otros.

El capital social se refiere a las relaciones sociales generadas por una buena interacción, es decir, relaciones que les permiten a los miembros colaborar mejor cuando están juntos, en vez de que generen estrés o problemas de comunicación y coordinación durante la interacción. Estas relaciones humanas se generan tras un tiempo de colaboración y adaptación mutua, en las cuales los miembros del equipo aplican sus capacidades sociales y profesionales para trabajar en conjunto con otros, formando de esta formas esas preciadas relaciones que permiten un trabajo colaborativo efectivo y beneficioso para todos.

El desarrollo humano se refiere al aprendizaje de nuevo conocimiento y habilidades, tanto humanas como profesionales, el cual con el tiempo también se vuelve un desarrollo humano compartido. El Awareness de Actividad puede verse como un modelado del Awareness requerido para realizar actividades colaborativas, a la vez que toma en cuenta el proceso de evolución de todos los integrantes del sistema. 
Parte de puntos de vista sociológicos y crea un modelo muy distinto a los anteriormente vistos, como los de Endsley y Gutwin. Sin embargo, este Tipo de Awareness complementa los otros marcos de trabajo con su visión social y evolutiva de lo que son las tareas colaborativas.

El Awareness de Actividad se aplica principalmente al trabajo colaborativo, de tal forma que permita a los miembros del equipo coordinar sus actividades. También puede utilizarse en entornos en donde la realización de las tareas dependa en gran medida del estado del entorno. Las cuatro visiones del Awareness de Actividad pueden apoyarse por otros tipos de Awareness específicas para ese objetivo. Es decir, para apoyar a los miembros del equipo en el desarrollo de estas habilidades de forma individual y grupal.

El soporte del Awareness de Actividad puede analizarse desde dos puntos de vista. El primero es brindar la información para soportar la colaboración durante el trabajo grupal. El segundo es brindar la información sobre las actividades actuales de cada miembro del equipo, así como información de cada actividad en su contexto de uso. Muchas de las interfaces propuestas para el soporte del Workspace Awareness se utilizan para dar soporte en la UI al Awareness de Actividad. Sin embargo, dependiendo de las necesidades de cada sistema, cada interfaz y mecanismo de distribución de datos pueden especializarse para cumplir el propósito deseado.

8) Knowledge Awareness y Shared-Knowledge Awareness

Estos tipos de Awareness se utilizan en entornos de aprendizaje colaborativo, aunque su propósito no es el mismo. Es importante diferenciar el conocimiento individual y el conocimiento grupal, el cual es la suma de todo el conocimiento individual. Por otra parte, el conocimiento compartido es el conocimiento igual y compartido que cada individuo del grupo tiene, es decir, lo que todos conocen. El Awareness del Conocimiento [34] se orienta al conocimiento individual y grupal y el Awareness del Conocimiento Compartido [35] o Shared-Knowledge Awareness (SKA) se orienta al conocimiento compartido y a su construcción.

El Awareness del Conocimiento según [34] permite conocer los siguientes aspectos sobre el conocimiento generado en el sistema: ¿Quién está buscando conocimiento igual o diferente al que yo estoy buscando?, ¿Quién está discutiendo conocimiento igual o diferente al que yo estoy discutiendo? Y ¿Quién está cambiando (agregando/borrando/modificando) conocimiento? Tabla IV. Las cuestiones de la Tabla IV se refieren al conocimiento que el usuario está utilizando y al que no está utilizando. El contexto de uso puede complementar este tipo de Awareness, ya que normalmente el aprendizaje se genera durante actividades individuales o colaborativas, además de permitir la adaptación de contenidos al nivel de los estudiantes [36].El Awareness del Conocimiento Compartido se enfoca en la construcción del conocimiento individual y en la construcción del conocimiento compartido.

TABLA IV. TIPOS DE MENSAJES DE KNOWLEDGE AWARENESS

\begin{tabular}{|l|l|l|}
\cline { 2 - 3 } \multicolumn{1}{c|}{} & Mismo Conocimiento & Conocimiento Diferente \\
\hline Tiempo & ¿Quiénes están discutiendo el & ¿Qué conocimiento están \\
& conocimiento? & discutiendo? \\
& ¿Quiénes están buscando & ¿Qué conocimiento están \\
& conocimiento? & buscando? \\
& ¿Quiénes están cambiando el & ¿Qué conocimiento están \\
& conocimiento? & cambiando? \\
\hline Diferente & ¿Quiénes discutieron sobre el & ¿Qué conocimiento \\
Tiempo & conocimiento? & discutieron? \\
& ¿Quiénes buscaron & ¿Qué conocimiento \\
& conocimento? & buscaron? \\
& ¿Quiénes cambiaron el & ¿Qué conocimiento \\
& conocimento? & cambiaron? \\
\hline
\end{tabular}

En [35] define el SKA a partir del aprendizaje generado por la realización de tareas colaborativas, ya sea por aprendizaje o por trabajo colaborativo y por la interacción entre los miembros del equipo. La Tabla $\mathrm{V}$ muestra una descripción de lo que representa el SKA y el tipo de conocimiento actualizado que proporciona, de tal forma que los usuarios puedan interactuar mejor y realizar más efectivamente las tareas conjuntas.

En el caso del SKA, la relación entre el conocimiento generado y el entorno de trabajo o aprendizaje está mejor definida. En la Figura 8 se muestra la relación entre el espacio de trabajo compartido, el aspecto social, la tarea y el concepto y el Conocimiento compartido.

Está claro que estos tipos del Awareness benefician a los entornos de aprendizaje y en algunos casos a los sistemas Groupware en general. Por ejemplo, los sistemas académicos son candidatos adecuados para estos tipos de Awareness. También los sistemas Groupware orientados a la capacitación y entrenamiento de personal pueden beneficiarse de este conocimiento.

Un entorno en el que se mezcla el trabajo colaborativo y la compartición de conocimiento es la traducción colaborativa asistida por ordenador. El trabajo presentado por [37] muestra la importancia de varios tipos de Awareness durante esta actividad, siendo directamente utilizado el Workspace Awareness e indirectamente el Knowledge Awareness.

TABLA V. AWARENESS DEL CONOCIMINETO COMPARTIDO O SHARED KNOWLIEDGE AWARENESS

\begin{tabular}{|l|l|}
\hline Awareness & Preguntas \\
\hline $\begin{array}{l}\text { Construcción } \\
\text { del }\end{array}$ & ¿Lo que estoy haciendo está ayudando a resolver la tarea? \\
(individual) & ¿Lo que hice está ayudando a resolver la tarea? ¿Necesesito \\
& más tiempo/recursos? \\
& ¿Qué necesito saber sobre este tema? \\
& ¿Qué más necesito encontrar sobre este tema? \\
& ¿De qué tanto tiempo dispongo? ¿Cúal es nuestro puntaje? \\
& ¿Qué y cómo aprendí de los otros miembros del grupo? \\
& ¿Terminé mi trabajo? \\
¿Qué es lo que estoy aprendiendo de este trabajo en equipo?
\end{tabular}

Tal vez la mayor dificultad para el soporte del Knowledge y Shared-Knowledge Awareness es identificar cuándo se crea, modifica o elimina el conocimiento de interés para el sistema. Sharlok [34] utiliza TRIAS [38] para representar el conocimiento en forma de triadas, algo parecido al modelo de datos RDF (Resource Description Framework).

La propuesta de [35] para el soporte del SKA al igual que el trabajo de [39] sobre el Awareness para el soporte de la creatividad en sistemas distribuidos utiliza un analizador de mensajes para detectar el conocimiento transmitido entre los miembros del equipo. La Figura 9 muestra el esquema completo del mecanismo para el SKA.

En las propuestas que utilizan el análisis de mensajes para detectar el intercambio de conocimiento sigue siendo necesaria una forma de representar ese conocimiento, a fin de poder transmitir el Awareness adecuado dependiendo de cómo se 
utiliza dicho conocimiento. Las ontologías pueden utilizarse para representar y almacenar conocimiento o "la situación", en el caso del Situation Awareness [19].

\section{Metodologías de Análisis y Diseño de Sistemas Colaborativos}

En esta sección se describe de forma general tres metodologías de desarrollo para sistemas de trabajo colaborativo, las cuales utilizan diferentes enfoques para su proceso de desarrollo. El objetivo de esta sección es detectar en cada una de ellas el soporte del Awareness, específicamente en la etapa del desarrollo de tareas de trabajo grupal, a fin de saber a que nivel está integrado el Awareness a las metodologías de desarrollo revisadas. Las metodologías revisadas son AMENITIES [40], TOUCHÉ [41] y CIAM [42].

\section{1) AMENITIES}

El objetivo de la metodología es abordar de forma sistemática el análisis y diseño de sistemas cooperativos facilitando el desarrollo posterior del software. AMENITIES proporciona un marco de referencia conceptual y metodológico, pero además propone una metodología concreta.

- Fases generales para analizar y diseñar sistemas cooperativos.

- Fases específicas para la construcción de los diferentes modelos implicados en la metodología.

- La definición de un marco conceptual de trabajo para dar soporte al modelado de estos sistemas.

- Una notación denominada COMO-UML (acrónimo de COOperative MOdel notation based on UML) que se basa en el lenguaje UML [43]

- Una semántica precisa de la notación anterior en el dominio del problema (sistemas cooperativos) mediante el formalismo de las Redes de Petri (CPN-Coloured Petri Nets) [44].

- Una herramienta denominada COMO-TOOL (acrónimo de COOperative MOdel TOOL) con diferentes funciones de apoyo al análisis y modelado de estos sistemas.

En la fase general se realiza un modelo cooperativo el cual es el núcleo central de AMENITIES. Es un modelo conceptual formado por un conjunto de modelos de comportamiento $\mathrm{y}$ tareas, los cuales son de utilidad para describir y representar cualquier sistema cooperativo desde el punto de vista de su estructura y funcionamiento. Su propósito es dar una descripción del sistema independientemente de su implementación, proporcionando así una mejor comprensión del dominio del problema, dada la complejidad que caracteriza a este tipo de sistemas. El modelo cooperativo se compone de cuatro vistas conceptuales. La vista organizacional, la vista cognitiva, la vista de interacción y la vista de información.

La vista organizacional permite describir cómo se estructuran los grupos que forman parte de las organizaciones, en concreto, aspectos tales como: grado de acoplamiento de los participantes, sus cargas de trabajo, la evolución del grupo, etc. AMENITIES permite especificar grupos de la organización y equipos de trabajo.

La vista cognitiva fundamentalmente representa el conocimiento de cada miembro del grupo en el contexto organizacional, tanto el conocimiento adquirido como el que se requiere.

El objetivo de la vista de interacción en el modelo cooperativo consiste en representar algunos o todos los siguientes aspectos que se hayan podido identificar para una actividad que requiere interacción directa entre participantes:
- La forma de llevarla a cabo, sus restricciones temporales (síncrona o asíncrona) y el marco de tiempo (largo, medio y corto).

- Los participantes (humanos, agentes, etc.) y sus grados de cooperación.

- Uso de protocolos sociales para alcanzar el objetivo.

La vista de la información es la encargada de representar datos tales como documentos y mensajes, cuya principal finalidad es comunicar información de una manera más o menos estructurada. Esto permite representar dentro del modelo:

- Información abstracta(a veces también denominada sin designación) como pueden ser los mensajes.

- Información concreta (o con designación) como pueden ser documentos o datos multimedia.

\section{2) $\mathrm{TOUCHE}$}

TOUCHÉ [45], es un modelo de proceso y una metodología para el desarrollo de interfaces de usuario para aplicaciones groupware desde la elicitación de requisitos hasta su implementación considerando las características y particularidades de estos sistemas desde el inicio. Una de las etapas de esta metodología es:

Análisis: La etapa del Análisis se trata del estudio del dominio. Describe los requerimientos del sistema sin describir las cuestiones de la implementación. Los roles y las tareas son identificados y descritos. El análisis del sistema se hace desde una perspectiva estructural a través de Diagramas de Clases y del Diagrama de la Estructura Organizacional; y desde la perspectiva del comportamiento a través del Diagrama de Tareas (La notación CTT se ha sido adoptada en este caso) y del Diagrama de Co-Interacción (desarrollado para identificar relaciones entre los actores del sistema).

El análisis de un sistema colaborativo comienza con la identificación previa de roles y tareas a partir de la información recabada en el Documento de Requisitos del Sistema de la etapa anterior. Por un lado, la identificación de los primeros roles permite al analista realizar un primer esbozo de la estructura organizativa de los actores del sistema. Este diagrama, junto con el diagrama de clases de UML modelan la estructura del sistema. Así mismo, la identificación de las primeras tareas permite ordenarlas, creando así un primer esbozo de los diagramas de tareas y los diagramas de cointeracciones, que modelan el comportamiento de los actores del sistema.Un diagrama especial se utiliza para representar las colaboraciones entre los actores del sistema. El llamado Diagrama de Co-Interacciones representa las colaboraciones establecidas entre los diferentes elementos organizativos de una estructura organizada, es decir, las interacciones que existen entre los actores (usuarios, agentes, grupos) de un sistema a través del mismo: tareas de grupo. El Diagrama de Co-Interacciones utiliza los elementos organizativos del sistema y la relación llamada Co-Interacción, la cual es una relación organizativa de grupo entre dos actores que expresa una interacción entre ellos, encaminada al logro de un objetivo común que no podría alcanzarse sin dicha interacción.

\section{3) CIAM}

La metodología CIAM [42] (Collaborative Interactive Applications Methodology) está enfocada al desarrollo de sistemas Groupware. Los primeros estados de la metodología se refieren al modelado centrado en los grupos, yendo hacia un modelado más centrado en los procesos (colaborativos, cooperativos y de coordinación) en las etapas siguientes. Yendo cada vez más profundo en los niveles de abstracción se alcanza un modelado más centrado en los usuarios, en el cual las tareas interactivas son modeladas. 


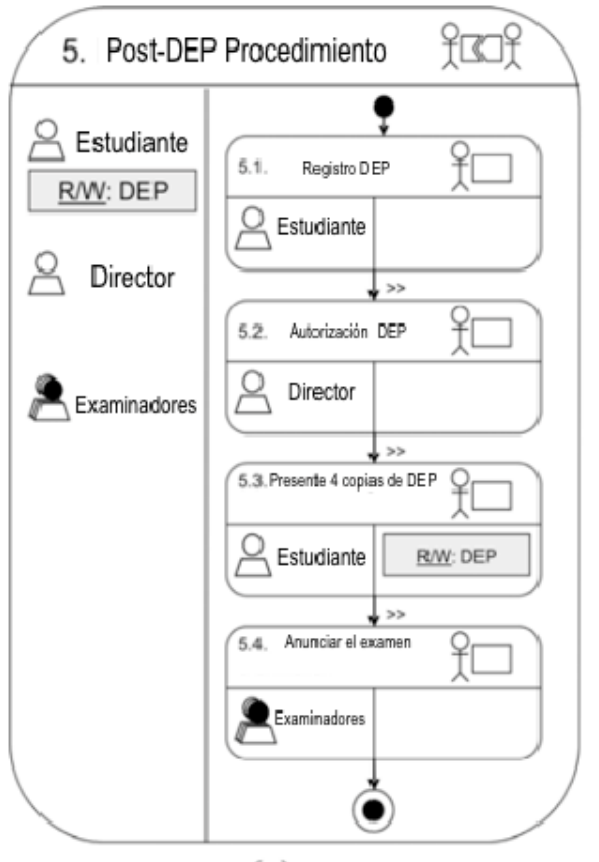

(a)

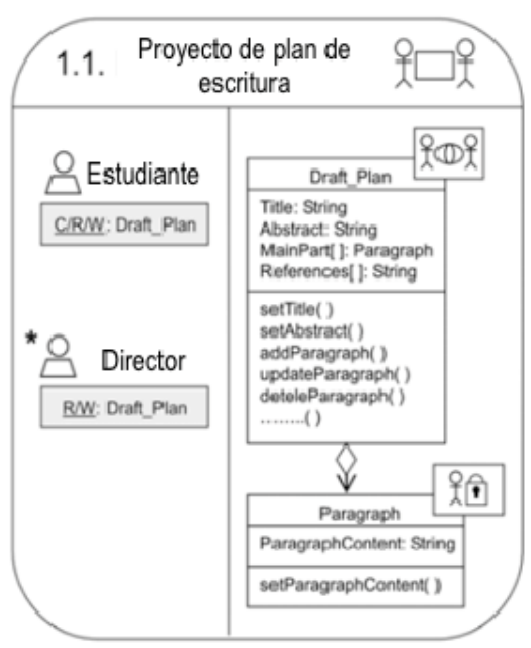

(b)

Fig. 17. Ejemplo de modelado de dos tareas grupales en CIAM [47]: a) una tarea cooperativa y b) una tarea colaborativa.

Las primeras dos etapas del modelado permiten definir el contexto en el cual se crea el modelo interactivo, además de que sirve como punto de inicio para la última fase. Una de las etapas de esta metodología es: Modelado de las tareas de trabajo en grupo. En esta fase se describen a mayor detalle las tareas grupales identificadas en las etapas previas. Se distinguen dos tipos de tareas, las cuales se modelan de forma distinta: tareas cooperativas y tareas colaborativas.

En esta fase se profundiza en el detalle con el cual se especifican las tareas colaborativas y cooperativas, las cuales se diferencían en dos importantes aspectos [46]: las tareas cooperativas implican la división de la tarea cooperativa en tareas individuales llevadas a cabo por usuarios o actores con un rol particular, y las tareas colaborativas implican la manipulación de objetos o entidades que se comparten por los usuarios que desarrolla dicha tarea.

La Figura 17a muestra el modelado de una tarea cooperativa de ejemplo llamada Post DEP Procedure. A la izquierda de la tarea pueden verse los roles participantes en la tarea y los objetos manipulados por cada rol. En la derecha aparece la gráfica de descomposición de responsabilidades. Los nodos de la gráfica deben representar tareas individuales, las cuales involucran un sólo rol.

Para modelar las tareas colaborativas se requiere conocer los roles implicados en su ejecución y los objetos del modelo de datos que son manipulados en la misma de forma compartida. La Figura 17b muestra el modelado de la tarea colaborativa llamada Draft Plan Writing. A la izquierda de la tarea se muestran los roles implicados y los objetos manipulados junto con sus indicadores de acceso a ellos. A la derecha se muestran los objetos del modelo de datos que constituyen el contexto compartido. Para especificar el modelo compartido se utiliza la notación UML a la cual se le agregan algunos iconos para expresar características de visualización y para expresar los permisos de acceso al contexto compartido (Figura 18).

\begin{tabular}{|c|c|}
\hline Icono & Definición \\
\hline & $\begin{array}{l}\text { Área del contexto compartido de la } \\
\text { visualización colaborativa }\end{array}$ \\
\hline & $\begin{array}{l}\text { Área del contexto compartido de la } \\
\text { visualización individual }\end{array}$ \\
\hline & $\begin{array}{l}\text { Segmento del contexto compartido de } \\
\text { acceso de exclusiva modificación }\end{array}$ \\
\hline
\end{tabular}

Fig. 18. Iconos para representar las características de visualización y acceso exclusivo al contexto compartido.

\section{DESCRIPCIÓN DEL PROBLEMA}

En este apartado se identifica el problema de investigación a partir de las dificultades provenientes en las teorías de awareness relevadas (sección $A$ ), se describe el problema de lo relevado en el estado de la cuestión (sección $B$ ), y se concluye con un sumario de investigación (sección $C$ ).

\section{A. Identificación del problema de investigación}

La evolución de las tecnologías de información y comunicación ha creado nuevos escenarios para la interacción entre las personas, este impacto ha hecho que las organizaciones no solo automaticen sus procesos y mejoren su calidad si no también brinden apoyo a la comunicación compleja entre sus miembros mas allá de las restricciones de tiempo y espacio. Esta evolución ha influido en la creación de entornos complejos en los que las organizaciones pueden tener equipos de trabajo compuestos por expertos, teletrabajadores o trabajadores móviles que estén geográficamente dispersos. El área de investigación que estudia el impacto de la tecnología en las interacciones grupales con el fin de facilitar el trabajo en grupo y desarrollo de herramientas colaborativas es el trabajo colaborativo soportado por computadoras (CSCW, Computer Supported Collaborative Work).

Estas herramientas crean un espacio virtual donde los miembros del grupo interactúan entre si y trabajan de forma conjunta y colaborativa [48], ese trabajo en grupo no es simplemente la unión de tareas individuales si no es un 
conjunto de actividades coherentes con buenas estrategias de comunicación, cooperación y coordinación entre los miembros del grupo. Para crear este tipo de estrategias los miembros del grupo tienen que estar al tanto sobre el estado y cambios en el espacio de trabajo y las acciones que otros miembros del grupo están realizando, este tipo de información se conoce como "Información Awareness" [49]. Entre las definiciones de awareness se señalan de interés las siguientes: [2] se define awareness como el conocimiento en detalle de las interacciones de otros participantes con el espacio de trabajo compartido ó en el ámbito de la estructura grupal se refiere al conocimiento de los roles y responsabilidades de los otros participantes. Estas definiciones implican que todos los participantes necesitan información de awareness acerca de los otros integrantes, todo el tiempo, sin embargo sabemos que algunos participantes necesitan mas awareness que otros dependiendo de sus roles o de la estructura grupal de la que se han parte. Tampoco incluye la idea que la información de awareness este basada según los roles de cada participante. Es importante mencionar que en el contexto de CSCL (Computer-Supported Collaborative Learning) se enfatiza en el análisis de interacciones para el soporte de roles y la necesidad de adaptar la información a los diferentes roles que participan en un entorno CSCL [50].

En los entornos CSCW existe esa misma necesidad y conforme con lo anterior el tipo de información de awareness que los integrantes de un grupo tienen no se considera completamente adecuada ya que en algunos casos es necesario adaptar la cantidad y tipo de información de awareness que cada participante necesita de acuerdo al rol especifico que este tome durante la actividad colaborativa que realiza. Además la dinámica real del trabajo colaborativo indica que los roles de los participantes pueden cambiar a lo largo de la actividad que estén realizando o la forma en la que interactúan y el no tener un marco de referencia de la información de awareness de cada rol pude afectar la colaboración entre los integrantes. Por tanto el poder identificar estos roles durante la actividad colaborativa y el poder adaptar de forma dinámica la información de awareness en virtud de las necesidades de los mismos puede ayudar a mejorar de manera global la experiencia de trabajo colaborativo [51; 52].

\section{B. Descripción del problema}

El soporte básico del Awareness implica identificarlo, modelarlo en el sistema, capturar los datos, procesarlos y proporcionárselos a los usuarios en las condiciones adecuadas y en el momento adecuado. Cada uno de estos pasos debe estar bien definidos y manejados para que no tener problemas durante la construcción o el soporte, teniendo esto en cuenta y la revisión de varias metodologías en el apartado de estado de la cuestión se encuentra que estas permiten llevar acabo un desarrollo de las funcionalidades generales de los sistemas de trabajo colaborativo pero se en dichas metodologías se contempla mínimamente una forma para especificar y restringir la información de Awareness manejada. Es por esto que se necesita realizar un análisis previo que sirva de guía para la construcción adecuada de estas situaciones colaborativas dando soporte a la información de awareness.

También del estudio realizado en el apartado del estado de la cuestión se observa una gran cantidad de definiciones de awareness lo cual conlleva a un problema de no se saber con certeza cual de todos estos tipos de awareness es el que se necesita soportar en el sistema una vez se requiera construirlo.

Cada tipo de entorno o situación puede necesitar información de awareness particular, es por esto que es necesario realizar un análisis y una exploración de las situaciones donde se realizan tareas de colaboración, en donde en estas existan interacciones entre dos o mas actores y estén basadas en las diferentes formas que los actores se pueden comunicar de acuerdo a las relaciones que estos tengan. Que contenga reglas en la información de awareness dada al usuario para no sobre cargarlo con información irrelevante.

\section{Sumario de investigación}

De lo expuesto precedentemente surgen las siguientes preguntas de investigación:

I. ¿ Dado la cantidad de tipos de awareness es posible generar una categorización de estas y lo que buscan caracterizar?

II. $i$ Es posible modelar las diferentes interacciones que ocurren en las actividades colaborativas dentro de los CSCW y a partir de estas interacciones identificar los roles asociados a cada interacción?

III. ¿ Es posible generar un método que permita suministrar la información de awareness necesaria para cada rol y tipo de interacción que se encuentre en una actividad colaborativa en entornos CSCW?

IV. ¿ Se puede realizar un análisis de las posibles situaciones colaborativas que sirva de guía en la construcción de estas?

Mediante esta investigación se pretende definir un modelo de interacciones grupales en los CSCW utilizando los lineamientos establecidos en el Modelado de Interacciones en Espacios Virtuales Dedicados a Trabajo Colaborativo propuesto en [4] y a partir de este obtener los posibles roles y asociar la información de awareness adecuada para cada modelo de interacción. También se busca realizar un análisis de las tareas colaborativas que se presentan en los sistemas colaborativos que sirva de guía para la construcción de estas y mezcle los diferentes componentes anteriormente mencionados. Este Modelo de interacciones grupales que se presenta en el apartado correspondiente a la Solución del problema identificado, pretende realizar un aporte en este sentido. Esto permitirá dar un mejor soporte a la información de tipo awareness en aplicaciones colaborativas.

\section{SOLUCIÓN}

En este apartado se presenta un modelo de awareness para las interacciones grupales en los entornos de trabajo colaborativo. En la primera parte se propone una taxonomía de mecanismos de awareness (sección $A$ ), se proponen características de awareness, se hace un estudio de comparación y luego se realiza una taxonomía para los mecanismos de awareness. Luego de esto se presentan diferentes modalidades de interacción grupal (sección $B$ ) y a partir de estas modalidades y sus ejemplos específicos se hace una propuesta de generalización de roles (sección $C$ ), finalmente se propone el modelo de awareness para las modalidades de interacción grupal (sección $D)$.

\section{A. Taxonomía de mecanismos de awareness}

En esta sección se introducen conceptos que permiten su caracterización (sub-sección 1), se presenta una comparación de los mecanismos de awareness estudiados (sub-sección 2) y se propone una taxonomía de este tipo de mecanismos (subsección 3).

\section{1) Caracterización del Awareness}

En esta sub-sección se definen las siguientes características del awareness: arquitectura auxiliar (sub-sección $a$ ), modo de awareness (sub-sección $b$ ), propagación del mensaje (subsección $c$ ), tipos de aplicación (sub-sección $d$ ), tipos de 
presentación (sub-sección e) y métodos de presentación (subsección $f$ ).

a) Arquitectura auxiliar: Esta constituida por las partes de los mecanismos de awareness que cumplen con un rol especifico dentro del sistema. Esta arquitectura puede ser tradicional como módulos de administración de información que se encargan de tareas básicas o módulos un poco mas avanzados que se encargan de clasificar o analizar. También se pueden implementar sistemas inteligentes que generen nueva información de tipo awareness, esto, con el fin de ayudar en el suministro de información contextual que de soporte al tipo de awareness en el que se este trabajando.

b) Modo de Awareness: Es el conjunto de eventos que permite una descripción del estado de situaciones de cooperación y permite proporcionar información para apoyar cada uno de los diferentes modos de awareness presentados a continuación:

- Síncrono Acoplado: lo que esta actualmente pasando en el ámbito de trabajo.

- Asíncrono Acoplado: lo que ha cambiado en el ámbito de trabajo desde el ultimo acceso.

- Síncrono Desacoplado: lo que ocurre actualmente en cualquier otro lugar de importancia.

- Asíncrono Desacoplado: Cualquier cosa de interés que haya ocurrido hace poco en otro lugar.

El awareness sincrónico se ocupa de los eventos, que en la actualidad se están produciendo, mientras que el awareness asíncrono considera eventos que han ocurrido en algún momento en el pasado. El apoyo a este último modo tiene que ser dado por una interpretación que resume toda una secuencia de acontecimientos, que han ocurrido en el intermedio. El awareness sincrónico debe estar apoyado por un reflejo inmediato del trabajo en curso en la interfaz gráfica de usuario del sistema. Se distinguen según el interés del usuario entre el awareness acoplado y desacoplado. El awareness acoplado denota el tipo de información general, que está estrechamente relacionado con la ocupación actual del usuario. Un ejemplo de este tipo de orientación es el conocimiento de un usuario que desea editar un documento determinado, que dicho documento esta siendo leído actualmente por otra persona. Con el awareness acoplado asíncrono son las situaciones, cuando un usuario está trabajando en un determinado objeto y es informado de cambios, que le pasaron a este objeto en el pasado durante un período de ausencia. El awareness desacoplado se aplica en situaciones donde la información sobre los eventos necesita ser dada independiente del actual enfoque de trabajo del usuario. A modo de ejemplo para el awareness asíncrono desacoplado se puede considerar una situación en la que el administrador del flujo de trabajo envía un objeto ( ej: hoja de cálculo, carpeta de documentos) en el que hay que trabajar, a alguien que esta en vacaciones. Si hay una fecha límite, entonces puede ser muy importante notificar al iniciador del flujo de trabajo de esto, aunque en el momento este ocupado con otra cosa.

c) Propagación del mensaje: La información que es de tipo awareness tiene que ser enviada o mostrada a las personas que sean parte del CSCW, este información puede ser enviada a todas las personas del grupo (multi - destino), a una persona del grupo (destino individual), estar basado en los intereses del usuario en situaciones de trabajo (relación usuario - objeto), o de acuerdo a algún nivel jerárquico que exista en el CSCW.

d) Tipos de Aplicación: En [12] se identifica la manera de descomponer los sistemas colaborativos a través de una matriz espacio-temporal, de acuerdo a esta matriz se pueden identificar los siguientes tipos de aplicaciones:

- Interacción Cara a Cara: Implica el mismo tiempo y el mismo lugar, puede dividirse en varias categorías; pantalla compartida para explicaciones, entornos de conversación y tormentas de ideas

- Interacción Asíncrona Centralizada: Implica el mismo lugar pero diferente tiempo. Ejemplo de esto es un foro de debate donde las personas aportan sus comentarios.

- Interacción Síncrona Distribuida: Implica el mismo tiempo pero diferente lugar. Ejemplos de esto son entornos de trabajo, el chat y la video conferencia.

- Interacción Asíncrona Distribuida: Implica diferente tiempo y lugar. Ejemplo de esto es el correo electrónico.

e) Tipos de Presentación: Se describen tres tipos de situaciones colaborativas que pueden ocurrir en la interfaz de los usuarios, estas situaciones pueden ser:

- Igual Tarea - Igual Vista: Esta situación involucra una interacción cercana y requiere awareness del lugar preciso y las acciones exactas de los otros usuarios, La vista igual en los sistemas groupware es llamado "strict WYSIWIS" ('What You See Is What I See').

- Igual Tarea - Diferente Vista: Esta situación involucra acciones coordinadas que ocurren en diferentes áreas del espacio de trabajo. La vista diferente en un espacio de trabajo común es llamado "relaxed WYSIWIS", también en este tipo de presentación se incluye el WYSIWID ('What You See Is What I Do').

- Igual Tarea - Situación de Enfoque Mixto: Esta situación involucra actividades individuales y compartidas en el espacio de trabajo se entrelazan, y los usuarios desplazan su atención periódicamente entre vistas separadas y compartidas en el espacio de trabajo.

f) Métodos de Presentación: Son componentes gráficos o herramientas que se muestran en la interfaz del usuario que dan soporte a la diferente información de awareness, estos componentes ofrecen una amplia variedad de información que pueden ser situados dentro o fuera de los objetos compartidos en los sistemas $\mathrm{CSCW}$, son representaciones literales $\mathrm{o}$ simbólicas de las acciones de otra persona, estos componente pueden incluir imágenes, video, indicadores de actividad o historial de actividades por mencionar algunas, estos componentes pueden proporcionar una transición entre detalles locales o una vista global y también pueden contener múltiples puntos de foco que pueden ser usados para mostrar detalles de las acciones de cada usuario.

2) Comparación de Mecanismos de Awareness Estudiados

Del estudio comparativo realizado se observa que el soporte a los diferentes tipos de awareness exige una combinación de vistas personalizadas y perspectivas sobre diversos objetivos (objetos, personas) en diferentes contextos de uso, dado que la mayoría de mecanismos de awareness relevados tienen un tipo de presentación (igual tarea - situación de enfoque mixto) en donde los usuarios desplazan su atención periódicamente entre vistas separadas y compartidas en el espacio de trabajo, y presentan la información a través de diversos métodos de presentación (Widget Globales, líneas de tiempo, líneas de conexión, gráficos de estado).

También se puede observar que la mayoría de mecanismos de awareness comparados realizan la propagación del mensaje a todos los usuarios del sistema (multi-destino), con excepción del mecanismo de eventos locales, el cual presenta una propagación diferente y que puede resultar mas útil para los usuarios, ya que este mecanismo propone una relación usuario- 
TABLA VI. COMPARACIÓN DE MECANISMOS DE AWARENESS

\begin{tabular}{|c|c|c|c|c|c|c|c|c|}
\hline \multirow{2}{*}{$\begin{array}{l}\text { mecanismos de } \\
\text { Awareness } \\
\text { /Características }\end{array}$} & \multirow[t]{2}{*}{ Nombre } & \multicolumn{2}{|c|}{ Recolección de datos } & \multicolumn{2}{|l|}{ Distribución } & \multicolumn{3}{|l|}{ Presentación } \\
\hline & & $\begin{array}{l}\text { Tipos de } \\
\text { Awareness }\end{array}$ & $\begin{array}{l}\text { Arquitectura } \\
\text { auxiliar }\end{array}$ & $\begin{array}{l}\text { Modo } \\
\text { Awareness }\end{array}$ & $\begin{array}{l}\text { Propagación } \\
\text { mensajes }\end{array}$ & $\begin{array}{l}\text { Tipo de } \\
\text { aplicación }\end{array}$ & $\begin{array}{l}\text { Tipo de } \\
\text { presentación }\end{array}$ & $\begin{array}{l}\text { Método de } \\
\text { presentación }\end{array}$ \\
\hline $\begin{array}{l}1995 \text { - Gutwin - } \\
\text { Support for } \\
\text { workspace } \\
\text { awareness in } \\
\text { educational } \\
\text { groupware }\end{array}$ & $\begin{array}{l}\text { Software } \\
\text { colaborativo y } \\
\text { educativo }\end{array}$ & $\begin{array}{l}\text { Awareness } \\
\text { social, } \\
\text { Awareness de } \\
\text { tareas, } \\
\text { Awareness de } \\
\text { conceptos, } \\
\text { Awareness de } \\
\text { espacios de } \\
\text { trabajo }\end{array}$ & & $\begin{array}{l}\text { Síncrono y } \\
\text { Acoplado. }\end{array}$ & $\begin{array}{l}\text { Multi - } \\
\text { destino }\end{array}$ & $\begin{array}{l}\text { interacción } \\
\text { sincrónica } \\
\text { distribuida }\end{array}$ & $\begin{array}{l}\text { 1. Igual tarea - } \\
\text { igual vista } \\
\text { (Strict } \\
\text { WYSIWIS) } \\
\text { 2. Igual tarea - } \\
\text { diferente vista } \\
\text { (Relaxed } \\
\text { WYSIWIS o } \\
\text { WYSIWID) } \\
\text { 3. Igual tarea - } \\
\text { situación de } \\
\text { enfoque mixto }\end{array}$ & $\begin{array}{l}\text { 1. Cursos } \\
\text { múltiple, cursor } \\
\text { semántico } \\
\text { 2. Scrollbar } \\
\text { multiusuario, } \\
\text { widget global } \\
\text { 3. mecanismos } \\
\text { de historial }\end{array}$ \\
\hline $\begin{array}{l}2003 \text { - Carroll - } \\
\text { Notification and } \\
\text { awareness } \\
\text { synchronizing } \\
\text { task-oriented } \\
\text { collaborative } \\
\text { activity }\end{array}$ & $\begin{array}{l}\text { Sistema de } \\
\text { notificaciones }\end{array}$ & $\begin{array}{l}\text { Awareness de } \\
\text { actividad, } \\
\text { Awareness } \\
\text { social, } \\
\text { Awareness de } \\
\text { Acción }\end{array}$ & & $\begin{array}{l}\text { Asíncrono y } \\
\text { acoplado. }\end{array}$ & $\begin{array}{l}\text { Multi - } \\
\text { destino }\end{array}$ & $\begin{array}{l}\text { Interacción } \\
\text { asíncrona } \\
\text { centralizada }\end{array}$ & $\begin{array}{l}\text { Igual tarea - } \\
\text { situación de } \\
\text { enfoque mixto }\end{array}$ & $\begin{array}{l}\text { Widget global. } \\
\text { Línea de tiempo } \\
\text { orientada a } \\
\text { actividades } \\
\text { hechas por el } \\
\text { grupo. } \\
\text { Línea de tiempo } \\
\text { de actividades } \\
\text { sobre un } \\
\text { documento }\end{array}$ \\
\hline $\begin{array}{l}2006 \text { - collazos - } \\
\text { Modelo de } \\
\text { awareness en } \\
\text { CSCL ALLEGRO } \\
\text { utilizando la } \\
\text { arquitectura } \\
\text { blackboard }\end{array}$ & $\begin{array}{l}\text { Sistema multi- } \\
\text { agente de } \\
\text { enseñanza }\end{array}$ & $\begin{array}{l}\text { Awareness del } \\
\text { conocimiento }\end{array}$ & $\begin{array}{l}\text { Agentes } \\
\text { inteligentes para } \\
\text { la recolección de } \\
\text { acciones, envió } \\
\text { de reportes y } \\
\text { sugerencias }\end{array}$ & $\begin{array}{l}\text { Síncrono y } \\
\text { Acoplado. } \\
\text { Síncrono y } \\
\text { desacoplado. } \\
\text { Asíncrono y } \\
\text { acoplado. } \\
\text { Asíncrono y } \\
\text { desacoplado. }\end{array}$ & $\begin{array}{l}\text { Multi - } \\
\text { destino }\end{array}$ & $\begin{array}{l}\text { Interacción cara a } \\
\text { cara, interacción } \\
\text { sincrónica } \\
\text { distribuida, } \\
\text { Interacción } \\
\text { asíncrona } \\
\text { centralizada, } \\
\text { Interacción } \\
\text { asíncrona } \\
\text { distribuida } \\
\end{array}$ & $\begin{array}{l}\text { Igual tarea - } \\
\text { situación de } \\
\text { enfoque mixto }\end{array}$ & $\begin{array}{l}\text { Widget global. } \\
\text { Tablero } \\
\text { (memoria } \\
\text { global).Mail. } \\
\text { mensaje directo. } \\
\text { sugerencias y } \\
\text { reportes. }\end{array}$ \\
\hline $\begin{array}{l}2002-\text { Gutwin - A } \\
\text { Descriptive } \\
\text { Framework of } \\
\text { Workspace } \\
\text { Awareness for } \\
\text { Real-Time } \\
\text { Groupware }\end{array}$ & $\begin{array}{l}\text { Groupware de } \\
\text { tiempo real }\end{array}$ & $\begin{array}{l}\text { Awareness de } \\
\text { espacios de } \\
\text { trabajo } \\
\text { Awareness de } \\
\text { situación }\end{array}$ & & & $\begin{array}{l}\text { Multi - } \\
\text { destino }\end{array}$ & & & $\begin{array}{l}\text { Lista de } \\
\text { participantes, } \\
\text { telepointers, } \\
\text { avatars, Vistas } \\
\text { duplicadas, } \\
\text { vistas esclavas }\end{array}$ \\
\hline $\begin{array}{l}2002 \text {-Collazos - } \\
\text { Introduccing } \\
\text { shared-knowledge } \\
\text { awareness }\end{array}$ & $\begin{array}{l}\text { Mecanismo de } \\
\text { conocimiento } \\
\text { compartido }\end{array}$ & $\begin{array}{l}\text { Awareness de } \\
\text { conocimiento - } \\
\text { compartido }\end{array}$ & $\begin{array}{l}\text { Modulo } \\
\text { analizador de } \\
\text { acciones. } \\
\text { Modulo } \\
\text { analizador de } \\
\text { mensajes. } \\
\text { Agente } \\
\text { generador de } \\
\text { Awareness de } \\
\text { conocimiento } \\
\text { compartido }\end{array}$ & $\begin{array}{l}\text { Síncrono y } \\
\text { Acoplado. }\end{array}$ & Multi-destino & & $\begin{array}{l}\text { Igual tarea - } \\
\text { situación de } \\
\text { enfoque mixto }\end{array}$ & $\begin{array}{l}\text { Widget global. } \\
\text { icono grafico que } \\
\text { puede } \\
\text { representar } 3 \\
\text { posibles estados: } \\
\text { pobre, bueno o } \\
\text { alto }\end{array}$ \\
\hline $\begin{array}{l}\text { 1995 - Fuchs - } \\
\text { Supporting } \\
\text { cooperative } \\
\text { Awareness with } \\
\text { local event } \\
\text { Mechanisms : } \\
\text { The groupdesk } \\
\text { system }\end{array}$ & $\begin{array}{l}\text { Mecanismo de } \\
\text { eventos } \\
\text { locales }\end{array}$ & $\begin{array}{l}\text { Awareness de } \\
\text { usuario }\end{array}$ & $\begin{array}{l}\text { Administrador de } \\
\text { eventos }\end{array}$ & $\begin{array}{l}\text { Síncrono y } \\
\text { Acoplado. } \\
\text { Síncrono y } \\
\text { desacoplado. } \\
\text { Asíncrono y } \\
\text { acoplado. } \\
\text { Asíncrono y } \\
\text { desacoplado. }\end{array}$ & $\begin{array}{l}\text { relación } \\
\text { usuario - } \\
\text { objeto }\end{array}$ & $\begin{array}{l}\text { Interacción cara a } \\
\text { cara, interacción } \\
\text { sincrónica } \\
\text { distribuida, } \\
\text { Interacción } \\
\text { asíncrona } \\
\text { centralizada, } \\
\text { Interacción } \\
\text { asíncrona } \\
\text { distribuida }\end{array}$ & $\begin{array}{l}\text { Igual tarea - } \\
\text { situación de } \\
\text { enfoque mixto }\end{array}$ & $\begin{array}{l}\text { Diferentes } \\
\text { colores de } \\
\text { iconos. } \\
\text { Líneas de } \\
\text { conexión con } \\
\text { color entre el } \\
\text { actor y el objeto. } \\
\text { niveles de } \\
\text { urgencia del } \\
\text { contexto de } \\
\text { interés }\end{array}$ \\
\hline
\end{tabular}

objeto, en donde se define por los contextos de interés, que consisten en un conjunto de tipos de relación, un conjunto de tipos de eventos y una lista de los usuarios interesados que se han suscrito en el contexto. Para cualquier clase de objeto determinado en el sistema, el usuario puede definir (y/o suscribirse a) un contexto de interés. Otra observación a formular es que los mecanismos de awareness que usan una arquitectura auxiliar dan mayor cobertura a los diferentes

Herrera, A. 2014. Modelo de Awareness Basado en Topologías de Interacción para Espacios Virtuales de Trabajo Colaborativo Revista Latinoamericana de Ingeniería de Software, 2(4): 219-261, ISSN 2314-2642 modos de awareness (síncrono, asíncrono, acoplado y desacoplado), también implementan todos los tipos de interacción proveyendo interacciones cara a cara, asíncronas centralizadas, síncronas y asíncronas distribuidas.

3) Propuesta de Taxonomía de Mecanismos de Awareness

De los mecanismos de awareness relevados y del estudio comparativo realizado, con base en una variación de la 
propuesta de análisis que se formula en [8] se propone un conjunto básico de conceptos que dan respuesta a las preguntas "quién, qué, dónde, cuándo y cómo" para el awareness en espacios de trabajo, con este conjunto básico se identifican elementos específicos de conocimiento que construyen el núcleo de awareness de espacios de trabajo y la lista de las preguntas que cada elemento puede responder. Los elementos son todas las cuestiones de sentido común que tienen que ver con las interacciones entre la persona y el entorno de trabajo. Con base en este conocimiento, se propone una taxonomía de los mecanismos de awareness centrándose en su definición y describiendo que "busca caracterizar" y que "trata de responder" cada tipo. La taxonomía propuesta se resume en la Tabla VII.

TABLA VII. TIPOS DE AWARENESS

\begin{tabular}{|c|c|c|c|}
\hline 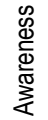 & Definición & $\begin{array}{l}\text { Busca } \\
\text { Caracteriz } \\
\text { ar }\end{array}$ & Tratando de responder a: \\
\hline \multirow{4}{*}{$\frac{\overline{\widetilde{T}}}{\mathrm{O}}$} & \multirow{4}{*}{$\begin{array}{l}\text { Información que una } \\
\text { persona mantiene sobre } \\
\text { otros en un contexto social } \\
\text { o de conversación: si una } \\
\text { persona está prestando } \\
\text { atención, su estado } \\
\text { emocional y su nivel de } \\
\text { interés. }\end{array}$} & $\begin{array}{l}\text { Intencione } \\
\mathrm{s}\end{array}$ & $\begin{array}{l}\text { ¿qué debo esperar de otros } \\
\text { miembros de este grupo? }\end{array}$ \\
\hline & & Acciones & $\begin{array}{l}\text { ¿cómo voy a interactuar con } \\
\text { este grupo? }\end{array}$ \\
\hline & & \multirow{2}{*}{$\begin{array}{l}\text { Habilidade } \\
\text { s }\end{array}$} & $\begin{array}{l}\text { ¿qué rol voy a tomar en este } \\
\text { grupo? }\end{array}$ \\
\hline & & & $\begin{array}{l}\text { ¿qué roles van a tomar los } \\
\text { miembros de este grupo? }\end{array}$ \\
\hline \multirow{6}{*}{ 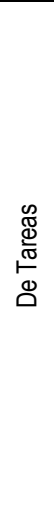 } & \multirow{6}{*}{$\begin{array}{l}\text { Es el conocimiento de cómo } \\
\text { se completará la tarea }\end{array}$} & \multirow[t]{2}{*}{$\begin{array}{l}\text { conocimie } \\
\text { nto }\end{array}$} & $\begin{array}{l}\text { ¿qué conozco acerca de este } \\
\text { tópico y la estructura de la } \\
\text { tarea? }\end{array}$ \\
\hline & & & $\begin{array}{l}\text { ¿qué conoces los otros acerca } \\
\text { de este tópico y la tarea? }\end{array}$ \\
\hline & & \multirow{2}{*}{ Acciones } & $\begin{array}{l}\text { ¿qué pasos debo tomar para } \\
\text { completar la tarea? }\end{array}$ \\
\hline & & & $\begin{array}{l}\text { ¿cómo el resultado será } \\
\text { evaluado? }\end{array}$ \\
\hline & & Artefacto & $\begin{array}{l}\text { ¿qué herramienta s/materiales } \\
\text { son necesarias para completar } \\
\text { la tarea? }\end{array}$ \\
\hline & & & $\begin{array}{l}\text { ¿qué tanto tiempo es } \\
\text { necesario? ¿cuanto tiempo } \\
\text { esta disponible? }\end{array}$ \\
\hline \multirow{4}{*}{ 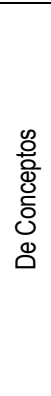 } & \multirow{4}{*}{$\begin{array}{l}\text { De cómo una determinada } \\
\text { actividad o conocimiento } \\
\text { encaja en el conocimiento } \\
\text { existente del estudiante / } \\
\text { miembro del grupo }\end{array}$} & \multirow{2}{*}{$\begin{array}{l}\text { Conocimie } \\
\text { nto }\end{array}$} & $\begin{array}{l}\text { ¿cómo esta tarea encaja } \\
\text { dentro de lo que ya se, acerca } \\
\text { del concepto? }\end{array}$ \\
\hline & & & $\begin{array}{l}\text { ¿qué mas necesito para } \\
\text { encontrar acerca de este } \\
\text { tópico? }\end{array}$ \\
\hline & & \multirow[t]{2}{*}{ Acciones } & $\begin{array}{l}\text { ¿necesito revisar algunas de } \\
\text { mis ideas actuales, en base a } \\
\text { esta nueva información? }\end{array}$ \\
\hline & & & $\begin{array}{l}\text { ¿puedo crear una hipótesis de } \\
\text { mi conocimiento actual para } \\
\text { predecir, la tarea que viene? }\end{array}$ \\
\hline \multirow{6}{*}{ 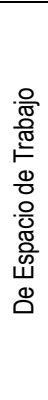 } & \multirow{6}{*}{$\begin{array}{l}\text { Preocupaciones de } \\
\text { presencia del usuario en el } \\
\text { área de trabajo y lo que los } \\
\text { usuarios están haciendo en } \\
\text { la actualidad: las } \\
\text { interacciones de hasta-al } \\
\text { minuto-conocimiento acerca } \\
\text { de otras personas con el } \\
\text { espacio de trabajo }\end{array}$} & \multirow[t]{2}{*}{ Acciones } & $\begin{array}{l}\text { ¿qué están haciendo los otros } \\
\text { miembros del grupo para } \\
\text { completar la tarea? }\end{array}$ \\
\hline & & & ¿qué están haciendo? \\
\hline & & $\begin{array}{l}\text { Acciones } \\
\text { anteriores }\end{array}$ & ¿qué han terminado ellos? \\
\hline & & Ubicación & ¿dónde están ellos? \\
\hline & & \multirow{2}{*}{$\begin{array}{l}\text { Intencione } \\
\mathrm{s}\end{array}$} & $\begin{array}{l}\text { ¿qué es lo siguiente que van } \\
\text { hacer? }\end{array}$ \\
\hline & & & $\begin{array}{l}\text { ¿cómo puedo ayudar a otros } \\
\text { miembros de grupo a } \\
\text { completar el proyecto? }\end{array}$ \\
\hline \multirow{4}{*}{ 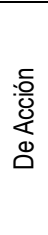 } & \multirow{4}{*}{$\begin{array}{l}\text { Describe avances en las } \\
\text { tareas aisladas, proporciona } \\
\text { información acerca de las } \\
\text { interacciones de otros } \\
\text { usuarios con los objetos del } \\
\text { espacio de trabajo }\end{array}$} & Acciones & ¿Qué esta pasando? \\
\hline & & Artefactos & ¿Qué objetos están usando? \\
\hline & & Cambios & $\begin{array}{l}\text { ¿Qué cambios están haciendo } \\
\text { y donde? }\end{array}$ \\
\hline & & $\begin{array}{l}\text { Nivel de } \\
\text { actividad }\end{array}$ & $\begin{array}{l}\text { ¿Qué tan activos son en el } \\
\text { espacio de trabajo? ¿Qué tan } \\
\text { frecuente ocupan un recurso? }\end{array}$ \\
\hline
\end{tabular}

\begin{tabular}{|c|c|c|c|}
\hline \multirow{9}{*}{ 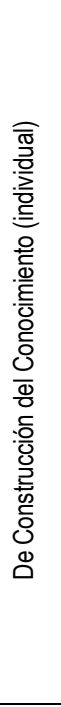 } & \multirow{9}{*}{$\begin{array}{l}\text { Corresponde a la } \\
\text { información que } \\
\text { necesitan las personas } \\
\text { obtener con el fin de } \\
\text { estar al tanto de sus } \\
\text { propios conocimientos. }\end{array}$} & $\begin{array}{l}\text { Acciones / } \\
\text { Expectativas }\end{array}$ & $\begin{array}{r}\text { ¿lo que estoy haciendo } \\
\text { esta ayudando a resolver el } \\
\text { problema? }\end{array}$ \\
\hline & & Artefacto & $\begin{array}{l}\text { ¿necesito mas } \\
\text { tiempo/recursos? }\end{array}$ \\
\hline & & \multirow{2}{*}{ Conocimiento } & $\begin{array}{l}\text { ¿qué mas necesito saber } \\
\text { acerca de este tópico? }\end{array}$ \\
\hline & & & $\begin{array}{l}\text { ¿cuánto tiempo hay } \\
\text { disponible? }\end{array}$ \\
\hline & & $\begin{array}{l}\text { Acciones / } \\
\text { Expectativas }\end{array}$ & $\begin{array}{l}\text { ¿lo que hice esta ayudando } \\
\text { a resolver el problema? }\end{array}$ \\
\hline & & $\begin{array}{l}\text { Conocimiento / } \\
\text { Acciones / } \\
\text { Habilidades }\end{array}$ & $\begin{array}{l}\text { ¿qué y como aprendí, de } \\
\text { los otros miembros del } \\
\text { grupo? }\end{array}$ \\
\hline & & $\begin{array}{l}\text { Conocimiento / } \\
\text { Nivel de } \\
\text { actividad }\end{array}$ & ¿termine el trabajo? \\
\hline & & \multirow[t]{2}{*}{ Conocimiento } & $\begin{array}{l}\text { ¿qué estoy aprendiendo del } \\
\text { grupo de trabajo? }\end{array}$ \\
\hline & & & $\begin{array}{l}\text { ¿qué necesito saber acerca } \\
\text { del tópico? }\end{array}$ \\
\hline \multirow{6}{*}{ 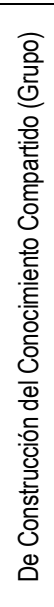 } & \multirow{6}{*}{$\begin{array}{l}\text { Corresponde a la } \\
\text { información que es } \\
\text { necesaria con el fin de } \\
\text { estar al tanto de los } \\
\text { conocimientos de los } \\
\text { otros miembros del grupo }\end{array}$} & Acciones & $\begin{array}{l}\text { ¿qué están haciendo los } \\
\text { otros miembros del grupo, } \\
\text { para completar la tarea? }\end{array}$ \\
\hline & & $\begin{array}{l}\text { Acciones/ } \\
\text { Expectativas }\end{array}$ & $\begin{array}{l}\text { ¿lo que los otros están } \\
\text { haciendo, esta ayudando a } \\
\text { resolver la tarea? }\end{array}$ \\
\hline & & Complemento & $\begin{array}{l}\text { ¿cómo puedo ayudar a } \\
\text { otros miembros a completar } \\
\text { la tarea? }\end{array}$ \\
\hline & & Conocimiento & $\begin{array}{l}\text { ¿qué saben los otros } \\
\text { miembros acerca el tópico? } \\
\text { ¿qué necesitan saber los } \\
\text { otros miembros acerca del } \\
\text { tópico? }\end{array}$ \\
\hline & & $\begin{array}{l}\text { Conocimiento / } \\
\text { Expectativas }\end{array}$ & $\begin{array}{l}\text { ¿qué aprendieron los otros } \\
\text { miembros del grupo de mi? }\end{array}$ \\
\hline & & Ubicación & $\begin{array}{l}\text { ¿dónde están los otros } \\
\text { miembros del grupo? }\end{array}$ \\
\hline \multirow{3}{*}{ 敢 } & \multirow{3}{*}{$\begin{array}{l}\text { Hace hincapié en la } \\
\text { importancia de los } \\
\text { factores contextuales de } \\
\text { actividad como la } \\
\text { planificación y la } \\
\text { coordinación. es el } \\
\text { awareness que apoya el } \\
\text { desempeño del grupo en } \\
\text { tareas complejas. Las } \\
\text { actividades son } \\
\text { esfuerzos a largo plazo } \\
\text { dirigidas a objetivos } \\
\text { importantes. }\end{array}$} & Expectativas & ¿Cómo van las cosas? \\
\hline & & \multirow{2}{*}{ Cambios } & $\begin{array}{l}\text { ¿Qué cambios hay en los } \\
\text { planes compartidos? }\end{array}$ \\
\hline & & & $\begin{array}{l}\text { ¿Qué modificaciones hay } \\
\text { en los roles del proyecto? }\end{array}$ \\
\hline 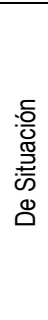 & $\begin{array}{l}\text { El conocimiento minuto a } \\
\text { minuto requerido para } \\
\text { operar o mantener un } \\
\text { sistema. la percepción } \\
\text { de los elementos } \\
\text { relevantes del entorno. } \\
\text { Comprensión de esos } \\
\text { elementos y predicción } \\
\text { del estado de esos } \\
\text { elementos }\end{array}$ & $\begin{array}{l}\text { Cambios en el } \\
\text { Entorno }\end{array}$ & $\begin{array}{l}\text { ¿Qué cambios están } \\
\text { ocurriendo en el entorno y } \\
\text { donde? }\end{array}$ \\
\hline
\end{tabular}

\section{B. Modalidades de Interacción}

En esta sección se presentan las siguientes modalidades de interacción grupal: punto a punto (sub-sección 1), estrella (subsección 2), malla (sub-sección 3), lineal (sub-sección 4), estrella - malla (sub-sección 5) y tabla de decisión de topologías (sub-sección 6).

\section{1) Punto a Punto}

En esta modalidad de interacción existen solamente dos actores conectados entre si. La comunicación la puede iniciar cualquiera de los actores en cualquier momento y pueden permanecer en una comunicación reciproca entre ellos.

El siguiente es un ejemplo de este tipo de interacción : 
- Comunicación Directa: A través de una aplicación se puede realizar un comunicación directa entre el profesor y el alumno, esta aplicación permite comunicarse por medio de una video conferencia donde se realizan y responden preguntas y cada uno va apropiando las observaciones y comentarios que se hagan. Cualquiera de los participantes puede iniciar la comunicación.

TABLA VIII. CCD DE INTERACCIÓN PUNTO A PUNTO - COMUNICACIÓN DIRECTA

\begin{tabular}{|l|l|l|}
\hline CONCEPTO & CATEGORIA & DEFINICIÓN \\
\hline PROFESOR & ACTOR & $\begin{array}{l}\text { Profesional que se dedica a } \\
\text { la enseñanza }\end{array}$ \\
\hline RLUMNO & ACTOR & $\begin{array}{l}\text { Persona interesada en } \\
\text { aprender un tema en } \\
\text { particular. }\end{array}$ \\
\hline INICIA COMUNICACIÓN & INTERACCIÓN & $\begin{array}{l}\text { Cualquier actor comienzan } \\
\text { una comunicación }\end{array}$ \\
\hline $\begin{array}{l}\text { RESPONDE } \\
\text { PREGUNTAS }\end{array}$ & INTERACCIÓN & $\begin{array}{l}\text { Cualquier actor puede } \\
\text { realizar preguntas acerca } \\
\text { del tema que se este } \\
\text { trabajando }\end{array}$ \\
\hline $\begin{array}{l}\text { APROPIA } \\
\text { OBSERVACIONES }\end{array}$ & INTERACCIÓN & $\begin{array}{l}\text { Cualquier actor da } \\
\text { respuesta a las preguntas } \\
\text { realizadas }\end{array}$ \\
\hline $\begin{array}{l}\text { APROPIA } \\
\text { COMENTARIOS }\end{array}$ & INTERACCIÓN & $\begin{array}{l}\text { El actor incorpora las } \\
\text { observaciones hechas. }\end{array}$ \\
\hline ARCHIVO & OBJETO & $\begin{array}{l}\text { Es el documentarios hechos. } \\
\text { interés entre los actores }\end{array}$ \\
\hline
\end{tabular}

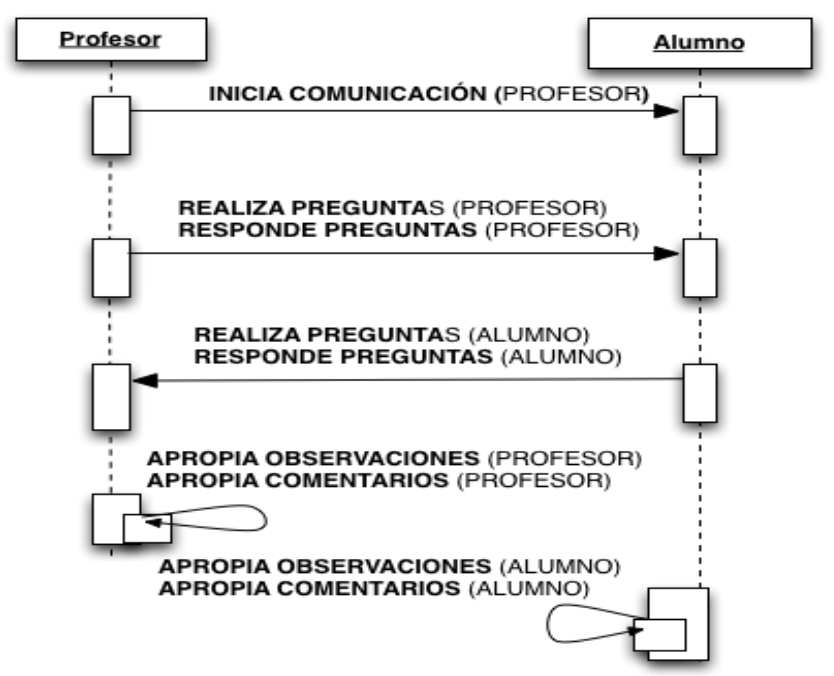

Fig. 19. Diagrama de secuencia de interacción punto a punto - Comunicación directa.

- Chat Colaborativo: Un sistema de mensajería instantánea que permite discutir en tiempo real con un cliente, un colega, un vendedor, realizar una colaboración y poder tomar decisiones. Un ejemplo mas concreto seria un diseñador y un líder de proyecto el cual estén trabajando sobre una ilustración del logo de un cliente, ambos pueden enviar y recibir mensajes realizando y respondiendo preguntas, pueden compartir uno o varias archivos y verlos directamente en la interfaz de su aplicación, y permite fácilmente dar y recibir retroalimentación e ir apropiando las observaciones y comentarios que se hagan. Cualquiera de los participantes puede iniciar la comunicación.
TABLA IX. CCD DE INTERACCIÓN PUNTO A PUNTO - CHAT COLABORATIVO

\begin{tabular}{|l|l|l|}
\hline CONCEPTO & CATEGORIA & DEFINICIÓN \\
\hline DISEÑADOR & ACTOR & $\begin{array}{l}\text { Profesional encargado de crear la } \\
\text { imagen de una aplicación }\end{array}$ \\
\hline LIDER DE PROYECTO & ACTOR & $\begin{array}{l}\text { Persona responsable de ejecutar un } \\
\text { proyecto }\end{array}$ \\
\hline $\begin{array}{l}\text { INICIA } \\
\text { COMUNICACIÓN }\end{array}$ & INTERACCIÓN & $\begin{array}{l}\text { Cualquier actor comienzan una } \\
\text { comunicación }\end{array}$ \\
\hline REALIZA PREGUNTAS & INTERACCIÓN & $\begin{array}{l}\text { Cualquier actor puede realizar } \\
\text { preguntas acerca del tema que se } \\
\text { este trabajando }\end{array}$ \\
\hline $\begin{array}{l}\text { RESPONDE } \\
\text { PREGUNTAS }\end{array}$ & INTERACCIÓN & $\begin{array}{l}\text { Cualquier actor da respuesta a las } \\
\text { preguntas realizadas }\end{array}$ \\
\hline ENVIA DOCUMENTOS & INTERACCIÓN & $\begin{array}{l}\text { Cualquier actor envía contenido de } \\
\text { interés sobre el tema que se este } \\
\text { trabajando }\end{array}$ \\
\hline $\begin{array}{l}\text { APROPIA } \\
\text { OBSERVACIONES }\end{array}$ & INTERACCIÓN & $\begin{array}{l}\text { El actor incorpora las observaciones } \\
\text { hechas. }\end{array}$ \\
\hline $\begin{array}{l}\text { APROPIA } \\
\text { COMENTARIOS }\end{array}$ & INTERACCIÓN & $\begin{array}{l}\text { El actor incorpora los comentarios } \\
\text { hechos. }\end{array}$ \\
\hline ARCHIVO & OBJETO & $\begin{array}{l}\text { Es el documento de común interés } \\
\text { entre los actores }\end{array}$ \\
\hline
\end{tabular}

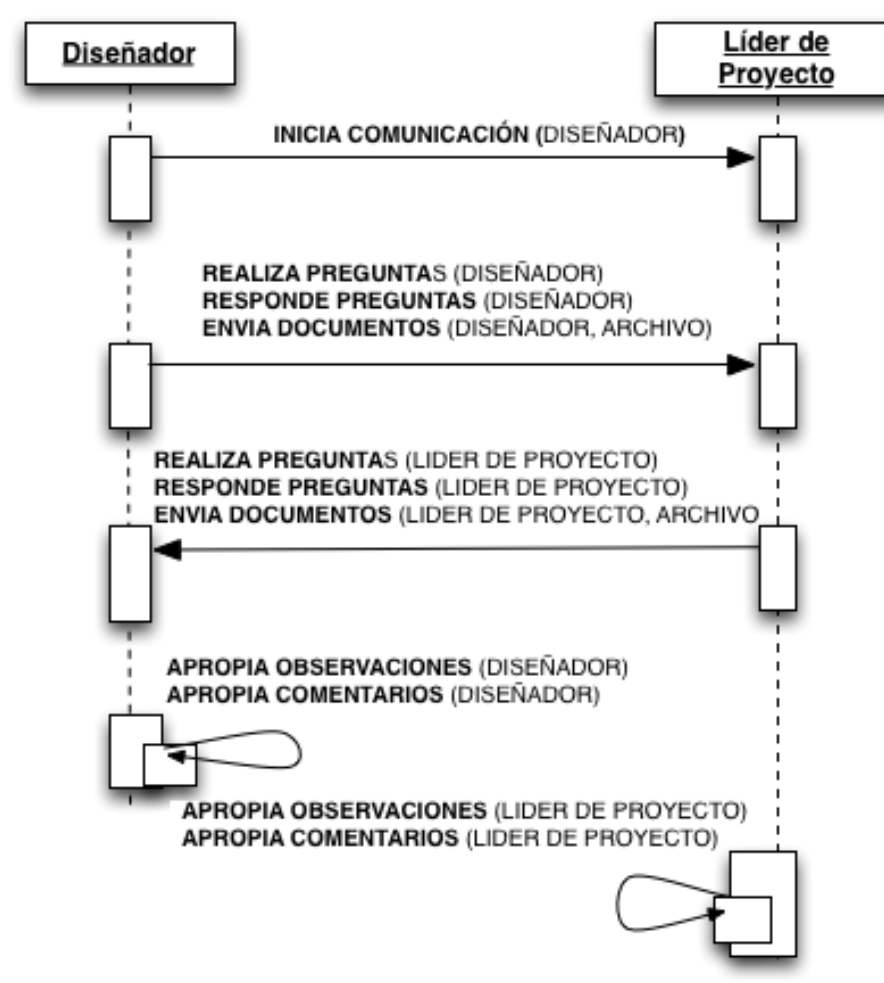

Fig. 20. Diagrama de secuencia de interacción punto a punto - Chat colaborativo

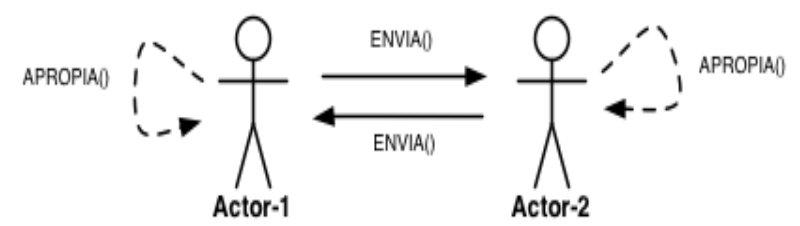

Fig. 21. Modalidad de interacción punto a punto

\section{2) Estrella}

Es una modalidad de interacción en la cual los actores están conectados directamente a un actor central. Hay un intercambio de comunicación entre el actor central y los demás actores, se puede iniciar la comunicación de dos formas, del actor central hacia los actores externos ó de los actores externos hacia el actor central. 
Los siguiente son un ejemplo de este tipo de interacción :

- Aprendizaje Virtual: Se considera una aplicación virtual de aprendizaje la cual consiste en un foro de preguntas, una herramienta de mensajería y un repositorio de archivos, el profesor asigna y coordina la actividad a realizar por los alumnos, también puede enviar por mensaje directo a los alumnos la actividad que desean que desarrollen y colocar material de apoyo en el repositorio, si los alumnos tienen alguna duda o pregunta la pueden realizar a través del foro o con un mensaje directo al profesor, este puede contestar a sus alumnos por cualquiera de las 2 formas (mensaje directo o en el foro), al terminar la actividad los alumnos deben enviar un mensaje al profesor con un archivo adjunto del resultado obtenido de la actividad para que este realiza la debida revisión.

TABLA X. CCD DE INTERACCIÓN ESTRELLA - APRENDIZAJE VIRTUAL

\begin{tabular}{|c|c|c|}
\hline CONCEPTO & CATEGORIA & DEFINICIÓN \\
\hline PROFESOR & ACTOR & $\begin{array}{l}\text { Profesional que se dedica a } \\
\text { la enseñanza }\end{array}$ \\
\hline ALUMNO & ACTOR & $\begin{array}{l}\text { Persona interesada en } \\
\text { aprender un tema en } \\
\text { particular. }\end{array}$ \\
\hline INICIA COMUNICACIÓN & INTERACCIÓN & $\begin{array}{l}\text { Cualquier actor comienzan } \\
\text { una comunicación }\end{array}$ \\
\hline REALIZA PREGUNTAS & INTERACCIÓN & $\begin{array}{l}\text { Cualquier actor puede } \\
\text { realizar preguntas acerca } \\
\text { del tema que se este } \\
\text { trabajando }\end{array}$ \\
\hline RESPONDE PREGUNTAS & INTERACCIÓN & $\begin{array}{l}\text { Cualquier actor da } \\
\text { respuesta a las preguntas } \\
\text { realizadas }\end{array}$ \\
\hline ENVIA DOCUMENTOS & INTERACCIÓN & $\begin{array}{l}\text { Cualquier actor envía } \\
\text { contenido de interés sobre } \\
\text { el tema que se este } \\
\text { tratando }\end{array}$ \\
\hline $\begin{array}{l}\text { APROPIA } \\
\text { OBSERVACIONES }\end{array}$ & INTERACCIÓN & $\begin{array}{l}\text { El actor incorpora las } \\
\text { observaciones hechas. }\end{array}$ \\
\hline ASIGNA ACTIVIDADES & INTERACCIÓN & $\begin{array}{l}\text { El actor asigna a otro actor } \\
\text { las actividades que se } \\
\text { espera realice. }\end{array}$ \\
\hline COORDINA ACTIVIDADES & INTERACCIÓN & $\begin{array}{l}\text { El actor coordina las } \\
\text { actividades que a asignado } \\
\text { o quiere asignar a otro } \\
\text { actor. }\end{array}$ \\
\hline REVISA ENTREGAS & INTERACCIÓN & $\begin{array}{l}\text { Se realiza una revisión de } \\
\text { lo que ha entregado otro } \\
\text { actor como resultado de } \\
\text { una actividad realizada }\end{array}$ \\
\hline REALIZA ACTIVIDADES & INTERACCIÓN & $\begin{array}{l}\text { La ejecución de una tarea } \\
\text { asignada para su } \\
\text { realización }\end{array}$ \\
\hline CONTENIDO & OBJETO & $\begin{array}{l}\text { Es el material, documento, } \\
\text { archivo, indicación que un } \\
\text { actor envía a otro actor. }\end{array}$ \\
\hline
\end{tabular}

- Aplicación Medica: Una aplicación medica llamada HomeCare en la cual los pacientes desde su casa usan la aplicación, que consiste de video, chat, pizarra electrónica y una herramienta llamada "estado de medicación", para comunicarse con los medico y enfermeros, acerca de su cuidado post operatorio. HomeCare provee una alerta audible cuando el paciente solicita atención, indicando la identidad del paciente y la modalidad de la comunicación, como video llamada, del mismo modo ocurre cuando un enfermero o medico se comunica con el paciente. Las enfermeras pueden ver cada movimiento del paciente con el cursor en la ventana del chat y un lápiz virtual en la pizarra. Por medio de HomeCare los enfermeros pueden coordinar los cuidados necesarios con el paciente. Con la herramienta de estado de medicación, el paciente y el equipo medico del paciente, pueden ver cuando las medicaciones fueron tomadas y si la prescripción cambio

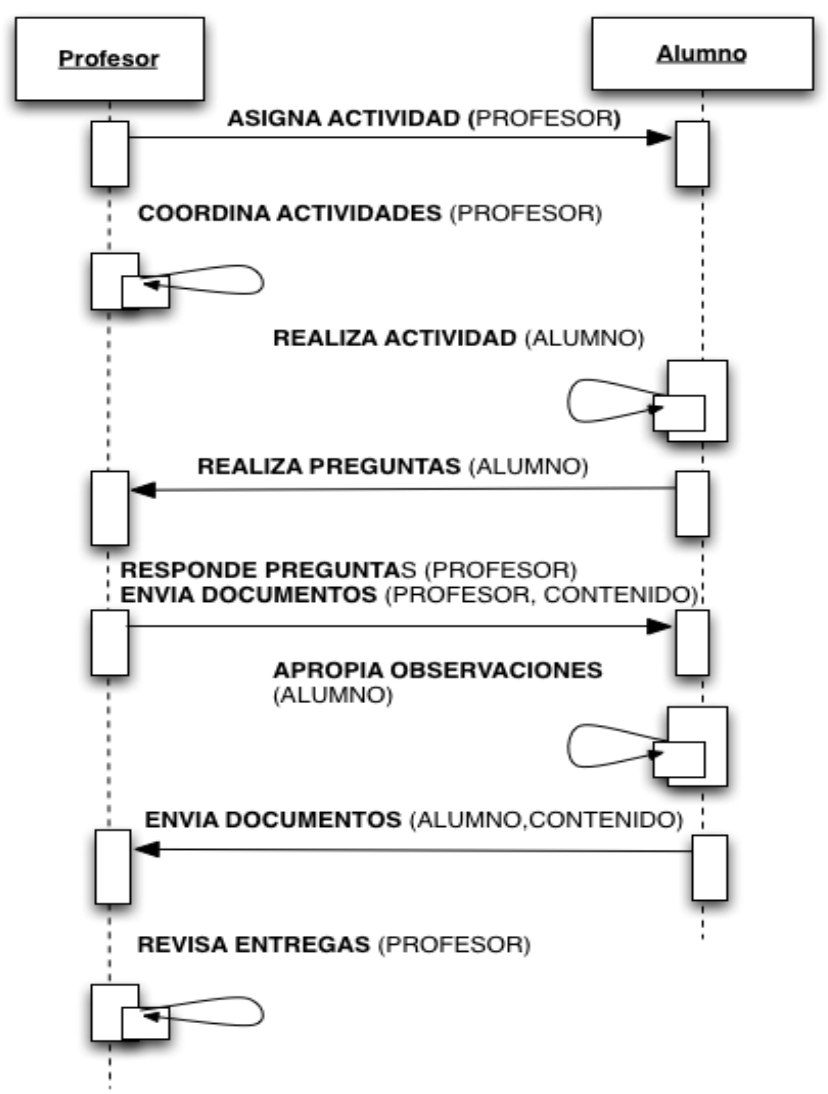

Fig. 22. Diagrama de secuencia de interacción estrella - Aprendizaje Virtual

TABLA XI. CCD DE INTERACCIÓN ESTRELLA - APLICACIÓN MEDICA

\begin{tabular}{|l|l|l|}
\hline CONCEPTO & CATEGORIA & DEFINICIÓN \\
\hline PACIENTE & ACTOR & $\begin{array}{l}\text { Profesional que se dedica a } \\
\text { la enseñanza }\end{array}$ \\
\hline ENFERMERO & ACTOR & $\begin{array}{l}\text { Persona interesada en } \\
\text { aprender un tema en } \\
\text { particular. }\end{array}$ \\
\hline MEDICO & ACTOR & $\begin{array}{l}\text { Persona interesada en } \\
\text { aprender un tema en } \\
\text { particular. }\end{array}$ \\
\hline INICIA COMUNICACIÓN & INTERACCIÓN & $\begin{array}{l}\text { Cualquier actor comienzan } \\
\text { una comunicación }\end{array}$ \\
\hline REALIZA PREGUNTAS & INTERACCIÓN & $\begin{array}{l}\text { Cualquier actor puede } \\
\text { realizar preguntas acerca } \\
\text { del tema que se este } \\
\text { trabajando }\end{array}$ \\
\hline $\begin{array}{l}\text { RESPONDE } \\
\text { PREGUNTAS }\end{array}$ & INTERACCIÓN & $\begin{array}{l}\text { Cualquier actor da } \\
\text { respuesta a las preguntas } \\
\text { realizadas }\end{array}$ \\
\hline $\begin{array}{l}\text { APROPIA } \\
\text { OBSERVACIONES }\end{array}$ & INTERACCIÓN & $\begin{array}{l}\text { El actor incorpora las } \\
\text { observaciones hechas. }\end{array}$ \\
\hline $\begin{array}{l}\text { COORDINA } \\
\text { ACTIVIDADES }\end{array}$ & $\begin{array}{l}\text { El actor coordina las } \\
\text { actividades que a asignado } \\
\text { o quiere asignar a otro } \\
\text { actor. }\end{array}$ \\
\hline INTERACCIÓN \\
\hline CONCITA ATENCIÓN \\
INFORMACIÓN & INTERACCIÓN & $\begin{array}{l}\text { El actor solicita a otro un } \\
\text { tiempo para poder } \\
\text { establecer una } \\
\text { comunicación }\end{array}$ \\
\hline ENVIA INDICACIONES & INTERACCIÓN & $\begin{array}{l}\text { Los actores consultan } \\
\text { información que se esta } \\
\text { disponible para todos o para } \\
\text { algunos }\end{array}$ \\
\hline $\begin{array}{l}\text { Un actor envía a otro las } \\
\text { tareas que quiere realice. }\end{array}$ \\
\hline ONTERACCIO & $\begin{array}{l}\text { Es el material, documento, } \\
\text { archivo, indicación que un } \\
\text { actor envía a otro actor. }\end{array}$ \\
\hline
\end{tabular}






Fig. 23. Diagrama de secuencia de interacción estrella - Aplicación Medica

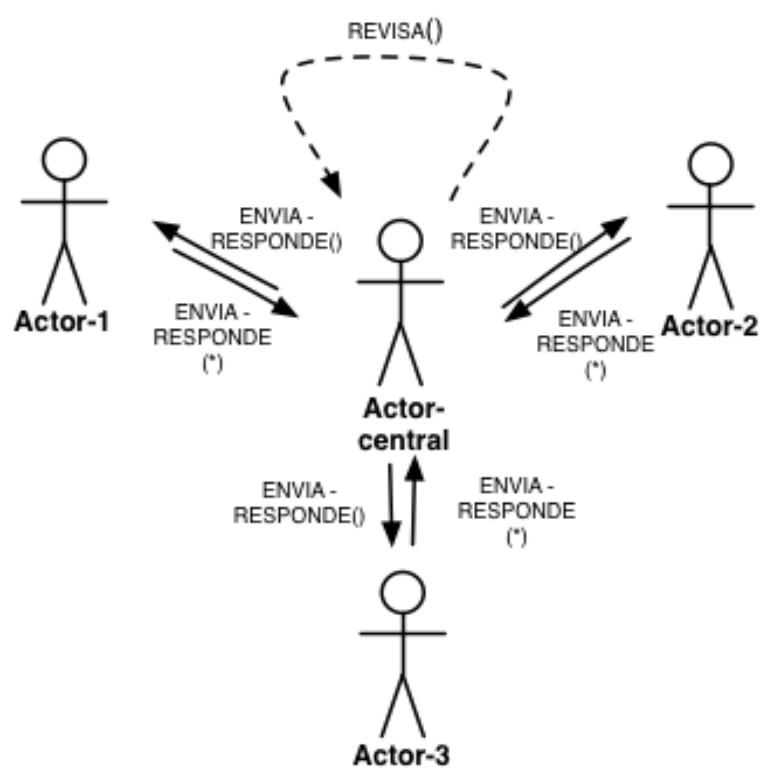

Fig. 24. Modalidad de Interacción Estrella

\section{3) Malla}

Es una modalidad de interacción en la cual existen 3 o mas actores que están conectados entre si. La comunicación puede fluir por diferentes caminos y pude ser dirigida a un actor o a todos. En este tipo de modalidad cualquier actor puede tener una jerarquía mayor a los demás.

Los siguiente son un ejemplo de este tipo de interacción :

- Outsourcing: Un grupo de desarrolladores los cuales se encuentran en diferentes ubicaciones geográficas tiene la responsabilidad de construir un aplicativo para un cliente, para la construcción de esta aplicación usan una herramienta que les permite la comunicación de forma síncrona y asíncrona (chat, videoconferencia, mail), también les permite compartir archivos y almacenarlos en un repositorio, a demás usan una herramienta de "progreso" en la cual pueden poner todas las actividades que hay que realizar para terminar la aplicación, estas actividades las pueden categorizar entre, "por hacer" , "en progreso" y "terminada", a cada una de estas actividades se les puede asignar un usuario responsable de llevar acabo esta actividad, también cuentas con una herramienta para compartir y unir el código que cada integrante va realizando. El desarrollo inicia cuando los integrantes se reúnen (videoconferencia, chat), para determinar de que forma se va separar la aplicación (fases) y cada fase en que actividades y así los integrantes seleccionen las tareas que cada uno va a desarrollar, en la herramienta se puede registrar las fases del proyecto con sus respectivos hitos y las actividades se van colocando en la herramienta de "progreso" en la categoría de "por hacer" con el nombre del desarrollador responsable en realizarla, luego cada desarrollador inicia su trabajo en las actividades que le fueron asignadas a medida que va trabajando en alguna la pone en la categoría de "progreso" y al terminarla comparte su código para que los demás lo puedan unir al de ellos y pasa la actividad a la categoría de "terminada". Si alguno de los desarrolladores tiene algún problema al unir el código puede crear un ticket con la descripción del problema (si hay usuarios en línea se les muestra una alerta, si no se envía un mail con la descripción del ticket) y este lo podrán ver todos los desarrolladores y aportar soluciones para resolver el problema. Además también se podrá crear tickets a cada actividad si fuera necesario, en este caso se enviara un correo al responsable de la actividad para que este al tanto. El manejo de las actividades anteriormente mencionado se realiza para cada fase hasta acabar el proyecto.

TABLA XII. CCD DE INTERACCIÓN MALLA - OUTSOURCING

\begin{tabular}{|l|l|l|}
\hline CONCEPTO & CATEGORIA & DEFINICIÓN \\
\hline DESARROLLADOR & ACTOR & $\begin{array}{l}\text { Profesional que se dedica a } \\
\text { ejecutar un proyecto de } \\
\text { informática }\end{array}$ \\
\hline $\begin{array}{l}\text { INICIA } \\
\text { COMUNICACIÓN }\end{array}$ & INTERACCIÓN & $\begin{array}{l}\text { Cualquier actor comienzan } \\
\text { una comunicación }\end{array}$ \\
\hline REALIZA PREGUNTAS & INTERACCIÓN & $\begin{array}{l}\text { Cualquier actor puede realizar } \\
\text { preguntas acerca del tema } \\
\text { que se este trabajando }\end{array}$ \\
\hline $\begin{array}{l}\text { RESPONDE } \\
\text { PREGUNTAS }\end{array}$ & INTERACCIÓN & $\begin{array}{l}\text { Cualquier actor da respuesta a } \\
\text { las preguntas realizadas }\end{array}$ \\
\hline ENVIA DOCUMENTOS & INTERACCIÓN & $\begin{array}{l}\text { Cualquier actor envía } \\
\text { contenido de interés sobre el } \\
\text { tema que se este tratando }\end{array}$ \\
\hline EDITA DOCUMENTOS & INTERACCIÓN & $\begin{array}{l}\text { Se edita el contenido de un } \\
\text { documento en el que se este } \\
\text { trabajando }\end{array}$ \\
\hline $\begin{array}{l}\text { APROPIA } \\
\text { OBSERVACIONES }\end{array}$ & INTERACCIÓN & $\begin{array}{l}\text { El actor incorpora las } \\
\text { observaciones hechas. }\end{array}$ \\
\hline ASIGNA ACTIVIDADES & INTERACCIÓN & $\begin{array}{l}\text { El actor asigna a otro actor las } \\
\text { actividades que se espera } \\
\text { realice. }\end{array}$ \\
\hline $\begin{array}{l}\text { SELECCIONAR } \\
\text { TAREAS }\end{array}$ & INTERACCIÓN & $\begin{array}{l}\text { El actor selecciona las tareas } \\
\text { a desarrollar }\end{array}$ \\
\hline $\begin{array}{l}\text { COORDINA } \\
\text { ACTIVIDADES }\end{array}$ & INTERACCIÓN & $\begin{array}{l}\text { El actor coordina las } \\
\text { actividades que a asignado o } \\
\text { quiere asignar a otro actor. }\end{array}$ \\
\hline DISCUTE ARCHIVOS & INTERACCIÓN & $\begin{array}{l}\text { Se realiza una discusión en } \\
\text { base a archivo enviado por } \\
\text { actor }\end{array}$ \\
\hline $\begin{array}{l}\text { REALIZA } \\
\text { ACTIVIDADES }\end{array}$ & $\begin{array}{l}\text { La ejecución de una tarea } \\
\text { asignada para su realización }\end{array}$ \\
\hline $\begin{array}{l}\text { Es el material, documento, } \\
\text { archivo, artefactos de software } \\
\text { que un actor envía a otro } \\
\text { actor. }\end{array}$ \\
\hline
\end{tabular}




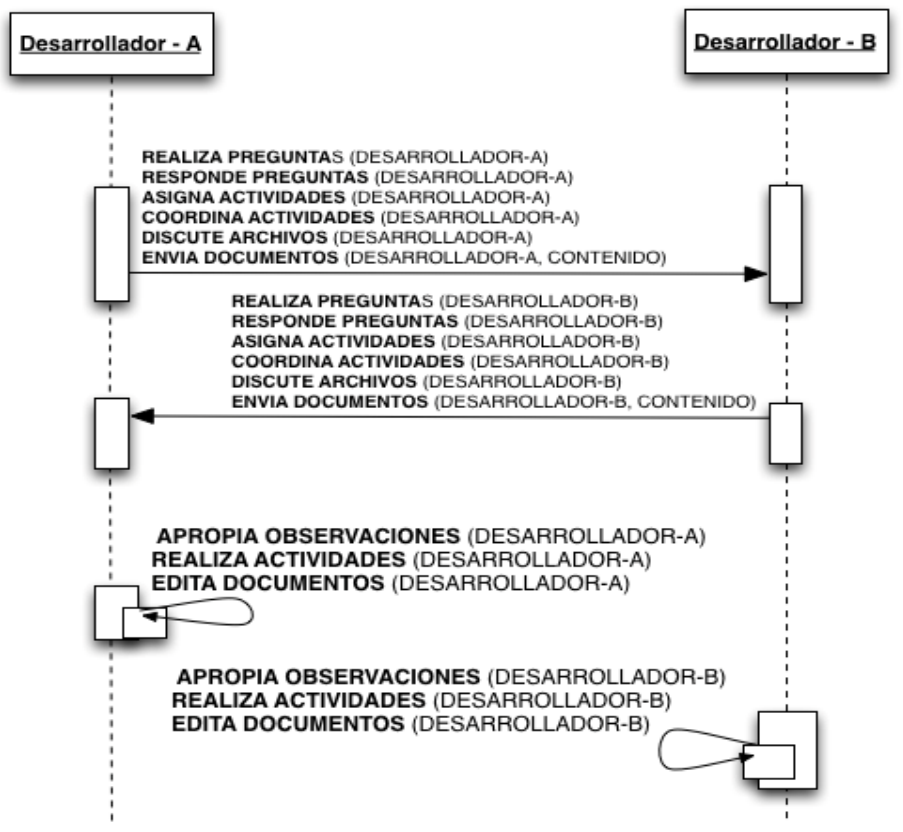

Fig. 25. Diagrama de secuencia de interacción malla - Outsourcing

- BrainStorming: La aplicación permite a los usuarios elaborar una lluvia de ideas de forma colaborativa para proyectos y actividades, donde los usuarios pueden acceder para agregar y modificar la información que allí aparece, en el espacio de trabajo se puede agregar información de todo tipo, texto, imágenes, iconos, enlaces, videos. Un usuario facilitador propone el tema sobre el cual se hará la lluvia de ideas, Las contribuciones que hace cada usuario las puede ver en tiempo real todos los integrantes del grupo, además los usuarios se pueden comunicar por medio de un chat o si no se encuentra conectado se envía un mail, también se pueden colocar comentarios sobre las contribuciones de otros usuarios, ya sea para pedir alguna aclaración o realizar un aporte, esto ayuda a fomentar la discusión en el grupo sobre las ideas que se van planteando. Los usuarios pueden cambiar y añadir todo el contenido que deseen, a medida que las participaciones crecen todos los integrantes van apropiando los aportes de los demás para ir mejorando la idea en la que se esta trabajando, finalmente eligen la mejor idea que les parezca y luego el usuario facilitador y puede publicar la idea final para poderla presentarla.

TABLA XIII. CCD DE INTERACCIÓN MALLA - BRAINSTORMING

\begin{tabular}{|l|l|l|}
\hline CONCEPTO & CATEGORIA & DEFINICIÓN \\
\hline PARTICIPANTE & ACTOR & $\begin{array}{l}\text { Usuario que ayuda a la } \\
\text { creación de una idea }\end{array}$ \\
\hline FACILITADOR & ACTOR & $\begin{array}{l}\text { Usuario que ayuda a la } \\
\text { creación de una idea, dando } \\
\text { un tema base y ayudado a que } \\
\text { la comunicación fluya }\end{array}$ \\
\hline $\begin{array}{l}\text { INICIA } \\
\text { COMUNICACIÓN }\end{array}$ & INTERACCIÓN & $\begin{array}{l}\text { El facilitador comienza la } \\
\text { comunicación }\end{array}$ \\
\hline $\begin{array}{l}\text { REALIZA } \\
\text { PREGUNTAS }\end{array}$ & INTERACCIÓN & $\begin{array}{l}\text { Cualquier actor puede realizar } \\
\text { preguntas acerca del tema } \\
\text { que se este trabajando }\end{array}$ \\
\hline $\begin{array}{l}\text { RESPONDE } \\
\text { PREGUNTAS }\end{array}$ & INTERACCIÓN & $\begin{array}{l}\text { Cualquier actor da respuesta a } \\
\text { las preguntas realizadas }\end{array}$ \\
\hline PUBLICA ARCHIVOS & INTERACCIÓN & $\begin{array}{l}\text { Cualquier actor envía } \\
\text { contenido de interés sobre el } \\
\text { tema que se este tratando }\end{array}$ \\
\hline PUBLICA AVANCES & INTERACCIÓN & $\begin{array}{l}\text { Se publica ideas previas para } \\
\text { la discusión del grupo }\end{array}$ \\
\hline $\begin{array}{l}\text { FACILITA } \\
\text { COMUNICACION }\end{array}$ & INTERACCIÓN & $\begin{array}{l}\text { Ayuda a que la idea base no } \\
\text { se disperse si no que este }\end{array}$ \\
\hline
\end{tabular}

\begin{tabular}{|l|l|l|}
\hline & & siempre enfocada \\
\hline REGISTRA IDEAS & INTERACCIÓN & $\begin{array}{l}\text { Se asegura que las ideas de } \\
\text { los participantes queden } \\
\text { registradas }\end{array}$ \\
\hline ELEGIR IDEAS & INTERACCIÓN & $\begin{array}{l}\text { Los actores eligen la mejor } \\
\text { idea. }\end{array}$ \\
\hline APORTA IDEAS & INTERACCIÓN & $\begin{array}{l}\text { Aporte parcial acerca de un } \\
\text { tema de interés }\end{array}$ \\
\hline $\begin{array}{l}\text { APROPIA } \\
\text { OBSERVACIONES }\end{array}$ & INTERACCIÓN & $\begin{array}{l}\text { El actor incorpora las } \\
\text { observaciones hechas. }\end{array}$ \\
\hline $\begin{array}{l}\text { COMENTA } \\
\text { ARCHIVOS }\end{array}$ & INTERACCIÓN & $\begin{array}{l}\text { Se realiza una discusión en } \\
\text { base a archivo enviado por } \\
\text { actor }\end{array}$ \\
\hline CONTENIDO & OBJETO & $\begin{array}{l}\text { Es el material, documento, } \\
\text { archivo, artefactos de software } \\
\text { que un actor envía a otro } \\
\text { actor. }\end{array}$ \\
\hline
\end{tabular}

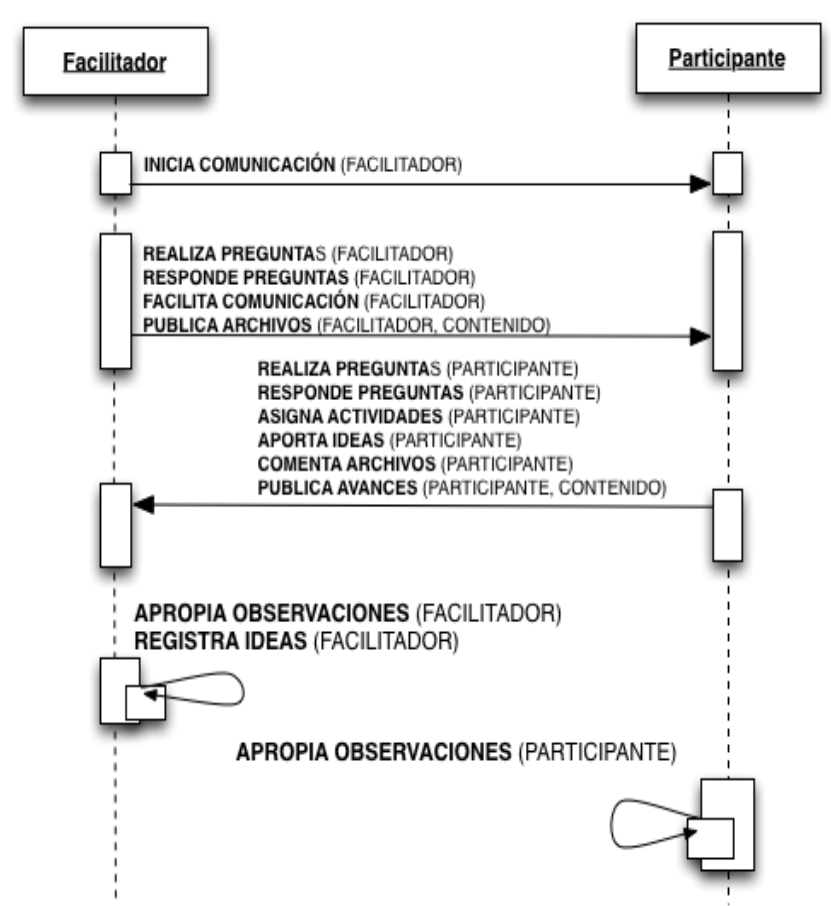

Fig. 26. Diagrama de secuencia de interacción malla-BrainStorming

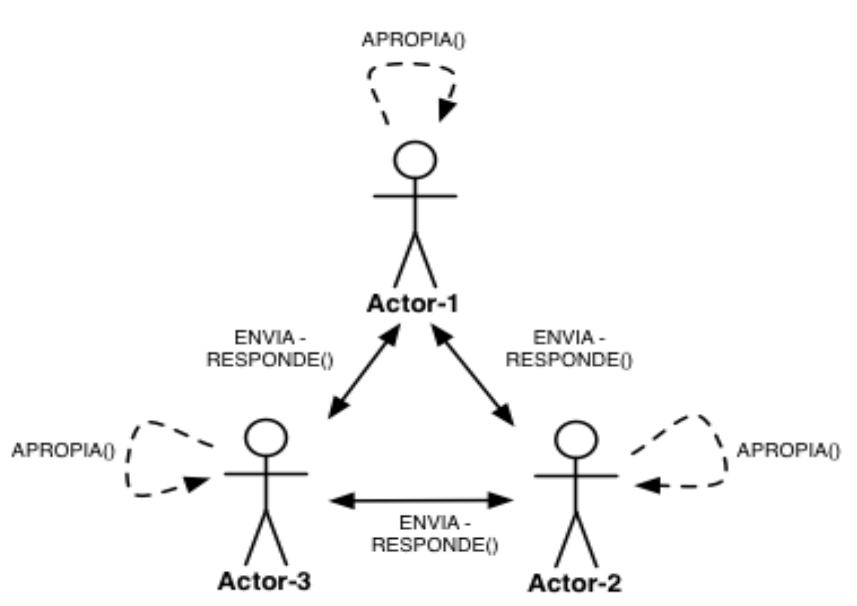

Fig. 27. Modalidad de Interacción Malla

\section{4) Lineal}

Es una modalidad de interacción en la cual existen dos o mas actores de forma jerárquica, la comunicación es lineal, bidireccional y ordenada en el tiempo, cualquiera de los actores puede iniciar la comunicación pero solo puede comunicarse con el que es inmediatamente superior a este.

El siguiente es un ejemplo de este tipo de interacción : 
Revisión Plan de Tesis: La situación descrita en el caso se basa en las interacciones mediadas por un espacio virtual desarrolladas durante la revisión del plan de tesis de maestría por un tesista de doctorado (co-director de la tesis de maestría) con la supervisión de dicha revisión por un investigador formado (director de la tesis de maestría y de la tesis de doctorado). La aplicación permite el envió de documentos, creación de comentarios y observaciones sobre los documentos, creación de versiones de los documentos. "El investigador tesista de maestría le envía al investigador tesista de doctorado su plan de tesis de maestría desarrollado a partir del tema previamente seleccionado. El investigador tesista de doctorado revisa el plan de tesis recibido y realiza las correcciones y observaciones que considera pertinentes para luego enviárselas al investigador tesista de maestría. Éste se apropia de las correcciones y observaciones recibidas para continuar trabajando en su plan de tesis de maestría. Una vez que el investigador tesista de doctorado considera que la versión del plan de tesis de maestría no presenta problemas, se la reenvía al investigador formado solicitándole que supervise que el documento se encuentra listo. El investigado formado supervisa las correcciones realizadas por el investigador tesista de doctorado. Como resultado de la supervisión, le puede enviar comentarios que pueden incluir observaciones sobre la corrección realizada y/o nuevas correcciones para realizar. Al recibir estos comentarios, el investigador tesista de doctorado se los apropia y se los reenvía al investigador tesista de maestría para que también se los apropie generando así nuevas versiones del documento....”.

TABLA XIV. CCD DE INTERACCIÓN LINEAL - REVISIÓN DE PLAN DE TESIS

\begin{tabular}{|c|c|c|}
\hline CONCEPTO & CATEGORIA & DEFINICIÓN \\
\hline $\begin{array}{l}\text { DIRECTOR DE } \\
\text { TESIS }\end{array}$ & ACTOR & $\begin{array}{l}\text { Profesional que está realizando una } \\
\text { carrera de doctorado con título de } \\
\text { magíster o formación académica } \\
\text { equivalente, con producción científica } \\
\text { de relevancia nacional, con } \\
\text { antecedentes en la codirección de } \\
\text { proyectos de I\&D }\end{array}$ \\
\hline $\begin{array}{l}\text { INVESTIGADOR } \\
\text { FORMADO }\end{array}$ & ACTOR & $\begin{array}{l}\text { Profesional con título de doctor o } \\
\text { formación académica equivalente, con } \\
\text { producción científica de relevancia } \\
\text { internacional, con antecedentes en la } \\
\text { dirección de proyectos de I\&D, con } \\
\text { antecedentes en la formación de } \\
\text { recursos humanos a nivel de } \\
\text { doctorado, maestría, especialización y } \\
\text { grado, y docente investigador } \\
\text { categoría I ó II de la SPU-ME. }\end{array}$ \\
\hline ALUMNO & ACTOR & $\begin{array}{l}\text { Profesional con título de grado que } \\
\text { está realizando una carrera de } \\
\text { maestría, }\end{array}$ \\
\hline $\begin{array}{l}\text { INICIA } \\
\text { COMUNICACIÓN }\end{array}$ & INTERACCIÓN & $\begin{array}{l}\text { Cualquier actor comienzan una } \\
\text { comunicación }\end{array}$ \\
\hline $\begin{array}{l}\text { REALIZA } \\
\text { PREGUNTAS }\end{array}$ & INTERACCIÓN & $\begin{array}{l}\text { Cualquier actor puede realizar } \\
\text { preguntas acerca del tema que se } \\
\text { este trabajando }\end{array}$ \\
\hline $\begin{array}{l}\text { REALIZA } \\
\text { ACTIVIDADES }\end{array}$ & INTERACCIÓN & $\begin{array}{l}\text { La ejecución de una tarea asignada } \\
\text { para su realización }\end{array}$ \\
\hline $\begin{array}{l}\text { EDITA } \\
\text { DOCUMENTOS }\end{array}$ & INTERACCIÓN & $\begin{array}{l}\text { Se edita el contenido de un } \\
\text { documento en el que se este } \\
\text { trabajando }\end{array}$ \\
\hline $\begin{array}{l}\text { ENVIA } \\
\text { DOCUMENTOS }\end{array}$ & INTERACCIÓN & $\begin{array}{l}\text { Cualquier actor envía contenido de } \\
\text { interés sobre el tema que se este } \\
\text { tratando }\end{array}$ \\
\hline $\begin{array}{l}\text { APROPIA } \\
\text { CORRECCIONES }\end{array}$ & INTERACCIÓN & $\begin{array}{l}\text { El actor incorpora las correcciones } \\
\text { hechas. }\end{array}$ \\
\hline $\begin{array}{l}\text { APROPIA } \\
\text { OBSERVACIONES }\end{array}$ & INTERACCIÓN & $\begin{array}{l}\text { El actor incorpora las observaciones } \\
\text { hechas. }\end{array}$ \\
\hline
\end{tabular}

\begin{tabular}{|l|l|l|}
\hline $\begin{array}{l}\text { RESPONDE } \\
\text { PREGUNTAS }\end{array}$ & INTERACCIÓN & $\begin{array}{l}\text { Cualquier actor da respuesta a las } \\
\text { preguntas realizadas }\end{array}$ \\
\hline $\begin{array}{l}\text { ASIGNA } \\
\text { ACTIVIDADES }\end{array}$ & INTERACCIÓN & $\begin{array}{l}\text { El actor asigna a otro actor las } \\
\text { actividades que se espera realice. }\end{array}$ \\
\hline REVISA ENTREGAS & INTERACCIÓN & $\begin{array}{l}\text { Se realiza una revisión de lo que ha } \\
\text { entregado otro actor como resultado } \\
\text { de una actividad realizada }\end{array}$ \\
\hline $\begin{array}{l}\text { REVISA } \\
\text { DOCUMENTOS }\end{array}$ & INTERACCIÓN & $\begin{array}{l}\text { Se realiza una revisión de los } \\
\text { documentos entregados por otro actor. }\end{array}$ \\
\hline COMENTA & INTERACCIÓN & $\begin{array}{l}\text { Se realiza comentarios sobre los } \\
\text { archivos entregados por otro actor. }\end{array}$ \\
\hline $\begin{array}{l}\text { REALIZA } \\
\text { CORRECCIONES }\end{array}$ & INTERACCIÓN & $\begin{array}{l}\text { Se realiza correcciones sobre los } \\
\text { documentos entregados por otro actor } \\
\text { o sobre las actividades realizadas por } \\
\text { algún actor. }\end{array}$ \\
\hline $\begin{array}{l}\text { REALIZA } \\
\text { OBSERVACIONES }\end{array}$ & INTERACCIÓN & $\begin{array}{l}\text { Se realiza observaciones sobre los } \\
\text { documentos entregados por otro actor } \\
\text { o sobre las actividades realizadas por } \\
\text { algún actor. }\end{array}$ \\
\hline $\begin{array}{l}\text { APROPIA } \\
\text { COMENTARIOS }\end{array}$ & INTERACCIÓN & $\begin{array}{l}\text { El actor incorpora los comentarios } \\
\text { hechos. }\end{array}$ \\
\hline $\begin{array}{l}\text { SUPERVISA } \\
\text { ACTIVIDADES }\end{array}$ & INTERACCIÓN & $\begin{array}{l}\text { El actor se asegura que las } \\
\text { actividades asignadas se ejecuten de } \\
\text { la manera correcta }\end{array}$ \\
\hline CONTENIDO & $\begin{array}{l}\text { Es el material, documento, archivo } \\
\text { que un actor envía a otro actor. }\end{array}$ \\
\hline
\end{tabular}

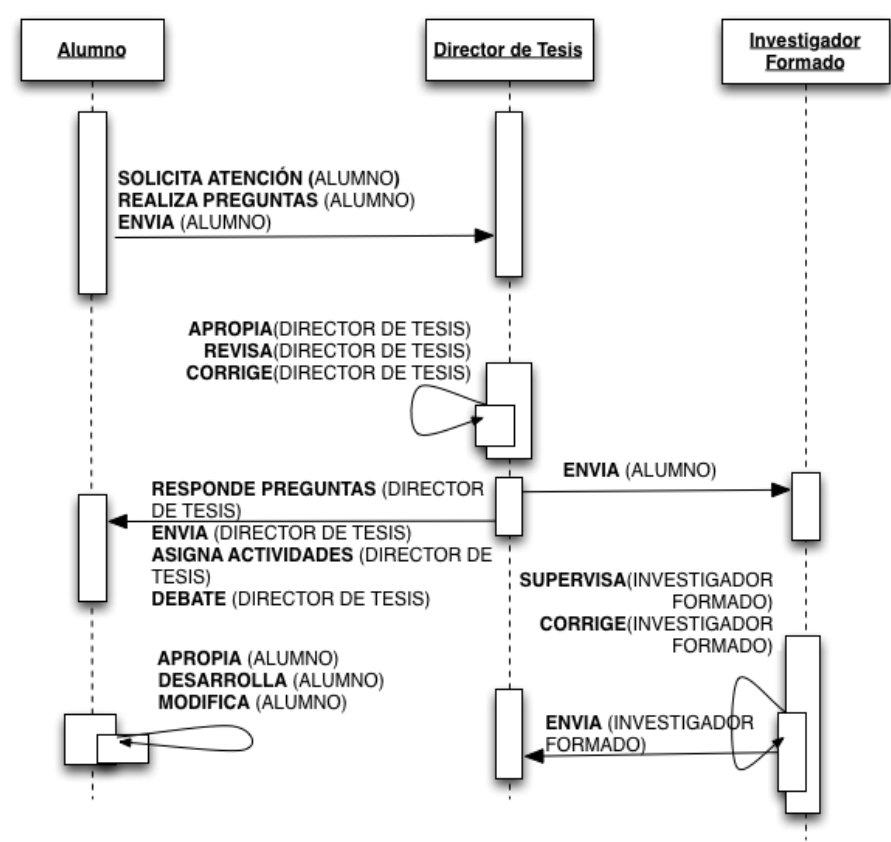

Fig. 28. Diagrama de secuencia de interacción lineal - - Revisión Plan de Tesis

- Revisión de Avances de un producto de software: En la construcción de un producto de software el equipo de desarrollo trabaja sobre un conjunto de tareas previamente establecidas, una vez completado el avance este se somete a una revisión de control de calidad por la persona encargada la cual en un equipo pequeño puede ser el líder del proyecto el cual realiza sugerencias y emite objeciones sobre los artefactos puestos a revisión, esto el equipo de desarrollo lo apropia y hace las correcciones necesarias, a su vez el líder del proyecto puede informar al stakeholder sobre los avances realizados y este da las observaciones correspondientes que sirven de retroalimentación al líder del proyecto. 
TABLA XV. CCD DE INTERACCIÓN LINEAL - REVISIÓN DE AVANCES DE UN PRODUCTO DE SOFTWARE

\begin{tabular}{|c|c|c|}
\hline CONCEPTO & CATEGORIA & DEFINICIÓN \\
\hline STAKEHOLDER & ACTOR & $\begin{array}{l}\text { Profesional que está interesado en } \\
\text { la realización de un proyecto de } \\
\text { software }\end{array}$ \\
\hline $\begin{array}{l}\text { LIDER DE } \\
\text { PROYECTO }\end{array}$ & ACTOR & $\begin{array}{l}\text { Profesional responsable de la } \\
\text { ejecución de un proyecto de } \\
\text { software }\end{array}$ \\
\hline DESARROLLADOR & ACTOR & $\begin{array}{l}\text { Profesional encargado de la } \\
\text { construcción de un producto de } \\
\text { software }\end{array}$ \\
\hline $\begin{array}{l}\text { INICIA } \\
\text { COMUNICACIÓN }\end{array}$ & INTERACCIÓN & $\begin{array}{l}\text { Cualquier actor comienzan una } \\
\text { comunicación }\end{array}$ \\
\hline $\begin{array}{l}\text { REALIZA } \\
\text { PREGUNTAS }\end{array}$ & INTERACCIÓN & $\begin{array}{l}\text { Cualquier actor puede realizar } \\
\text { preguntas acerca del tema que se } \\
\text { este trabajando }\end{array}$ \\
\hline $\begin{array}{l}\text { REALIZA } \\
\text { ACTIVIDADES }\end{array}$ & INTERACCIÓN & $\begin{array}{l}\text { La ejecución de una tarea asignada } \\
\text { para su realización }\end{array}$ \\
\hline $\begin{array}{l}\text { APROPIA } \\
\text { CORRECCIONES }\end{array}$ & INTERACCIÓN & $\begin{array}{l}\text { El actor incorpora las correcciones } \\
\text { hechas. }\end{array}$ \\
\hline $\begin{array}{l}\text { APROPIA } \\
\text { OBSERVACIONES }\end{array}$ & INTERACCIÓN & $\begin{array}{l}\text { El actor incorpora las } \\
\text { observaciones hechas. }\end{array}$ \\
\hline $\begin{array}{l}\text { RESPONDE } \\
\text { PREGUNTAS }\end{array}$ & INTERACCIÓN & $\begin{array}{l}\text { Cualquier actor da respuesta a las } \\
\text { preguntas realizadas }\end{array}$ \\
\hline ENVIA ENTREGAS & INTERACCIÓN & $\begin{array}{l}\text { Cualquier actor envía contenido de } \\
\text { interés sobre el tema que se este } \\
\text { tratando }\end{array}$ \\
\hline $\begin{array}{l}\text { ASIGNA } \\
\text { ACTIVIDADES }\end{array}$ & INTERACCIÓN & $\begin{array}{l}\text { El actor asigna a otro actor las } \\
\text { actividades que se espera realice. }\end{array}$ \\
\hline REVISA ENTREGAS & INTERACCIÓN & $\begin{array}{l}\text { Se realiza una revisión de lo que } \\
\text { ha entregado otro actor como } \\
\text { resultado de una actividad } \\
\text { realizada }\end{array}$ \\
\hline $\begin{array}{l}\text { REALIZA } \\
\text { CORRECCIONES }\end{array}$ & INTERACCIÓN & $\begin{array}{l}\text { Se realiza correcciones sobre los } \\
\text { documentos entregados por otro } \\
\text { actor o sobre las actividades } \\
\text { realizadas por algún actor. }\end{array}$ \\
\hline $\begin{array}{l}\text { REALIZA } \\
\text { OBSERVACIONES }\end{array}$ & INTERACCIÓN & $\begin{array}{l}\text { Se realiza observaciones sobre los } \\
\text { documentos entregados por otro } \\
\text { actor o sobre las actividades } \\
\text { realizadas por algún actor. }\end{array}$ \\
\hline $\begin{array}{l}\text { SUPERVISA } \\
\text { ACTIVIDADES }\end{array}$ & INTERACCIÓN & $\begin{array}{l}\text { El actor se asegura que las } \\
\text { actividades asignadas se ejecuten } \\
\text { de la manera correcta }\end{array}$ \\
\hline CONTENIDO & OBJETO & $\begin{array}{l}\text { Es el material, documento, archivo } \\
\text { que un actor envía a otro actor. }\end{array}$ \\
\hline
\end{tabular}

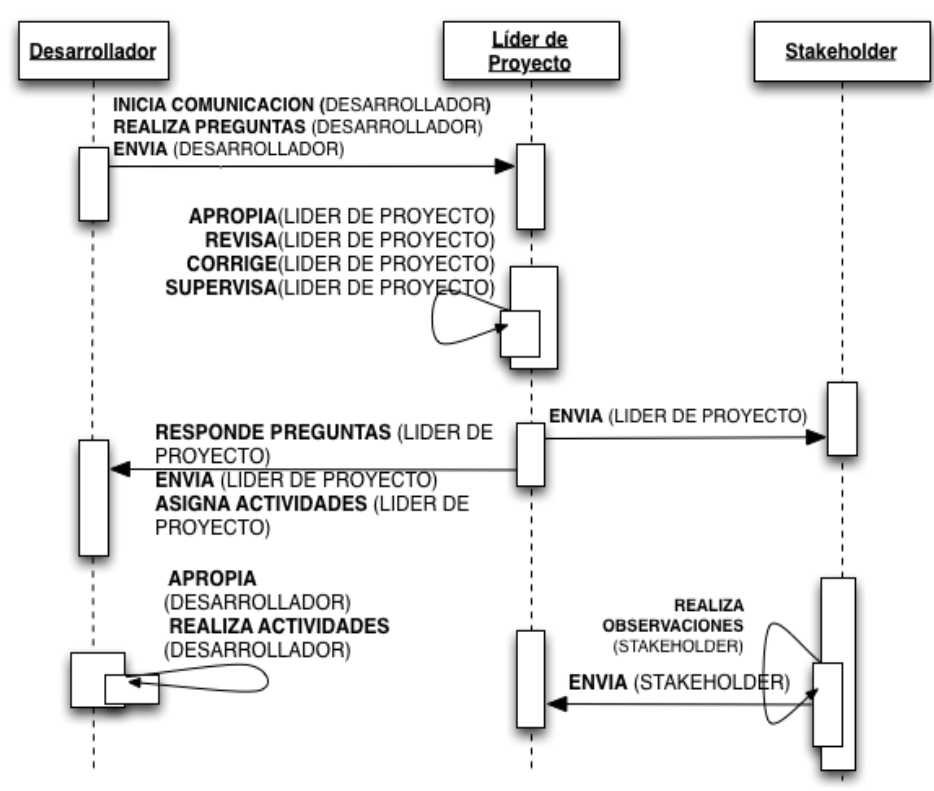

Fig. 29. Diagrama de secuencia de interacción lineal - Revisión de Avances de un producto de software

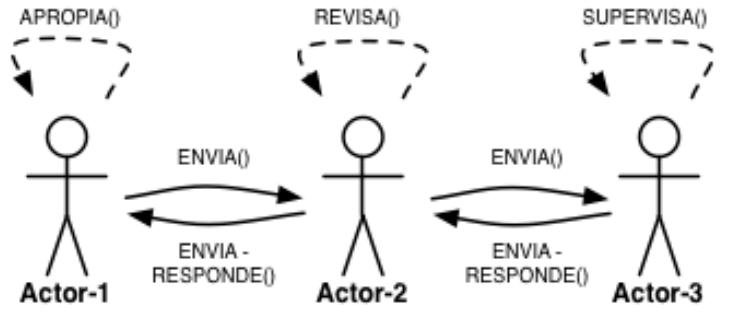

Fig. 30. Modalidad de Interacción Lineal

\section{5) Modalidades de Interacción Compuesta}

Dado que hay algunas funcionalidades de los sistema que tienen varias formas de interacción, pueden existir algunas combinaciones de las modalidades anteriormente mencionadas.

a) Estrella-Malla : Es una modalidad de interacción en la cual existen grupos de actores en donde cada grupo es integrado por dos o mas actores y están conectados entre si, estos grupos están conectados directamente a un actor central. Hay un intercambio de comunicación entre el actor central y los grupos de actores, El actor central es la que inicia la comunicación y al llegar al grupo este tiene autonomía de poderse comunicar libremente unos con otros y luego poder responder al actor central.

El siguiente es un ejemplo de este tipo de interacción :

- Aprendizaje Virtual Grupal: Se tiene un aplicación de aprendizaje en línea para el desarrollo de actividades grupales con la supervisión del profesor, este asigna los problemas a resolver para los grupos de alumnos y los publica en un tablero para que todos los grupos lo puedan visualizar, el docente publica en un repositorio de archivos información especializada de acuerdo a cada problemática planteada, Cada uno de los problemas tienen la característica de propiciar la interacción social, la discusión y la colaboración y esta en el contexto de desarrollo de aplicativos. Los alumnos se pueden comunicar entre si utilizando mecanismos de comunicación síncrona y asíncrona, (chat, videoconferencia, mail, edición en línea de documentos de texto, y una herramienta para compartir código). cuando se publica un nuevo aporte de código, el sistema se encarga de enviar un mensaje vía correo electrónico indicando que se ha expuesto una nueva contribución, si el alumno no se encuentra conectado. Cuando sí lo esta, (en línea) aparece el mensaje en la parte inferior derecha de su pantalla. El objetivo es permitir que los integrantes del grupo tengan una percepción de lo que hacen los demás para que incluyan este referente dentro de su propio trabajo. El grupo puede ir publicando avances parciales del trabajo que van realizando, El docente observa constantemente los aportes publicados dándose cuenta de la calidad de estos y del nivel de avance de los grupos, así mismo puede dar recomendaciones a cada grupo. Al final cada grupo publica su desarrollo y de allí el docente evalúa el trabajo y realiza recomendaciones finales.

TABLA XVI. CCD DE INTRACCIÓN ESTRELLA - MALLA, APRENDIZAJE VIRTUAL GRUPAL

\begin{tabular}{|l|l|l|}
\hline CONCEPTO & CATEGORIA & DEFINICIÓN \\
\hline PROFESOR & ACTOR & Profesional que se dedica a la enseñanza \\
\hline ALUMNO & ACTOR & $\begin{array}{l}\text { Persona interesada en aprender un tema } \\
\text { en particular. }\end{array}$ \\
\hline $\begin{array}{l}\text { INICIA } \\
\text { COMUNICACIÓN }\end{array}$ & INTERACCIÓN & $\begin{array}{l}\text { Cualquier actor comienzan una } \\
\text { comunicación }\end{array}$ \\
\hline
\end{tabular}




\begin{tabular}{|l|l|l|}
\hline $\begin{array}{l}\text { REALIZA } \\
\text { PREGUNTAS }\end{array}$ & INTERACCIÓN & $\begin{array}{l}\text { Cualquier actor puede realizar preguntas } \\
\text { acerca del tema que se este trabajando }\end{array}$ \\
\hline $\begin{array}{l}\text { RESPONDE } \\
\text { PREGUNTAS }\end{array}$ & INTERACCIÓN & $\begin{array}{l}\text { Cualquier actor da respuesta a las } \\
\text { preguntas realizadas }\end{array}$ \\
\hline $\begin{array}{l}\text { PUBLICA } \\
\text { ARCHIVOS }\end{array}$ & INTERACCIÓN & $\begin{array}{l}\text { Un actor envía un archivo a todos los } \\
\text { demás actores para que puedan verlo, o } \\
\text { lo envía a una aplicación donde puedan } \\
\text { acceder los demás actores }\end{array}$ \\
\hline $\begin{array}{l}\text { PUBLICA } \\
\text { ACTIVIDADES }\end{array}$ & INTERACCIÓN & $\begin{array}{l}\text { Un actor envía una actividad a todos los } \\
\text { demás actores para que puedan verlo, o } \\
\text { lo envía a una aplicación donde puedan } \\
\text { acceder los demás actores }\end{array}$ \\
\hline $\begin{array}{l}\text { PUBLICA } \\
\text { AVANCES }\end{array}$ & $\begin{array}{l}\text { Un actor envía una resultado parcial de la } \\
\text { actividad a todos los demás actores para } \\
\text { que puedan verlo, o lo envía a una } \\
\text { aplicación donde puedan acceder los } \\
\text { demás actores }\end{array}$ \\
\hline APORTA IDEAS & INTERACCIÓN & $\begin{array}{l}\text { Un actor realiza un aporte sobre el tema } \\
\text { que se este trabajando dentro del grupo. }\end{array}$ \\
\hline $\begin{array}{l}\text { APROPIA } \\
\text { OBSERVACIONE } \\
\text { S }\end{array}$ & INTERACCIÓN & $\begin{array}{l}\text { El actor incorpora las observaciones } \\
\text { hechas. }\end{array}$ \\
\hline $\begin{array}{l}\text { ASIGNA } \\
\text { ACTIVIDADES }\end{array}$ & INTERACCIÓN & $\begin{array}{l}\text { El actor asigna a otro actor las actividades } \\
\text { que se espera realice. }\end{array}$ \\
\hline $\begin{array}{l}\text { COORDINA } \\
\text { ACTIVIDADES }\end{array}$ & INTERACCIÓN & $\begin{array}{l}\text { El actor coordina las actividades que a } \\
\text { asignado o quiere asignar a otro actor. }\end{array}$ \\
\hline $\begin{array}{l}\text { SUPERVISA } \\
\text { ACTIVIDADES }\end{array}$ & INTERACCIÓN & $\begin{array}{l}\text { El actor se asegura que las actividades } \\
\text { asignadas se ejecuten de la manera } \\
\text { correcta }\end{array}$ \\
\hline $\begin{array}{l}\text { DISCUTE } \\
\text { ARCHIVOS }\end{array}$ & INTERACCIÓN & $\begin{array}{l}\text { Se realiza una discusión en base a } \\
\text { archivo enviado por actor }\end{array}$ \\
\hline $\begin{array}{l}\text { REALIZA } \\
\text { ACTIVIDADES }\end{array}$ & INTERACCIÓN & $\begin{array}{l}\text { La ejecución de una tarea asignada para } \\
\text { su realización }\end{array}$ \\
\hline $\begin{array}{l}\text { REVISA } \\
\text { ENTREGAS }\end{array}$ & INTERACCIÓN & $\begin{array}{l}\text { Se realiza una revisión de lo que ha } \\
\text { entregado otro actor como resultado de } \\
\text { una actividad realizada }\end{array}$ \\
\hline CONTENIDO & OBJETO & $\begin{array}{l}\text { Es el material, documento, archivo que un } \\
\text { actor envía a otro actor. }\end{array}$ \\
\hline
\end{tabular}

que las enfermeras desde la habitación del paciente puedan llamar al cirujano para que vaya y atienda alguna urgencia, o en la sala de operaciones el medico puede enviar un mensaje a todos los involucrados que la cirugía a sido cancelada, también existe un calendario central donde el coordinador donde realiza la planificación de las cirugías y puede comunicarse con los diferentes equipos médicos notificándoles si existe algún cambio en la planificado, ya sea que ha cambiado la hora, o el quirófano.

TABLA XVII. CCD DE INTRACCIÓN ESTRELLA - MALLA, AWAREMEDIA

\begin{tabular}{|l|l|l|}
\hline CONCEPTO & CATEGORIA & DEFINICIÓN \\
\hline COORDINADOR & ACTOR & $\begin{array}{l}\text { Persona encargada de coordinar } \\
\text { actividades }\end{array}$ \\
\hline MEDICO & ACTOR & Profesional del área de la medicina \\
\hline ENFERMERA & ACTOR & Profesional del área de la medicina \\
\hline $\begin{array}{l}\text { INICIA } \\
\text { COMUNICACIÓN }\end{array}$ & INTERACCIÓN & $\begin{array}{l}\text { Cualquier actor comienzan una } \\
\text { comunicación }\end{array}$ \\
\hline $\begin{array}{l}\text { REALIZA } \\
\text { PREGUNTAS }\end{array}$ & INTERACCIÓN & $\begin{array}{l}\text { Cualquier actor puede realizar } \\
\text { preguntas acerca del tema que se } \\
\text { este trabajando }\end{array}$ \\
\hline $\begin{array}{l}\text { RESPONDE } \\
\text { PREGUNTAS }\end{array}$ & INTERACCIÓN & $\begin{array}{l}\text { Cualquier actor da respuesta a las } \\
\text { preguntas realizadas }\end{array}$ \\
\hline NOTIFICA & INTERACCION & $\begin{array}{l}\text { Cualquier actor puede avisar a los } \\
\text { demás sobre alguna situación de } \\
\text { interés }\end{array}$ \\
\hline $\begin{array}{l}\text { PUBLICA } \\
\text { ACTIVIDADES }\end{array}$ & $\begin{array}{l}\text { Un actor envía una actividad a todos } \\
\text { los demás actores para que puedan } \\
\text { verlo, o lo envía a una aplicación } \\
\text { donde puedan acceder los demás } \\
\text { actores }\end{array}$ \\
\hline $\begin{array}{l}\text { APROPIA } \\
\text { OBSERVACIONES }\end{array}$ & INTERACCIÓN & $\begin{array}{l}\text { El actor incorpora las observaciones } \\
\text { hechas. }\end{array}$ \\
\hline $\begin{array}{l}\text { ASIGNA } \\
\text { ACTIVIDADES }\end{array}$ & INTERACCIÓN & $\begin{array}{l}\text { El actor asigna a otro actor las } \\
\text { actividades que se espera realice. }\end{array}$ \\
\hline $\begin{array}{l}\text { COORDINA } \\
\text { ACTIVIDADES }\end{array}$ & INTERACCIÓN & $\begin{array}{l}\text { El actor coordina las actividades que } \\
\text { a asignado o quiere asignar a otro } \\
\text { actor. }\end{array}$ \\
\hline $\begin{array}{l}\text { REALIZA } \\
\text { ACTIVIDADES }\end{array}$ & INTERACCIÓN & $\begin{array}{l}\text { La ejecución de una tarea asignada } \\
\text { para su realización }\end{array}$ \\
\hline CONTENIDO & OBJETO & $\begin{array}{l}\text { Es el material, documento, archivo } \\
\text { que un actor envía a otro actor. }\end{array}$ \\
\hline
\end{tabular}

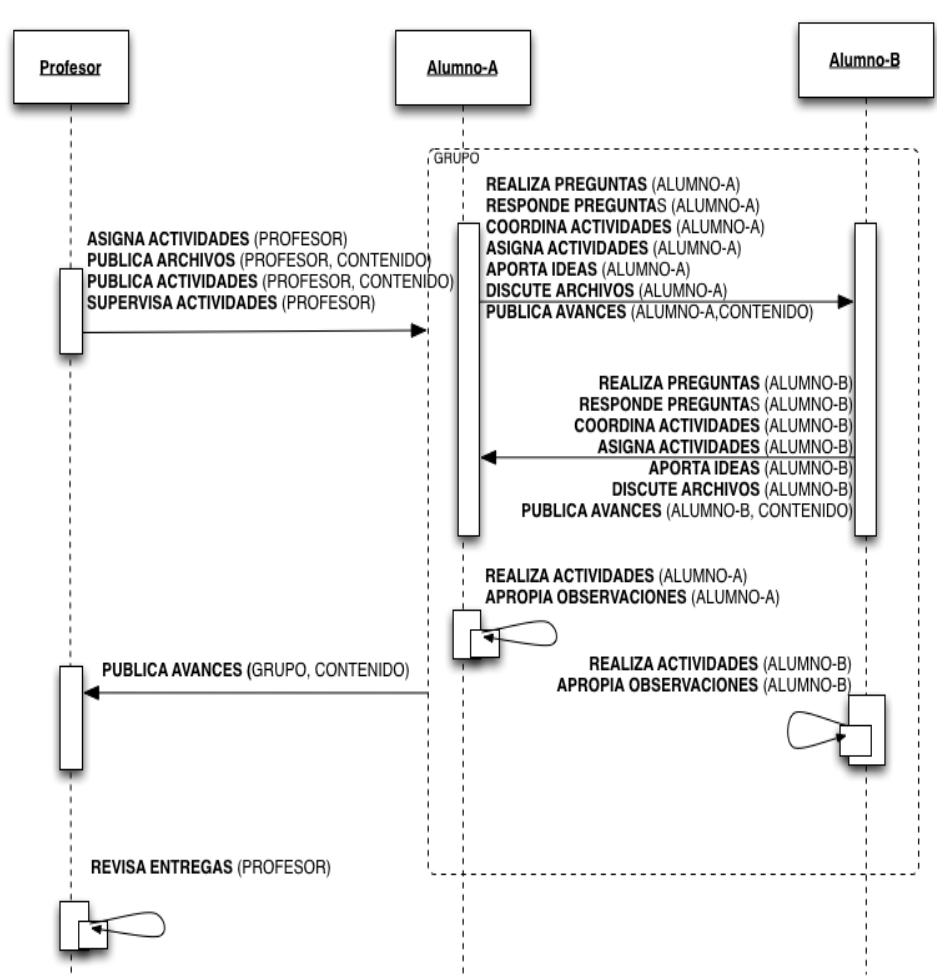

Fig. 31. Diagrama de secuencia de interacción estrella-malla Aprendizaje virtual grupal

- AwareMedia - Coordinación de cirugías en hospitales: Se considera un sistema el cual permite un canal de comunicación por mensajes discretos y fáciles entre el personal medico que participa en una operación, es posible

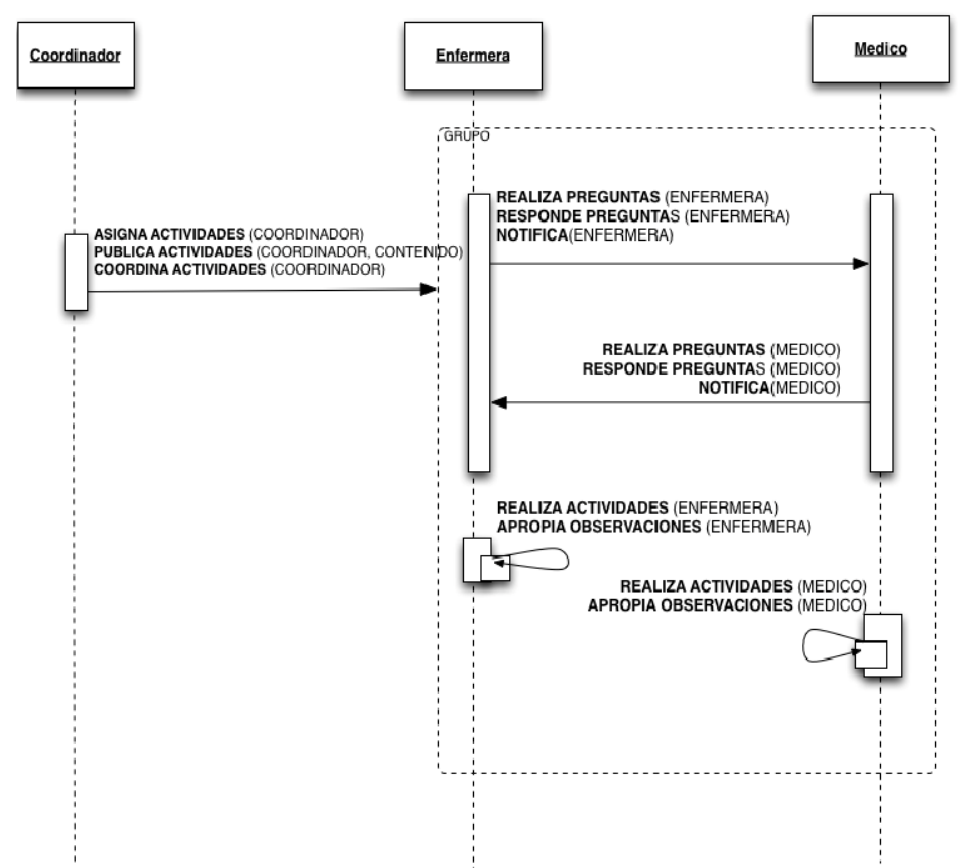

Fig. 32. Diagrama de secuencia de interacción estrella-malla awaremedia 




Fig. 33. Modalidad de Interacción Estrella-Malla

\section{6) Tabla de decisión de topologías}

Se plantean algunos criterios y sub criterios necesarios para analizar que topología se adapta mejor al tipo de interacción que se quiere modelar.

- Cantidad de actores : De acuerdo a las topologías modeladas pueden haber dos posibilidad, una interacción solamente entre dos actores lo cual es lo mínimo que puede existir o una interacción entre 3 o mas actores.

- Existe un actor central (Líder) : En las diferentes interacciones puede existir un actor con un rol de jerarquía mayor a los demás.

- Hay liderazgos intermedios : Dentro de los actores que componen las topologías en sus diferentes formas, pueden existir algunos que tengan un rol con algunas tareas con mas responsabilidad a los demás actores.

- Existe una comunicación únicamente con el actor central : La comunicación que existe entre los actores puede fluir solamente por el actor con una jerarquía mayor (Líder) o puede fluir entre todos los actores.

TABLA XVIII. TABLA DE DECISÓN DE TOPOLOGIAS

\begin{tabular}{|c|c|c|c|c|c|c|c|c|c|}
\hline & & \multicolumn{8}{|c|}{ Reglas } \\
\hline \multirow{4}{*}{ 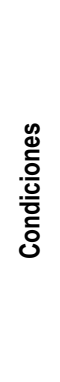 } & $\begin{array}{l}\text { Cantidad de } \\
\text { actores }\end{array}$ & 2 & 2 & $3+$ & $3+$ & $3+$ & $3+$ & $3+$ & $3+$ \\
\hline & $\begin{array}{l}\text { Existe un actor } \\
\text { central (Líder) }\end{array}$ & NO & SI & SI & SI & SI & NO & NO & SI \\
\hline & $\begin{array}{l}\text { Hay liderazgos } \\
\text { intermedios }\end{array}$ & NO & NO & NO & SI & NO & NO & SI & SI \\
\hline & $\begin{array}{l}\text { Existe una } \\
\text { comunicación } \\
\text { únicamente } \\
\text { con el actor } \\
\text { central (líder) }\end{array}$ & NO & SI & SI & NO & NO & NO & NO & SI \\
\hline & Punto a punto & & & & & & & & \\
\hline & Estrella & & & $\square$ & & & & & \\
\hline 응 & Malla & & & & n & & & a & \\
\hline & Lineal & & & & & & & & 7 \\
\hline
\end{tabular}

Si la funcionalidad que se quiere modelar tiene varias interacción se debe descomponer hasta poder modelarlo en alguna de las topologías básicas y luego estas se combinan con una comunicación bidireccional o unidireccional entre las topologías.

\section{Roles}

En esta sección se presenta una propuesta de modelo de generalización de roles estructurada en tres partes: clasificación de roles en entornos $\mathrm{CSCW}$ (sub-sección 1), propuesta de niveles de interacción (sub-sección 2) y elementos básicos (sub-sección 3).

\section{1) Clasificación de Roles en Entornos $\mathrm{CSCW}$}

Se realiza una revisión de los diferentes definiciones de tipos de roles existentes en la literatura, para ellos se ha centrado fundamentalmente en las propuestas relativas a los roles en CSCW. El análisis de los diferentes ejemplos de cada modelo de interacción muestra diferentes roles en los participantes.

En el primer modelo de interacción punto a punto, encontramos que se mencionan en el ejemplo que es un entorno de comunicación genérico, los roles de profesor y alumno claramente diferenciados que comparten las mismas posibilidades de interacción, donde el profesor y el alumno pueden dialogar abiertamente sobre la actividad esta desempeñando el alumno. En el segundo ejemplo tenemos una aplicación de chat colaborativa en donde dos actores un diseñador y un líder de proyecto pueden interactuar y recibir retroalimentación uno del otro sobre el tema de interés que estén tratando.

En el segundo modelo de interacción estrella, encontramos dos ejemplos, el primero es un ambiente de aprendizaje virtual donde se destaca la presencia de un profesor que por sus conocimientos o habilidades ayuda a un grupo de alumnos, que es el segundo rol que encontramos, a desarrollar la actividad que estén desempeñando. El segundo ejemplo es una aplicación medica donde se mencionan tres roles, el paciente, el enfermero y el medico, donde los dos primeros tienen una interacción constante y el medicó interviene en la flujo de comunicación esporádicamente.

En el tercer modelo de interacción malla, se encuentran dos diferentes ejemplos, el primero es un outsorcing donde se observa la interacción de varios actores con un único rol de desarrollador, el segundo ejemplo es una sesión de lluvia de ideas en donde varios actores pueden tomar dos posibles roles, facilitador o participante, en donde la mayoría tomaría el rol de participante y unos pocos o al menos uno seria el encargado de facilitar el tema a los demás.

En el cuarto modelo de interacción estrella - malla encontramos un ejemplo de aprendizaje virtual grupal en donde existen dos posibles roles profesor o alumno, el primero debe ayudar a varios grupos de estudiantes a desempeñar las actividades que les hayan sido asignadas. En el segundo ejemplo de este modelo se encuentra tres roles coordinador, medico, enfermero en donde el coordinador designa y notifica a el grupo de médicos y enfermeros sobre el estado de los quirófanos y su disponibilidad. 
En el quito modelo de interacción lineal, tenemos un ejemplo en el que se observan tres diferentes actores cada uno con un roles especifico, alumno, director de tesis e investigador formado, cada rol interactúa con el que este inmediatamente superior, como en una jerarquía, en diferentes momentos en el tiempo. En el segundo ejemplo de este modelo es una revisión de avances de un producto de software en el cual se encuentran el rol de desarrollador, líder de proyecto y stakeholder en donde el líder de proyecto revisa lo hecho por el desarrollador y se comunica con el stakeholder para realizar revisiones, estas interacciones se realizan en diferentes momentos del tiempo.

Tras analizar los diferentes ejemplos, hemos creado dos agrupaciones: una que representa las funciones especificas que cada rol puede ejercer y otra la generalización de dichas funciones. Se presenta a continuación, en forma de tabla, la lista de los roles encontrados por cada agrupación. En cada tabla se representa, en filas la lista de interacciones y en columnas los roles. Una "'" en una celda representa que ese rol de la lista (columna) realiza la interacción definida (fila).

En la primera agrupación, referida a todos los roles encontrados en los ejemplos de modelos de interacciones que intervienen en un escenario CSCW, se muestra en la tabla XIX. En ella se puede apreciar los roles a que ejemplo y topología pertenecen y las interacciones que cada rol realiza.

TABLA XIX. NTERACCIONES ESPECIFICAS DE CADA ROL BASADA EN LOS EJEMPLOS DE CADA TOPOLOGIA

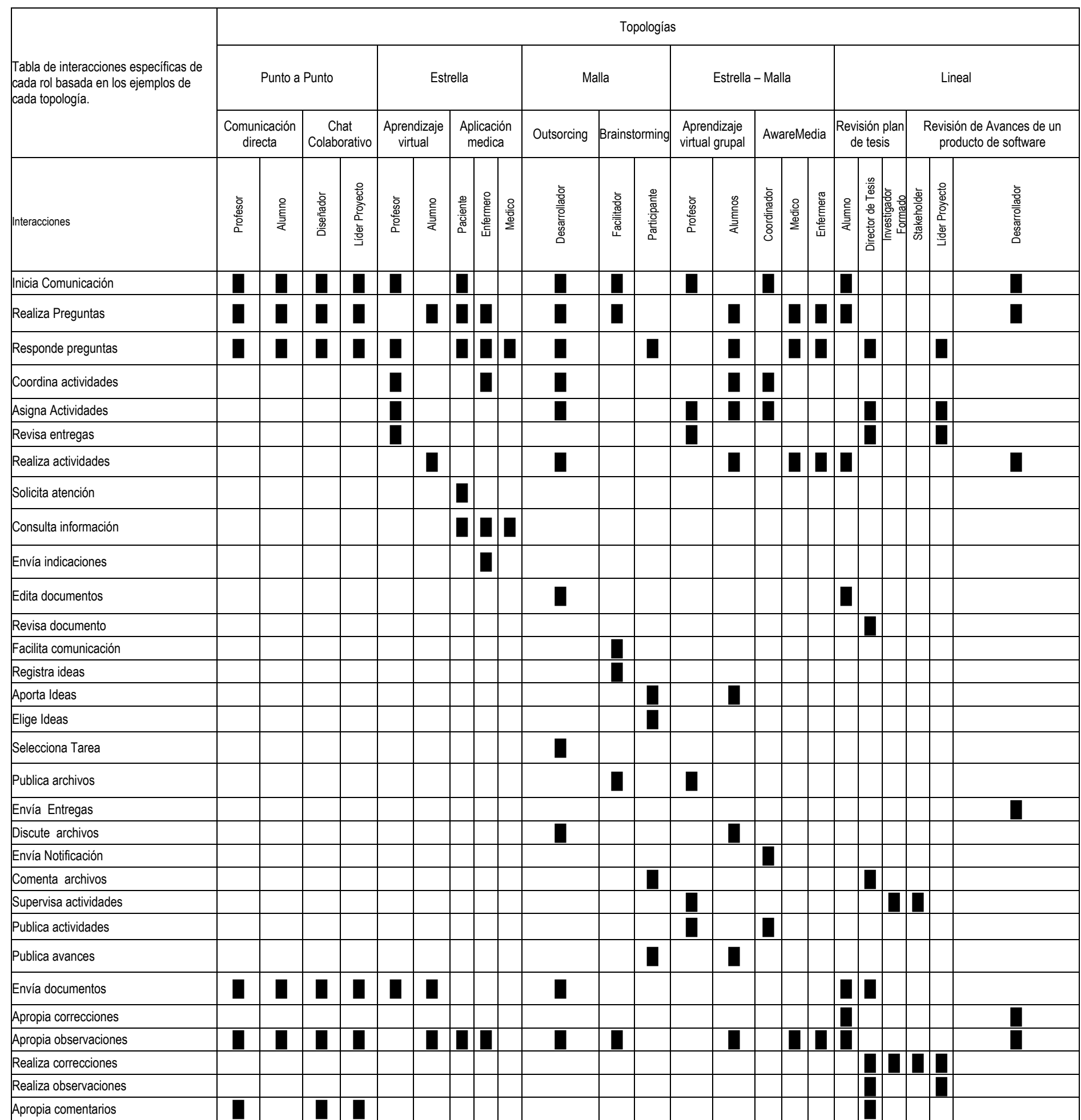


En cuanto al análisis de las interacciones de cada rol genero la agrupación mostrada en la tabla XX. Observando su contenido podemos decir que hay menos interacciones dado que interacciones parecidas se realizo una generalización de estas. Dando como resultado unas interacciones genéricas las cuales se conforman de la siguiente manera:

- Solicitar : inicia comunicación y solicitar atención.

- Coordinar: facilitar comunicación y coordinar actividades.

- Revisar: revisar entregas y revisar documentos.

- Desarrollar: realizar actividades y registrar ideas.

- Enviar: envía documentos, envía indicaciones, envía notificación y envía entregas.

- Modificar: editar documentos.

- Contribuir: aporta ideas.

- Publicar: publicar archivos, avances y actividades.

- Debatir: discute archivos y comenta archivos.

- Apropiar: apropiar correcciones, observaciones y comentarios.

- Seleccionar: Seleccionar tarea y Elegir Idea

\section{2) Nivel de Interacción}

A partir de la tabla XX de generalización de interacciones se propone una agrupación de estas en niveles de interacción, para la realización de estas agrupaciones se observo si un rol especifico realizaba alguna de estas interacciones y si eran comunes entre los demás roles específicos. Dando como resultado 5 niveles de interacciones los cuales se componen de la siguiente manera:

- Nivel 1 : Solicitar, Formular preguntas, Responder preguntas, Enviar, Apropiar

- Nivel 2: Coordinar actividades, Asignar actividades, Revisar

- Nivel 3: Desarrollar, Consultar información, Modificar, Seleccionar

- Nivel 4: Contribuir, Publicar, Debatir

- Nivel 5: Supervisar, Corregir

De acuerdo a la propuesta de niveles de interacción y realizando una análisis de cómo se corresponde cada nivel a los roles específicos de cada topología, se propone una generalización de estos roles de acuerdo al nivel de interacción que tengan, estos roles generales se encuentran en la tabla XXI.

- Rol General A: Este rol puede realizar una o todas las interacciones que se encuentre dentro del nivel 1.

- Rol General B: Este rol puede realizar una o todas las interacciones que se encuentre dentro del nivel $1 \mathrm{y}$ al menos una interacción que este en el nivel 2.

- Rol General C: Este rol puede realizar una o todas las interacciones que se encuentre dentro del nivel $1 \mathrm{y}$ al menos una interacción que este en el nivel 3.

TABLA XX. GENERALIZACIÓN DE INTERACCIONES

\begin{tabular}{|c|c|c|c|c|c|c|c|c|c|c|c|c|c|c|c|c|c|c|c|c|c|c|c|}
\hline \multirow{4}{*}{$\begin{array}{l}\begin{array}{l}\text { Tabla de } \\
\text { interacciones } \\
\text { generales de } \\
\text { cada rol }\end{array} \\
\text { Interacciones }\end{array}$} & \multicolumn{23}{|c|}{ Topologías } \\
\hline & \multicolumn{4}{|c|}{ Punto a Punto } & \multicolumn{5}{|c|}{ Estrella } & \multicolumn{3}{|c|}{ Malla } & \multicolumn{5}{|c|}{ Estrella - Malla } & \multicolumn{6}{|c|}{ Lineal } \\
\hline & \multicolumn{2}{|c|}{  } & \multicolumn{2}{|c|}{ 喜 } & \multicolumn{2}{|c|}{ 惫 } & \multicolumn{3}{|c|}{ 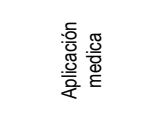 } & \multirow{2}{*}{  } & \multicolumn{2}{|c|}{ 言 } & \multicolumn{2}{|c|}{ 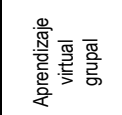 } & \multicolumn{3}{|c|}{ 要 } & \multicolumn{3}{|c|}{ 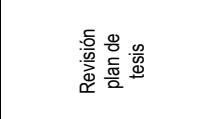 } & \multicolumn{3}{|c|}{ 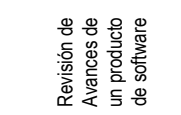 } \\
\hline & 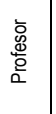 & 熟 & 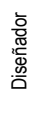 & 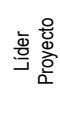 & 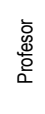 & 哀 & 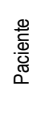 & 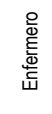 & $\frac{\frac{8}{5}}{\frac{10}{2}}$ & & 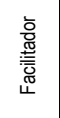 & $\begin{array}{l}\frac{0}{0} \\
\text { 产 } \\
\text { 产 } \\
\text { o. }\end{array}$ & 产 & 总 & $\begin{array}{l}\text { 형 } \\
\text { 言 } \\
\text { के } \\
0\end{array}$ & $\frac{\frac{8}{6}}{\frac{0}{2}}$ &  & 量 & 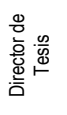 & 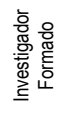 & $\begin{array}{l}\frac{\overline{\mathrm{s}}}{\frac{\mathrm{o}}{\mathrm{o}}} \\
\frac{\mathrm{o}}{\mathrm{w}} \\
\frac{\mathrm{w}}{\mathrm{\omega}}\end{array}$ & 遆 & 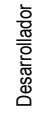 \\
\hline Solicitar & D & ] & ] & $\square$ & $\square$ & & D & & & ] & $\square$ & & $\pi$ & & $\bar{T}$ & & & $\pi$ & & & & & 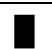 \\
\hline $\begin{array}{l}\text { Formular } \\
\text { preguntas }\end{array}$ & 口 & प & [ & $\boldsymbol{\theta}$ & & 口 & 口 & 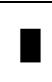 & & 口 & $\square$ & & & $\square$ & & $\boldsymbol{\square}$ & $\square$ & - & & & & (1) & \\
\hline $\begin{array}{l}\text { Responder } \\
\text { preguntas }\end{array}$ & प & प & 口 & 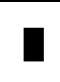 & 口 & & 口 & 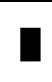 & 口 & 口 & & 口 & 口 & $\square$ & & D & $\square$ & & $\square$ & & & & 口 \\
\hline Enviar & 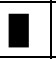 & प & प & $\square$ & $\square$ & प & & $\bar{\square}$ & & $\square$ & & & & & $\square$ & & & $\square$ & $\square$ & ] & & & $\square$ \\
\hline Apropiar & $\mathbf{D}$ & प & प & $\square$ & & च & [ & D & & [ & $\square$ & & & $\square$ & & & & (1) & $\square$ & & & & 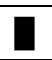 \\
\hline $\begin{array}{l}\text { Coordinar } \\
\text { actividades }\end{array}$ & & & & & $\square$ & & & 口 & & 口 & $\square$ & & & $\square$ & & & & & & & & & \\
\hline $\begin{array}{l}\text { Asignar } \\
\text { actividades }\end{array}$ & & & & & 口 & & & & & 口 & & & $\square$ & $\square$ & & & & & $\square$ & & & ] & \\
\hline Revisar & & & & & $\square$ & & & & & & & & $\square$ & & & & & & $\square$ & & & [ & \\
\hline Desarrollar & & & & & & $\square$ & & & & $\square$ & & & & $\square$ & & & & $\square$ & & & & & $\square$ \\
\hline Seleccionar & & & & & & & & & & [ & & D & & & & & & & & & & & \\
\hline $\begin{array}{l}\text { Consultar } \\
\text { información }\end{array}$ & & & & & & & 口 & 口 & 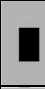 & & & & & & & & & & & & & & \\
\hline Modificar & & & & & & & & & & $\bar{\square}$ & & & & & & & & $\square$ & & & & & \\
\hline Contribuir & & & & & & & & & & & & $\square$ & & $\square$ & & & & & & & & & \\
\hline Publicar & & & & & & & & & & & $\square$ & $\square$ & $\square$ & $\square$ & & & & & & & & & \\
\hline Debatir & & & & & & & & & & $\square$ & & $\square$ & & 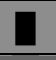 & & & & & $\square$ & & & & \\
\hline $\begin{array}{l}\text { Supervisar } \\
\text { Corregir }\end{array}$ & & & & & & & &  & & - & & & $\square$ & & & -- & C. & & $\square$ & 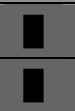 & $\square$ & ] & \\
\hline
\end{tabular}


- Rol General D: Este rol puede realizar una o todas las interacciones que se encuentre dentro del nivel 1 , al menos una interacción que este en el nivel 2 y al menos una interacción que este en el nivel 3.

- Rol General E: Este rol puede realizar una o todas las interacciones que se encuentre dentro del nivel 1 , al menos una interacción que este en el nivel 2, al menos una interacción que este en el nivel 3 y al menos una interacción que este en el nivel 4.

- Rol General F: Este rol puede realizar una o todas las interacciones que se encuentre dentro del nivel 1 , al menos una interacción que este en el nivel 2, al menos una interacción que este en el nivel 3 y al menos una interacción que este en el nivel 5.

- Rol General G: Este rol puede realizar una o todas las interacciones que se encuentre dentro del nivel 2, al menos una interacción que este en el nivel 3 y al menos una interacción que este en el nivel 4.

- Rol General H: Este rol puede realizar una o todas las interacciones que se encuentre dentro del nivel 1 , al menos una interacción que este en el nivel 2 y al menos una interacción que este en el nivel 4.

- Rol General I: Este rol puede realizar una o todas las interacciones que se encuentre dentro del nivel $1 \mathrm{y}$ al menos una interacción que este en el nivel 4.

- Rol General J: Este rol puede realizar una o todas las interacciones que se encuentre dentro del nivel $3 \mathrm{y}$ al menos una interacción que este en el nivel 4.

- Rol General K: Este rol puede realizar una o todas las interacciones que se encuentre dentro del nivel 1 , al menos una interacción que este en el nivel 2, al menos una interacción que este en el nivel 4 y al menos una interacción que este en el nivel 5.

- Rol General L: Este rol puede realizar una o todas las interacciones que se encuentre dentro del nivel 5.

- Rol General M : Este rol puede realizar una o todas las interacciones que se encuentre dentro del nivel 5 y al menos una interacción que este en el nivel 1.

TABLA XXI. ROLES GENERALES EN BASE A LOS NIVELES DE INTERACCIÓN

\begin{tabular}{|c|c|c|c|c|c|}
\hline & Nivel 1 & Nivel 2 & Nivel 3 & Nivel 4 & Nivel 5 \\
\hline \multicolumn{6}{|l|}{ Rol General A } \\
\hline \multicolumn{6}{|l|}{ Rol General B } \\
\hline \multicolumn{6}{|l|}{ Rol General C } \\
\hline \multicolumn{6}{|l|}{ Rol General D } \\
\hline \multicolumn{6}{|l|}{ Rol General E } \\
\hline \multicolumn{6}{|l|}{ Rol General F } \\
\hline \multicolumn{6}{|l|}{ Rol General G } \\
\hline \multicolumn{6}{|l|}{ Rol General H } \\
\hline \multicolumn{6}{|l|}{ Rol General I } \\
\hline \multicolumn{6}{|l|}{ Rol General J } \\
\hline \multicolumn{6}{|l|}{ Rol General K } \\
\hline \multicolumn{6}{|l|}{ Rol General L } \\
\hline Rol General M & & & & &  \\
\hline
\end{tabular}

3) Propuesta de formalismos para elementos básicos

A los elementos básicos que se proponen en [4] los cuales el autor los define de la siguiente manera:

- Los objetos son la materia o asunto que recibe el ejercicio de las facultades de interaccionar de los actores. < Objeto $>::=<$ objeto $1>\mid<$ objeto $2>|\ldots|<$ objeto $\mathrm{N}>$

- Las acciones definen procesos que los actores acuerdan ejecutar sobre objetos. A la definición hecha por [4] sobre las acciones se propone hacer una ampliación de la definición, la cual quedaría de la siguiente forma:

- Acción: Define un proceso que los actores acuerdan ejecutar sobre objetos o sobre los demás actores. < Acción $>::=<\mathrm{obj}>$, donde

obj $=$ Es un conjunto de objetos

- Niveles de interacción: es una agrupación de las posibles acciones que un rol puede desempeñar $<$ Niveles Interacción $>::=<$ Acc $>$, donde

\section{Acc $=$ Es un conjunto de acciones}

- Rol : Es el conjunto de acciones que el actor puede realizar en el sistema, derechos y responsabilidades $<$ Rol $>::=<\mathrm{u}$, obj , ni $>$, donde $\mathrm{u}=$ Es un conjunto de usuarios que tienen este rol, obj $=$ Es un conjunto de objetos que puede acceder este rol, $\mathrm{ni}=$ Son los niveles de interacción asociados a este rol

- Actores : los actores son los sujetos de la dinámica grupal. $<$ Actor $>::=<$ rs , gs $>$, donde rs $=$ Es un conjunto de roles que el usuario tiene, gs $=$ Es un conjunto de grupos al que el usuario pertenece

- Awareness Message : Es el medio por el cual se facilita la comunicación $<$ Awareness Message $>::=<$ rolE , rolR , $\mathrm{c}>$, donde rolE $=\mathrm{El}$ rol emisor del mensaje, rolR $=\mathrm{El}$ rol receptor del mensaje, $\mathrm{c}=$ contenido del mensaje

A demás se propone agregar los siguientes elementos básicos:

- Grupo: Es un conjunto de actores < Grupo $>::=<$ us $>$, donde us $=$ Es un conjunto de usuarios pertenecientes al grupo

De acuerdo a los elementos mencionados anteriormente se realiza un ejemplo del flujo entre los diferentes elementos en donde los actores trabajan en grupo y poseen roles, cada trabajo que realizan se hace para cumplir con una tarea, los miembros del grupo interactúan entre si y con los objetos, este flujo puede verse en la figura 34 .

En donde hay tres diferentes niveles de interacción, el primer nivel se compone de 5 posibles actividades, el segundo y tercer nivel se compone de tres actividades cada una, algunas de esas actividades pueden o no relacionarse con objetos. El rol A puede ejecutar actividades del nivel de interacción uno, el rol $\mathrm{B}$ del nivel de interacción uno y dos, el rol $\mathrm{C}$ del nivel de interacción uno y tres. Los actores A1 y A2 toman el rol A, los actores $\mathrm{B} 1$ y $\mathrm{B} 2$ tienen el rol $\mathrm{B}$ y los actores $\mathrm{C} 1$ y $\mathrm{C} 2$ toman el rol C.

\section{Awareness}

Esta sección se centra en la propuesta de modelo de awareness para las modalidades de interacción presentadas anteriormente, este modelos de awareness se presenta en (sección 1). 


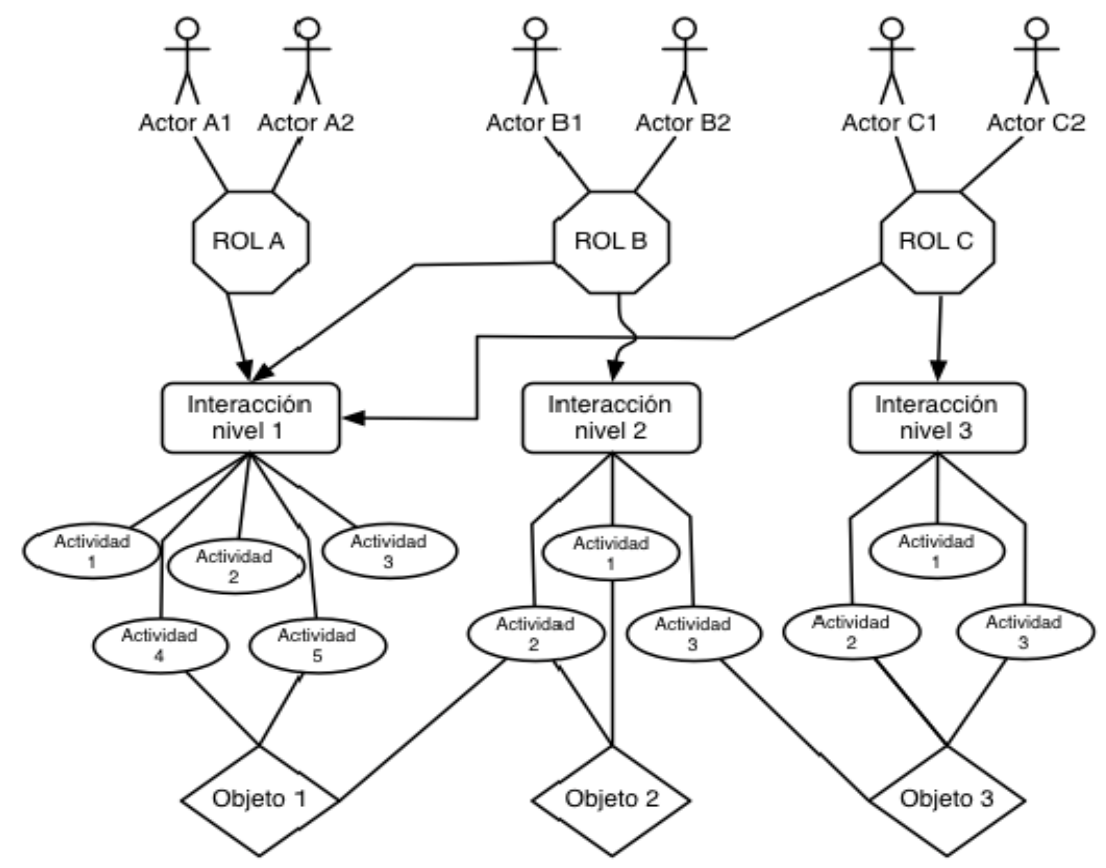

Fig. 34. Estructura de elementos de interacción

\section{1) Awareness de modalidades de interacción}

De acuerdo a la estructura de elementos de interacción (Figura 34) se toma cada elemento mas la relación que existe entre el que envía y el que recibe como factores de importancia.

que se deben tener en cuenta para construir un modelo de awareness basado en las interacciones grupales.

Awareness 1: Un mensaje de awareness puede ser enviado a todos los roles que están en el mismo grupo.

Awareness 2: Un mensaje de awareness puede ser enviado a un rol especifico que este en el mismo grupo.

Awareness 3: Un mensaje de awareness puede ser enviado a un actor que tiene el mismo rol del que envía el mensaje.

Awareness 4: Un mensaje de awareness puede ser enviado a los roles que estén realizando la misma actividad que pertenezca a la misma interacción.

Awareness 5: Un mensaje de awareness puede ser enviado a uno o varios actores que estén desempeñando diferentes roles siempre y cuando tengan una relación directa con la interacción

A partir de la propuesta de awareness se realiza una análisis en donde se muestra a cada topología de interacción propuesta que tipos de awareness corresponden tabla XXII.

TABLA XXII. AWARENESS DE MODALIDAD DE INTERACCIÓN

\begin{tabular}{|l|c|c|c|c|c|}
\hline & $\begin{array}{c}\text { Punto a } \\
\text { Punto }\end{array}$ & Estrella & Malla & $\begin{array}{c}\text { Estrella- } \\
\text { Malla }\end{array}$ & Lineal \\
\hline Awareness 1 & $\mathbf{\square}$ & $\mathbf{\square}$ & $\mathbf{\square}$ & $\mathbf{\square}$ & $\mathbf{\square}$ \\
\hline Awareness 2 & $\mathbf{\square}$ & $\mathbf{\square}$ & $\mathbf{\square}$ & $\mathbf{\square}$ & $\mathbf{\square}$ \\
\hline Awareness 3 & & & $\mathbf{\square}$ & $\mathbf{\square}$ & \\
\hline Awareness 4 & & & $\mathbf{\square}$ & $\mathbf{\square}$ & \\
\hline Awareness 5 & $\mathbf{\square}$ & $\mathbf{\square}$ & $\mathbf{\square}$ & $\mathbf{\square}$ & $\mathbf{\square}$ \\
\hline
\end{tabular}

La topología punto a punto, estrella y lineal por sus características puede realizar el awareness 1,2 y 5. Para las topología malla puede realizar todos los 5 tipos de awareness propuestos. Y para la topología de Estrella - Malla ya que es una topología compuesta se aplica una regla de herencia en donde las reglas de awareness tanto de malla como de estrella son aplicables.

2) Elementos de una Situación Colaborativa de Awareness

Una situación colaborativa de Awareness representa la necesidad de información actualizada que tiene un grupo de actores del sistema durante una situación específica. Esta debe expresar todo lo necesario para saber que información requieren los usuarios, quiénes exactamente, cuándo, cómo, que y dónde de acuerdo a las preguntas base propuestas en [8]. De esta forma, la identificación de esta situación colaborativa representa una necesidad que debe cubrir el sistema. La Tabla XXIII muestra el modelo de los elementos de una situación colaborativa de Awareness expresado como una plantilla.

a) Identificación del tipo de Awareness: La Identificación de los tipos de awareness, tiene como objetivo generar a partir de la descripción de la situación colaborativa, una estructura en la que se identifiquen los conceptos que forman parte del mismo, junto con lo que se busca caracterizar. Los componentes se muestran en la tabla XXIV.

TABLA XXIII. PlantILLA PARA REPRESENTAR UNA SITUACIÓN COLABORATIVA DE AWARENESS

\begin{tabular}{|l|l|}
\hline \multicolumn{2}{|c|}{ Plantilla de Situación Colaborativa } \\
\hline Id & Identificador \\
\hline Actor (Quien) & Actor o grupo de actores en una situación colaborativa \\
\hline Tarea (Donde) & Tarea en la que se requiere el Awareness \\
\hline Información (Que) & $\begin{array}{l}\text { Información de Awareness requerida. Su estructura } \\
\text { general }\end{array}$ \\
\hline Aplicabilidad (Cuándo) & $\begin{array}{l}\text { Si se cumplen las condiciones se proporciona la } \\
\text { información de Awareness }\end{array}$ \\
\hline Interacción (Cómo) & La manera en la que los actores selacionan \\
\hline
\end{tabular}

TABLA XXIV. TABLA DEFINICIÓN - CATEGORIA

\begin{tabular}{|l|l|}
\hline \multicolumn{1}{|c|}{ Definición } & Categoría \\
\hline $\begin{array}{l}\text { Parte de la definición de cada } \\
\text { situación colaborativa que se } \\
\text { puede asociar a alguna } \\
\text { categoría }\end{array}$ & $\begin{array}{l}\text { La intención que busca la definición correspondiente, } \\
\text { de acuerdo a lo propuesto en la taxonomía de } \\
\text { awareness, tabla VII, estas pueden ser (Intenciones, } \\
\text { Acciones, Habilidades, Conocimiento, Acciones } \\
\text { Anteriores, Artefacto, Ubicación, Expectativa, Nivel } \\
\text { de Actividad, Cambios). }\end{array}$ \\
\hline
\end{tabular}


b) Plantilla de los elementos de Awareness: Son varios los elementos que intervienen en la generación de la información de awareness apropiada de acuerdo a cada situación colaborativa que tiene un sistema de software, De acuerdo a los elementos en la sección de roles, sub-sección 3 se propone una plantilla en la que se definan estos elementos para la construcción de la información de awareness, la plantilla se muestra en la tabla XXV.

\section{CASOS DE VALIDACIÓN}

En este apartado se presentan tres casos de validación pertenecientes a dominios de conocimiento con diferentes características para implementar el modelo de interacciones de awareness basado en interacciones grupales . En la sección $A$ se analiza un primer caso de validación correspondiente a un Sistema de control de versiones de código en el Contexto de un desarrollo de un sistema colaborativo.

TABLA XXV. Plantilla de awareness

\begin{tabular}{|l|l|}
\hline Id & Identificador \\
\hline $\begin{array}{l}\text { Modalidad de } \\
\text { interacción }\end{array}$ & $\begin{array}{l}\text { Para esta información se necesita el campo actores con su } \\
\text { cardinalidad y el campo interacción de la plantilla de la situación } \\
\text { colaborativa, con esta información se corresponde con alguno } \\
\text { de los modelos de interacción propuestos. }\end{array}$ \\
\hline Objeto & $\begin{array}{l}\text { De acuerdo a la información de la situación colaborativa si en } \\
\text { este interviene algún material en particular. }\end{array}$ \\
\hline $\begin{array}{l}\text { Niveles de } \\
\text { interacción }\end{array}$ & Se corresponde con el campo tarea , realizada por los actores. \\
\hline Roles Generales & $\begin{array}{l}\text { De acuerdo con la combinación de los niveles de interacción, ver } \\
\text { tabla XXI }\end{array}$ \\
\hline $\begin{array}{l}\text { Mensaje de } \\
\text { Awareness }\end{array}$ & $\begin{array}{l}\text { Se compone de acuerdo a la interacción que existe en la } \\
\text { situación colaborativa }\end{array}$ \\
\hline $\begin{array}{l}\text { Reglas de } \\
\text { Awareness }\end{array}$ & $\begin{array}{l}\text { Se obtienen a partir de la modalidad de interacción } \\
\text { correspondiente a la situación colaborativa, ver tabla XXII }\end{array}$ \\
\hline $\begin{array}{l}\text { Tipos de } \\
\text { Awareness }\end{array}$ & $\begin{array}{l}\text { Se obtiene a partir de las categorías encontradas en la tabla } \\
\text { XXIV y si estas se corresponden con alguna categorización de la } \\
\text { taxonomía en la tabla VII }\end{array}$ \\
\hline
\end{tabular}

En la sección $B$ se analiza un segundo caso de validación correspondiente a un una técnica específica de aprendizaje colaborativo basada en la interacción social (jigsaw) en el Contexto de los ambientes de aprendizaje colaborativos, En la sección $C$ se analiza un ultimo caso de validación correspondiente a diferentes técnicas de tele-medicina en un ambiente de trabajo colaborativo.

\section{A. CASO DE VALIDACION: SISTEMA DE CONTROL DE VERSIONES DE CODIGO}

En esta sección se analiza el caso de validación correspondiente a un Sistema de control de versiones de código. En la sección 1 se realiza la descripción del caso y en la sección 2 se desarrolla el modelo de awareness basado en la solución propuesta.

\section{1) Descripción del caso}

El sistema de control de versiones de código provee un entorno de trabajo a los desarrolladores de software que utilizan sistemas de control de versiones y que se encuentran distanciados geográficamente, lo cual es algo muy común en el desarrollo de software. Este sistema busca proporcionar canales más elaborados para la colaboración entre desarrolladores y el proceso de revisión colaborativa de código, el sistema pretende proveer un espacio de trabajo colaborativo para dicha situación. Además tiene la capacidad para promover encuentros informales en tiempo real. la realización de las revisiones de código debe promover la interacción asíncrona entre los usuarios, dado que no siempre pueden estar presentes en tiempo real pero es importante que conozcan el trabajo realizado por otros usuarios. Este sistema debe proporcionar un Awareness general del estado del desarrollo del proyecto a los usuarios. El ciclo de trabajo, una vez que se está en un proyecto es el siguiente:

- Crear copia de trabajo local o clonar el repositorio principal.

- Realizar aportes/cambios.

- Integrar aportes/cambios de otros usuarios.

- Resolver conflictos en el repositorio local.

- Guardar cambios en repositorio local.

- Enviar cambios al repositorio principal para sincronizarlo. Realizar cambios y volver a empezar el proceso.

En este ciclo de trabajo debe existir coordinación entre los desarrolladores para saber en que parte trabajar sin afectar el trabajo de los demás, ó si se da el caso resolver los conflictos de código que existan por haber trabajo sobre el mismo archivo. En ocasiones se requiere compartir código entre varios desarrolladores con el fin de analizarlo, cambiarlo y aprobarlo para tener un código definitivo. Este proceso llega a ser ineficiente si se utilizan medios de comunicación tradicionales como el correo electrónico o el chat. Se necesitan mejores formas de interacción para agilizar este proceso de revisión colaborativa de código.

El trabajar en una revisión de código se compone de unas subtareas en donde varios usuarios del sistema revisan y cambian un código de forma conjunta y en tiempo real, teniendo cada uno ciertos roles que les permiten hacer o no determinadas acciones. El creador (dueño) de la revisión es el que controla la edición del código revisado, en esta puede participar un o varios desarrolladores que le ayuden a analizar el código y a editarlo (colaboradores), y también pueden haber solo desarrolladores junior que están para aprender el proceso e interactuar pero no pueden editar el código (visitantes).

De una forma mas concreta el usuario dueño de la revisión es el encargado de dar los permisos de edición al código y de invitar o sacar desarrolladores de la revisión, este usuario es el que requiere mas información del resto de los usuarios ya que es el encargado de coordinar la revisión, la información que se necesita proporcionar durante esta tarea es, mostrar el código que esta bajo revisión, los mensajes entre los desarrolladores y mostrar los desarrolladores que están participando de la revisión. También es importante mostrar información acerca del código como quien lo ha modificado anteriormente.

Para los usuarios colaboradores solo pueden editar el código, no pueden asignar permisos, ni invitar a otros usuarios y tampoco cerrar la revisión. Los usuarios visitantes solamente pueden comunicarse con los otros desarrolladores pero no pueden editar el código ni realizar ninguna otra de las acciones anteriormente mencionadas.

El objetivo de la revisión colaborativa es combinar la experiencia e ideas de varios desarrolladores a fin de resolver un problema importante, mejorar substancialmente un código o simplemente compartir puntos de vista y aumentar el conocimiento general del grupo de trabajo.

\section{2) Desarrollo del requerimiento : Revisión General.}

Revisión General: puede participar varios desarrolladores que ayuden a analizar el código y a editarlo (colaboradores), y también pueden haber solo desarrolladores junior que están para aprender el proceso e interactuar pero no pueden editar el código (visitantes). 


\section{a) Situación Colaborativa de Awareness .}

TABLA XXVI. Plantilla DE SITUACIÓN COLABORATIVA - REVISIÓN GENERAL

\begin{tabular}{|l|l|}
\hline \multicolumn{2}{|l|}{ Plantilla de Situación Colaborativa } \\
\hline Id & 1 \\
\hline Actor (Quien) & Desarrolladores \\
\hline Tarea (Donde) & Edición del código. \\
\hline Información (Que) & $\begin{array}{l}\text { Información de la revisión, tiempo transcurrido, información } \\
\text { de la lista de participantes, el código en revisión con la } \\
\text { edición actualizada }\end{array}$ \\
\hline Aplicabilidad (Cuándo) & Mostrar siempre \\
\hline Interacción (Cómo) & $\begin{array}{l}\text { Se crea una revisión y los participantes se comunican entre } \\
\text { ellos y editan el código que se este revisando. }\end{array}$ \\
\hline
\end{tabular}

\section{b) Identificación de los tipos de Awareness .}

TABLA XXVII. IDENTIFICACIÓN DE TIPOS DE AWARENESS - REVISIÓN GENERAL

\begin{tabular}{|l|l|}
\hline Definición & Categoría \\
\hline "varios desarrolladores que ayuden a & Acción : Que están haciendo los otros \\
analizar el código y a editarlo." & desarrolladores \\
& Complemento : Como puedo ayudar a \\
& completar la tarea \\
& Ubicación : Donde están los otros \\
& miembros del grupo \\
\hline $\begin{array}{l}\text { "pueden haber solo desarrolladores } \\
\text { junior que están para aprender el } \\
\text { proceso" }\end{array}$ & Conocimiento : Que saben los otros \\
usuarios, que necesitan saber, que \\
aprendieron de mi
\end{tabular}

\section{c) Tabla de decisión de topologías}

La interacción que se realiza en la revisión general involucra a varios desarrolladores, de acuerdo a la descripción de la interacción no se menciona un líder, tampoco se menciona otros rangos intermedios y tampoco se menciona que la comunicación pase únicamente por el líder.

TABLA XXVIII. DECISIÓN DE TOPOLOGIAS - REVISIÓN GENERAL

\begin{tabular}{|l|l|l|}
\hline \multirow{4}{*}{ Condiciones } & Cantidad de actores & $3+$ \\
\cline { 2 - 3 } & Existe un actor central (Líder) & no \\
\cline { 2 - 3 } & Hay liderazgos intermedios & no \\
\cline { 2 - 3 } & $\begin{array}{l}\text { Existe una comunicación únicamente con el actor central } \\
\text { (líder) }\end{array}$ & no \\
\hline
\end{tabular}

De acuerdo a los resultados de la tabla anterior podemos decir que la topología que corresponde en este tipo de interacción es la de Malla.

\section{d) Plantilla de los elementos de Awareness}

TABLA XXIX. Plantilla DE ElEMENTOS DE AWARENESS - REvisión GENERAL

\begin{tabular}{|l|l|}
\hline \multicolumn{2}{|l|}{ Plantilla de Awareness } \\
\hline Id & 1 \\
\hline Modalidad de interacción & Malla \\
\hline Objeto & Código en revisión. \\
\hline Niveles de interacción & Edita : Nivel de interacción 3 \\
\hline Roles Generales & Rol General C \\
\hline Mensaje de Awareness & Líneas de código editadas y el autor de la edición \\
\hline Reglas de Awareness & Reglas 1,2,3,4 y 5 \\
\hline Tipos de Awareness & $\begin{array}{l}\text { Awareness de Construcción del conocimiento } \\
\text { compartido }\end{array}$ \\
\hline
\end{tabular}

3) Desarrollo del requerimiento : Cambios y permisos

El usuario dueño de la revisión es el encargado de dar los permisos de edición al código y de invitar o eliminar desarrolladores de la revisión, este usuario es el que requiere mas información del resto de los usuarios ya que es el encargado de coordinar la revisión. a) Situación Colaborativa de Awareness

TABLA XXX. Plantilla de SITUACIÓN COLABORATIVA-CAMBIOS Y PERMISOS

\begin{tabular}{|l|l|}
\hline \multicolumn{2}{|l|}{ Plantilla de Situación Colaborativa } \\
\hline Id & 2 \\
\hline Actor (Quien) & Dueño de la revisión, Colaboradores \\
\hline Tarea (Donde) & Asignar permisos de edición. \\
\hline Información (Que) & $\begin{array}{l}\text { Información de los colaboradores, Cantidad de cambios } \\
\text { realizados, usuarios que solicitan permisos de edición }\end{array}$ \\
\hline Aplicabilidad (Cuándo) & Mostrar siempre \\
\hline Interacción (Cómo) & $\begin{array}{l}\text { Los colaboradores solicitan permisos de edición, el } \\
\text { dueño de la revisión asigna los permisos por turnos para } \\
\text { que puedan editar el código. }\end{array}$ \\
\hline
\end{tabular}

\section{b) Identificación de los tipos de Awareness}

TABLA XXXI. IDENTIFICACIÓN DE TIPOS DE AWARENESS - CAMBIOS Y PERMISOS

\begin{tabular}{|l|l|}
\hline Definición & Categoría \\
\hline $\begin{array}{l}\text { "es el encargado de dar los permisos de } \\
\text { edición" }\end{array}$ & $\begin{array}{l}\text { Cambio : Quienes solicitan / tienen } \\
\text { permisos de edición }\end{array}$ \\
\hline
\end{tabular}

c) Tabla de decisión de topologías

La interacción que se realiza en los cambios y permisos involucra a varios desarrolladores, de acuerdo a la descripción de la interacción no se menciona que existe un líder, no se menciona otros rangos intermedios y se menciona que la comunicación pasa únicamente por el líder que es el que asigna los permisos.

TABLA XXXII. DECISIÓN DE TOPOLOGIAS - CAMBIOS Y PERMISOS

\begin{tabular}{|l|l|l|}
\hline \multirow{4}{*}{ Condiciones } & Cantidad de actores & $3+$ \\
\cline { 2 - 3 } & Existe un actor central (Líder) & si \\
\cline { 2 - 3 } & Hay liderazgos intermedios & no \\
\cline { 2 - 3 } & $\begin{array}{l}\text { Existe una comunicación únicamente con el actor } \\
\text { central (líder) }\end{array}$ & si \\
\hline
\end{tabular}

De acuerdo a los resultados de la tabla anterior podemos decir que la topología que corresponde en este tipo de interacción es la de Estrella.

\section{d) Plantilla de los elementos de Awareness}

TABLA XXXIII. Plantilla DE ELEMENTOS DE AWARENESS - CAMBIOS Y PERMISOS

\begin{tabular}{|l|l|}
\hline \multicolumn{2}{|c|}{ Plantilla de Awareness } \\
\hline Id & 2 \\
\hline Modalidad de interacción & Estrella \\
\hline Objeto & Ninguno. \\
\hline Niveles de interacción & Asigna : Nivel de interacción 2 \\
\hline Roles Generales & Rol General B \\
\hline Mensaje de Awareness & Lista de solicitud para permisos de edición \\
\hline Reglas de Awareness & Reglas 1,2 y 5 \\
\hline Tipos de Awareness & Awareness de actividad \\
\hline
\end{tabular}

\section{B. CASO DE VALIDACIÓN: ACTIVIDAD DE APRENDIZAJE JIGSAW}

En esta sección se analiza el caso de validación correspondiente a la actividad de aprendizaje jigsaw en un entorno de sistema colaborativo . En la sección 1 se realiza la descripción del caso y en la sección 2 se desarrolla el modelo de awareness basado en la solución propuesta.

\section{1) Descripción del caso}

Técnicas de evaluación en el aula (CAT) pueden ayudar a los estudiantes en el desarrollo de la solución de problemas y las habilidades de trabajo en grupo. Hay muchos tipos de 
actividades de colaboración que los estudiantes puedan llevar a cabo. Una actividad simple que se puede poner en práctica en una amplia gama de contextos es la actividad de jigsaw (rompecabezas) [53]. Esta es una técnica de aprendizaje cooperativo en el que los estudiantes de forma individual hacer una investigación a un problema propuesto y luego se enseñan unos a otros lo que han aprendido, compartiendo cada punto de vista individual del problema.

Los estudiantes se dividen en grupos pequeños. A cada estudiante se le da una pieza del rompecabezas para aprender o para investigar. Por ejemplo, una asignación de una lectura de varias hojas se puede dividir en partes más pequeñas. Cada estudiante toma un pedazo y se convierte en un experto en ese contenido. Cuando las piezas del rompecabezas se juntan o cuando el grupo llega de nuevo juntos, cada estudiante compartirá lo que él / ella ha aprendido. Hay una gran cantidad de variantes de actividad del rompecabezas. En nuestro caso de estudio, se a utilizara un enfoque de aprendizaje soportado por computación en tiempo real . Cuando esta actividad se lleva a cabo por medio de un sistema de aprendizaje asistido por computador, incluye estos cuatro pasos una vez se han creado los equipos de trabajo:

- Trabajo individual:. En primer lugar, los miembros del grupo tienen que designar a un coordinador para el equipo. Luego, cada miembro del grupo debe seleccionar una pieza del rompecabezas. En este paso cada miembro tiene que hacer la investigación individual para explicar lo que él / ella ha aprendido con el resto del grupo después. Cada estudiante tiene que hacer un informe de trabajo individual que describe lo que él / ella ha descubierto.

- Reunión de expertos: En este paso, los estudiantes con la misma pieza del rompecabezas tienen una "reunión de expertos". En primer lugar, cada grupo de expertos designa a un coordinador. Entonces, cada miembro explica su trabajo individual con el resto del grupo con el fin de mejorar el trabajo de cada miembro. Cada grupo de expertos tiene que hacer un informe de los expertos, de una manera colaborativa.

- Reunión del equipo: Después de la reunión de expertos, los grupos de trabajo se reúnen de nuevo para enseñar a los demás lo que han aprendido y mejorado gracias al conocimiento del otro experto. Al igual que en el paso anterior, tienen que elaborar un informe de manera colaborativa, en este paso el profesor puede enviar información al coordinador acerca de los diferentes temas que exponen los expertos para que complemente lo que cada uno enseña a los demás .

- Evaluar la actividad: El último paso consiste en la evaluación del trabajo individual y colaborativo del estudiante. Para ello, el profesor evalúa al individuo, los expertos y el informe del equipo. Por último, el profesor proporciona retroalimentación a los estudiantes a través de un documento de evaluación que envía al coordinador del equipo.

2) Desarrollo del requerimiento : Trabajo Individual

Trabajo individual:. En primer lugar, los miembros del grupo tienen que designar a un coordinador para el equipo. Luego, cada miembro del grupo debe seleccionar una pieza del rompecabezas. En este paso cada miembro tiene que hacer la investigación individual para explicar lo que él / ella ha aprendido con el resto del grupo después. Cada estudiante tiene que hacer un informe de trabajo individual que describe lo que él / ella ha descubierto.

\section{a) Situación Colaborativa de Awareness}

TABLA XXXIV. Plantilla de Situación Colaborativa - trabajo INDIVIDUAL

\begin{tabular}{|l|l|}
\hline \multicolumn{2}{|c|}{ Plantilla de Situación Colaborativa } \\
\hline Id & 1 \\
\hline Actor (Quien) & Estudiantes \\
\hline Tarea (Donde) & $\begin{array}{l}\text { - Designar un coordinador. } \\
\text { - Seleccionar una parte del trabajo a realizar. } \\
\text { - Desarrollar la investigación de forma individual. } \\
\text { - Realizar un reporte de lo encontrado. }\end{array}$ \\
\hline Información (Que) & $\begin{array}{l}\text { - Información de los miembros del grupo } \\
\text { - Información del coordinador una vez seleccionado. } \\
\text { - Información de las partes del trabajo asignadas / no } \\
\end{array}$ \\
& $\begin{array}{l}\text { asignadas, de haber alguna asignada, mostrar } \\
\text { información del usuario que la tiene asignada }\end{array}$ \\
\hline Aplicabilidad (Cuándo) & Mostrar siempre \\
\hline Interacción (Cómo) & $\begin{array}{l}\text { Los estudiantes seleccionan / votan por un } \\
\text { coordinador, luego los estudiantes escogen una parte } \\
\text { del trabajo a desarrollar }\end{array}$ \\
\hline
\end{tabular}

\section{b) Identificación de los tipos de Awareness}

TABLA XXXV. IDENTIFICACIÓN DE TIPOS DE AWARENESS - TRABAJO INDIVIDUAL

\begin{tabular}{|l|l|}
\hline Definición & Categoría \\
\hline $\begin{array}{l}\text { "Ios miembros del grupo tienen que } \\
\text { designar a un coordinador para el equipo" }\end{array}$ & $\begin{array}{l}\text { Acción : como se va a interactuar. } \\
\text { Habilidades : Que rol va a tomar el } \\
\text { usuario y el resto del grupo. }\end{array}$ \\
\hline $\begin{array}{l}\text { "cada miembro del grupo debe seleccionar } \\
\text { una pieza del rompecabezas" }\end{array}$ & $\begin{array}{l}\text { Intención : Que parte del trabajo } \\
\text { corresponde al usuario. }\end{array}$ \\
\hline
\end{tabular}

\section{c) Tabla de decisión de topologías}

La interacción que se realiza en el desarrollo del trabajo individual involucra a tres estudiantes dado que ese es el numero mínimo de estudiantes que pueden conformar un grupo, de acuerdo a la descripción de las tareas el grupo debe designar un coordinador (Líder), no se menciona de otros rangos intermedios y tampoco se menciona que la comunicación pase únicamente por el líder.

TABLA XXXVI. DECISIÓN DE TOPOLOGIAS - TRABAJO INDIVIDUAL

\begin{tabular}{|l|l|c|}
\hline \multirow{4}{*}{ Condiciones } & Cantidad de actores & $3+$ \\
\cline { 2 - 3 } & Existe un actor central (Líder) & $\mathrm{si}$ \\
\cline { 2 - 3 } & Hay liderazgos intermedios & no \\
\cline { 2 - 3 } & $\begin{array}{l}\text { Existe una comunicación únicamente con el actor central } \\
\text { (líder) }\end{array}$ & no \\
\hline
\end{tabular}

De acuerdo a los resultados de la tabla anterior podemos decir que la topología que corresponde en este tipo de interacción es la de Malla.

\section{d) Plantilla de los elementos de Awareness}

TABLA XXXVII. Plantilla de ELEMENTOS DE AWARENESS TRABAJO INDIVIDUAL

\begin{tabular}{|l|l|}
\hline \multicolumn{2}{|c|}{ Plantilla de Awareness } \\
\hline Id & 1 \\
\hline Modalidad de interacción & Malla \\
\hline Objeto & Ninguno. \\
\hline Niveles de interacción & Desarrollar, Realizar y Seleccionar : Nivel de interacción \\
& 3 \\
\hline Roles Generales & Rol General C \\
\hline Mensaje de Awareness & Lista de miembros del equipo. \\
& Partes de trabajo asignadas / sin asignar \\
\hline Reglas de Awareness & Reglas 1,2,3,4 y 5. \\
\hline Tipos de Awareness & Awareness Social \\
\hline
\end{tabular}

3) Desarrollo del requerimiento : Reunión de Expertos

Reunión de expertos: En este paso, los estudiantes con la misma pieza del rompecabezas tienen una "reunión de 
expertos". En primer lugar, cada grupo de expertos designa a un coordinador. Entonces, cada miembro explica su trabajo individual con el resto del grupo con el fin de mejorar el trabajo de cada miembro. Cada grupo de expertos tiene que hacer un informe de los expertos, de una manera colaborativa.

\section{a) Situación Colaborativa de Awareness}

TABLA XXXVIII. PlantILLA DE SITUACIÓN COLABORATIVA REUNION DE EXPERTOS

\begin{tabular}{|c|c|}
\hline \multicolumn{2}{|c|}{ Plantilla de Situación Colaborativa } \\
\hline Id & 2 \\
\hline Actor (Quien) & Estudiantes \\
\hline Tarea (Donde) & $\begin{array}{l}\text { - Designar un coordinador experto. } \\
\text { - Exponer el trabajo realizado cada } \\
\text { - Reerto. } \\
\text { colizaborativa. }\end{array}$ \\
\hline Información (Que) & $\begin{array}{l}\text { - Información del coordinador una vez } \\
\text { seleccionado. } \\
\text { - Información de la lista de los miembros } \\
\text { - Vel grupo con orden de exposición. } \\
\text { - Ver en donde y que están escribiendo } \\
\text { cada usuario con la identificación de } \\
\text { cada uno asociada. }\end{array}$ \\
\hline Aplicabilidad (Cuándo) & $\begin{array}{l}\text { Mostrar siempre la información del } \\
\text { coordinador y la lista de exposición. } \\
\text { Mostrar la información de los usuarios } \\
\text { solamente cuando están escribiendo en el } \\
\text { reporte }\end{array}$ \\
\hline Interacción (Cómo) & $\begin{array}{l}\text { Los miembros del grupo seleccionan / } \\
\text { votan por un coordinador, el coordinador } \\
\text { da la lista de exposición y el orden, cada } \\
\text { miembro expone a los demás, realizan un } \\
\text { reporte de forma colaborativa }\end{array}$ \\
\hline
\end{tabular}

\section{b) Identificación de los tipos de Awareness}

TABLA XXXIX. IDENTIFICACIÓN DE TIPOS DE AWARENESS - REUNION DE EXPERTOS

\begin{tabular}{|l|l|}
\hline Definición & Categoría \\
\hline "Cada grupo de expertos tiene que hacer & Acción : Que están haciendo los otros \\
un informe de los expertos, de una & expertos para completar la tarea \\
manera colaborativa." & Complemento : Como puedo ayudar a \\
& completar la tarea \\
& Ubicación : Donde están los otros \\
& miembros del grupo \\
\hline "cada miembro explica su trabajo & Conocimiento : Que saben los otros \\
individual con el resto del grupo con el fin & usuarios, que necesitan saber, que \\
de mejorar el trabajo de cada miembro" & aprendieron de mi \\
\hline
\end{tabular}

\section{c) Tabla de decisión de topologías}

La interacción que se realiza en el desarrollo de la reunión de expertos involucra a tres estudiantes dado que ese es el numero mínimo de estudiantes que pueden conformar un grupo, de acuerdo a la descripción de las tareas el grupo debe designar un coordinador (Líder), no se menciona de otros rangos intermedios y tampoco se menciona que la comunicación pase únicamente por el líder.

TABLA XL. DECISIÓN DE TOPOLOGIAS - REUNION DE EXPERTOS

\begin{tabular}{|l|l|c|}
\hline \multirow{4}{*}{ Condiciones } & Cantidad de actores & $3+$ \\
\cline { 2 - 3 } & Existe un actor central (Líder) & $\mathrm{si}$ \\
\cline { 2 - 3 } & Hay liderazgos intermedios & $\mathrm{no}$ \\
\cline { 2 - 3 } & $\begin{array}{l}\text { Existe una comunicación únicamente con el actor central } \\
\text { (líder) }\end{array}$ & $\mathrm{no}$ \\
\hline
\end{tabular}

De acuerdo a los resultados de la tabla anterior podemos decir que la topología que corresponde en este tipo de interacción es la de Malla.

\section{d) Plantilla de los elementos de Awareness}

TABLA XLI. Plantilla de ElEMENTos De AWARENESS -REUNION DE EXPERTOS

\begin{tabular}{|l|l|}
\hline \multicolumn{2}{|l|}{ Plantilla de Awareness } \\
\hline Id & 2 \\
\hline Modalidad de interacción & Malla \\
\hline Objeto & Reporte Colaborativo de Expertos. \\
\hline Niveles de interacción & $\begin{array}{l}\text { Exponer : Nivel de interacción 4 } \\
\text { Desarrollar, Realizar y Seleccionar: Nivel de } \\
\text { interacción 3 }\end{array}$ \\
\hline Roles Generales & Rol General J \\
\hline Mensaje de Awareness & $\begin{array}{l}\text { Lista de miembros del equipo con orden de exposición. } \\
\text { Ver la actividad de los otros expertos en la construcción } \\
\text { del reporte }\end{array}$ \\
\hline Reglas de Awareness & Reglas 1,2,3,4 y 5 \\
\hline Tipos de Awareness & $\begin{array}{l}\text { Awareness de Construcción del conocimiento } \\
\text { compartido }\end{array}$ \\
\hline
\end{tabular}

4) Desarrollo del requerimiento : Reunión de Equipo

Reunión del equipo: : Después de la reunión de expertos, los grupos de trabajo se reúnen de nuevo para enseñar a los demás lo que han aprendido $\mathrm{y}$ mejorado gracias al conocimiento del otro experto. Al igual que en el paso anterior, tienen que elaborar un informe de manera colaborativa, en este paso el profesor puede enviar información al coordinador acerca de los diferentes temas que exponen los expertos para que complemente lo que cada uno enseña a los demás.

\section{a) Situación Colaborativa de Awareness}

TABLA XLII. Plantilla de Situación COlaborativa - REUNION DE EQUIPO

\begin{tabular}{|l|l|}
\hline \multicolumn{2}{|c|}{ Plantilla de Situación Colaborativa } \\
\hline Id & 3 \\
\hline Actor (Quien) & Profesor , Estudiantes \\
\hline Tarea (Donde) & $\begin{array}{l}\text { - Exponer el trabajo realizado cada miembro del grupo. } \\
\text { - Realizar un reporte de forma colaborativa. } \\
\text { - Enviar información complementaria }\end{array}$ \\
\hline Información (Que) & $\begin{array}{l}\text { - Información de la lista de los miembros del grupo con } \\
\text { orden de exposición. }\end{array}$ \\
& $\begin{array}{l}\text { - Ver en donde y que están escribiendo cada usuario con la } \\
\text { identificación de cada uno asociada. }\end{array}$ \\
\hline Aplicabilidad (Cuándo) & $\begin{array}{l}\text { Mostrar siempre la información del coordinador y la lista de } \\
\text { exposición. Mostrar la información de los usuarios solamente } \\
\text { cuando están escribiendo en el reporte }\end{array}$ \\
\hline Interacción (Cómo) & $\begin{array}{l}\text { El coordinador da la lista de exposición y el orden , cada } \\
\text { miembro expone a los demás, realizan un reporte de forma } \\
\text { colaborativa }\end{array}$ \\
\hline
\end{tabular}

\section{b) Identificación de los tipos de Awareness}

TABLA XLIII. IDENTIFICACIÓN DE TIPOS DE AWARENESS - REUNION DE EQUIPO

\begin{tabular}{|l|l|}
\hline \multicolumn{1}{|c|}{ Definición } & \multicolumn{1}{|c|}{ Categoría } \\
\hline $\begin{array}{l}\text { "tienen que elaborar un informe de } \\
\text { manera colaborativa" }\end{array}$ & $\begin{array}{l}\text { Acción : Que están haciendo los otros } \\
\text { miembros del grupo para completar la } \\
\text { tarea } \\
\text { Complemento : Como puedo ayudar a } \\
\text { completar la tarea } \\
\text { Ubicación : Donde están los otros } \\
\text { miembros del grupo }\end{array}$ \\
\hline $\begin{array}{l}\text { "los grupos de trabajo se reúnen de } \\
\text { nuevo para enseñar a los demás lo que } \\
\text { han aprendido y mejorado gracias al } \\
\text { conocimiento del otro experto" }\end{array}$ & $\begin{array}{l}\text { Conocimiento : Que saben los otros } \\
\text { usuarios, que necesitan saber, que } \\
\text { aprendieron de mi }\end{array}$ \\
\hline
\end{tabular}

\section{c) Tabla de decisión de topologías}

La interacción que se realiza en el desarrollo de la reunión de equipo se divide en dos partes, la primera es la exposición 
del conocimiento que cada experto a adquirido a sus demás compañeros de equipo y la segunda parte es la interacción de el profesor con el coordinador al enviar material complementario para las exposiciones, en la primera parte tenemos que involucra a tres estudiantes dado que ese es el numero mínimo de estudiantes que pueden conformar un grupo, de acuerdo las interacciones anteriores el grupo a designado un coordinador, no se menciona de otros rangos intermedios y tampoco se menciona que la comunicación pase únicamente por el líder.

TABLA XLIV. DECISIÓN DE TOPOLOGIAS 1 - REUNION DE EQUIPO

\begin{tabular}{|l|l|c|}
\hline \multirow{4}{*}{ Condiciones } & Cantidad de actores & $3+$ \\
\cline { 2 - 3 } & Existe un actor central (Líder) & $\mathrm{si}$ \\
\cline { 2 - 3 } & Hay liderazgos intermedios & no \\
\cline { 2 - 3 } & $\begin{array}{l}\text { Existe una comunicación únicamente con el actor central } \\
\text { (líder) }\end{array}$ & no \\
\hline
\end{tabular}

De acuerdo a los resultados de la tabla anterior podemos decir que la topología que corresponde en este tipo de interacción es la de Malla.

En la segunda parte tenemos que involucra al profesor y a todos los coordinadores de los equipos no se menciona liderazgos intermedios, y existe un actor central que es el profesor por el cual existe únicamente comunicación a los coordinadores.

TABLA XLV. DECISIÓN DE TOPOLOGIAS 2 - REUNION DE EQUIPO

\begin{tabular}{|l|l|c|}
\hline \multirow{4}{*}{ Condiciones } & Cantidad de actores & $3+$ \\
\cline { 2 - 3 } & Existe un actor central (Líder) & $\mathrm{si}$ \\
\cline { 2 - 3 } & Hay liderazgos intermedios & $\mathrm{no}$ \\
\cline { 2 - 3 } & $\begin{array}{l}\text { Existe una comunicación únicamente con el actor central } \\
\text { (líder) }\end{array}$ & $\mathrm{si}$ \\
\hline
\end{tabular}

De acuerdo a los resultados de la tabla anterior podemos decir que la topología que corresponde en este tipo de interacción es la de Estrella.

Como se puede observar esta interacción se compone de dos partes, una primera que ocurre dentro del grupo de estudiantes que es de tipología malla y una segunda parte que ocurren entre el profesor y los coordinadores de cada grupo que es de tipología estrella, por lo tanto es un interacción que se ajusta a una topología compuesta de Estrella - Malla de comunicación unidireccional dado que el profesor es el único que se comunica con los coordinadores no existe una comunicación de respuesta.

\section{d) Plantilla de los elementos de Awareness}

TABLA XLVI. Plantilla de ElEmentos DE AWARENESS -REUNION DE EQUIPO

\begin{tabular}{|l|l|}
\hline \multicolumn{2}{|l|}{ Plantilla de Awareness } \\
\hline Id & 3 \\
\hline Modalidad de interacción & Estrella-Malla con comunicación unidireccional \\
\hline Objeto & Reporte Colaborativo de Miembros del grupo. \\
\hline Niveles de interacción & $\begin{array}{l}\text { Enviar : Nivel de interacción 1 } \\
\text { Exponer : Nivel de interacción 4 } \\
\text { Desarrollar y Realizar : Nivel de interacción 3 }\end{array}$ \\
\hline Roles Generales & $\begin{array}{l}\text { Rol general A (Topología estrella) } \\
\text { Rol General J (Topología Malla) }\end{array}$ \\
\hline Mensaje de Awareness & $\begin{array}{l}\text { Lista de miembros del equipo con orden de exposición. } \\
\text { Ver la actividad de los otros expertos en la } \\
\text { construcción del reporte }\end{array}$ \\
\hline Reglas de Awareness & Reglas 1,2,3,4 y 5 \\
\hline Tipos de Awareness & $\begin{array}{l}\text { Awareness de Construcción del conocimiento } \\
\text { compartido }\end{array}$ \\
\hline
\end{tabular}

5) Desarrollo del requerimiento : Evaluar la actividad

Evaluar la actividad: El último paso consiste en la evaluación del trabajo individual y colaborativo del estudiante.
Para ello, el profesor evalúa al individuo, los expertos y el informe del equipo. Por último, el profesor proporciona retroalimentación a los estudiantes a través de un documento de evaluación que envía al coordinador del equipo.

\section{a) Situación Colaborativa de Awareness}

TABLA XLVII. Plantilla de Situación Colaborativa - EVAluar ACTIVIDAD

\begin{tabular}{|l|l|}
\hline \multicolumn{2}{|l|}{ Plantilla de Situación Colaborativa } \\
\hline Id & 4 \\
\hline Actor (Quien) & Profesor, Estudiantes \\
\hline Tarea (Donde) & $\begin{array}{l}\text { - Supervisa las actividades de los estudiantes } \\
\text { - Evaluar las actividades de los estudiantes. }\end{array}$ \\
& $\begin{array}{l}\text { - Envía retroalimentación. } \\
\text { - Interactuar con los equipos y los miembros de los } \\
\text { equipos }\end{array}$ \\
\hline Información (Que) & $\begin{array}{l}\text { - Ver la ubicación de los estudiantes } \\
\text { - Ver en que actividades están trabajando los estudiantes } \\
\text { - Hablar con los grupos cuando sea necesario o cuando } \\
\text { ellos lo requieran }\end{array}$ \\
\hline Interacción (Cómo) & $\begin{array}{l}\text { Mostrar siempre la información de cada grupo con sus } \\
\text { correspondientes miembros, con la actividad que cada uno } \\
\text { este desempeñando }\end{array}$ \\
\hline $\begin{array}{l}\text { El profesor supervisa y evalúa constantemente las } \\
\text { actividades de los usuarios, habla con ellos cuando para dar } \\
\text { instrucciones o cuando ellos lo requieran. Recibe los } \\
\text { informes finales en cada etapa y realiza la retroalimentación } \\
\text { respectiva }\end{array}$ \\
\hline
\end{tabular}

\section{b) Identificación de los tipos de Awareness}

TABLA XLVIII. IDENTIFICACIÓN DE TIPOS DE AWARENESS - EVALUAR ACTIVIDAD

\begin{tabular}{|l|l|}
\hline Definición & Categoría \\
\hline "el profesor evalúa al & Acción : Que están los otros miembros del grupo \\
individuo, los expertos y el & Acción anterior : Que han terminado \\
informe del equipo" & $\begin{array}{l}\text { Ubicación : Donde están los miembros del grupo. } \\
\text { Intención : Que es lo siguiente que van hacer. }\end{array}$ \\
\hline
\end{tabular}

\section{c) Tabla de decisión de topologías}

La interacción que se realiza en el desarrollo de la evaluación de la actividad involucra al profesor y a los coordinadores de todos los grupos, la comunicación que se hace de la retroalimentación se envía a al coordinador del equipo que es el actor central del grupo.

TABLA XLIX. Decisión DE TOPOlOgias - EVALUAR ACTIVIDAD

\begin{tabular}{|l|l|l|}
\hline \multirow{4}{*}{ Condiciones } & Cantidad de actores & $3+$ \\
\cline { 2 - 3 } & Existe un actor central (Líder) & $\mathrm{si}$ \\
\cline { 2 - 3 } & Hay liderazgos intermedios & no \\
\cline { 2 - 3 } & $\begin{array}{l}\text { Existe una comunicación únicamente con el actor central } \\
\text { (líder) }\end{array}$ & $\mathrm{si}$ \\
\hline
\end{tabular}

De acuerdo a los resultados de la tabla anterior podemos decir que la topología que corresponde en este tipo de interacción es la de Estrella.

\section{d) Plantilla de los elementos de Awareness}

TABla L. Plantilla de elementos de awareness -EVAluar ACTIVIDAD

\begin{tabular}{|l|l|}
\hline \multicolumn{2}{|c|}{ Plantilla de Awareness } \\
\hline Id & 4 \\
\hline Modalidad de interacción & Estrella \\
\hline Objeto & $\begin{array}{l}\text { Reportes Colaborativo de los grupos. } \\
\text { Informe de Evaluación }\end{array}$ \\
\hline Niveles de interacción & $\begin{array}{l}\text { Evalúa y Supervisa : Nivel de interacción 5 } \\
\text { Envía e Interactúa : Nivel de interacción 1 }\end{array}$ \\
\hline Roles Generales & Rol General M \\
\hline
\end{tabular}




\begin{tabular}{|l|l|}
\hline Mensaje de Awareness & $\begin{array}{l}\text { Lista de participantes con su ubicación y la tarea actual } \\
\text { que están realizando } \\
\text { Estado de tarea (en proceso / finalizada) }\end{array}$ \\
\hline Reglas de Awareness & Reglas 1,2 y 5 \\
\hline Tipos de Awareness & Awareness de Espacio de trabajo \\
\hline
\end{tabular}

\section{CASO DE VALIDACIÓN: TELEMEDICINA}

En esta sección se analiza el caso de validación correspondiente a la actividad de telemedicina en un entorno de sistema colaborativo . En la sección 1 se realiza la descripción del caso y en la sección 2 se desarrolla el modelo de awareness basado en la solución propuesta.

\section{1) Descripción del caso}

Una de las áreas más prometedoras de la innovación es el uso de la tecnología, y en este contexto específicamente el uso de software dentro de servicios de salud, la telemedicina en su núcleo conecta profesionales de la salud o profesionales, pacientes y cuidadores juntos utilizando herramientas de software. Actualmente se frecen alta resolución de imágenes de forma rápida, los registros de los pacientes están disponibles simultáneamente, y las posibilidades de esta tecnología para ser aplicada en el cuidado de la salud se expande exponencialmente. Es útil sobre todo en grandes geografías, con difícil acceso a las comunidades o grupos de atención, donde la atención clínica es escasa y distribuida. Las circunstancias en las que los profesionales de la medicina y los pacientes pueden beneficiarse pueden ser en : facilitar consultas rápidas, superar los retos de la distancia, reducir los viajes innecesarios, acceso a las redes de las clínicas, poder educar y entrenar al personal y a los ciudadanos.

En nuestro caso de estudio, se analizaran tres formas distintas de interacción entre el ámbito interior del personal medico y también entre los profesionales de la salud y los pacientes Cuando esta actividades se llevan a cabo por medio de un sistema de trabajo colaborativo asistido por computador.

- Consulta externa: Para la gente con cuidados a largo plazo o de atención residencial, el viaje al hospital para una revisión ambulatoria puede ser una actividad estresante y perturbadora. Es bien reconocido que algunos los pacientes son ingresados en la atención ambulatoria en las que podría haber sido posible la entrega segura de un buen cuidad y que ellos pudieron haber permanecido en su lugar habitual de residencia. A menudo, la falta de confianza dentro del equipo de atención en la gestión de determinados escenarios clínicos conduce a una persona se ingrese en el hospital; ofreciendo apoyo clínico adecuado del equipo de atención utilizando herramientas de software, algunos de estos ingresos se pueden prevenir. En una atención planificada, el paciente y la enfermera puede asistir a una consulta externa del hospital "Virtualmente", siendo capaz de administrar los pacientes planificados con el acceso a historias clínicas y de imágenes adecuadas, también puede tener acceso a una monitorización de pacientes a distancia que podrían incluir una lectura de varios indicadores recogidos de forma remota y en donde la enfermera puede realizar su interpretación. de esta forma puede existir un dialogo paciente - enfermero ya sea que el paciente quiera resolver alguna duda que tenga respecto a su estado de salud o que el enfermero quiera enviar algunas recomendaciones acerca de su tratamiento, eliminando el inconveniente con el tiempo del viaje.

- Tele Consulta : Es posible la tele consulta gracias a un software que permite a los proveedores de la atención de salud en zonas remotas y carentes de servicios médicos cargar un formulario de consulta de caso incluyendo imágenes digitales, el software envía las consultas a residentes de medicina de acuerdo a la especialidad solicitada, el software permite a los residentes responder los casos con consejos clínicos a través de las herramientas de comunicación que provee el software, si el residente necesita consultar sobre algún caso o tiene alguna pregunta sobre una enfermedad, puede preguntar a algún medico experto a distancia. el residente comparte las imágenes e información de la consulta con el experto y ellos pueden discutir de forma cara a cara por medio de una cámara web y un micrófono. El experto remoto puede dibujar o marcar en las interfaz las imágenes usando el tele puntero para recordarle al residente los segmentos de importancia. la parte que no sea clara en la comunicación oral puede ser ilustrada con mensajes instantáneos.

- Diagnostico colaborativo de imágenes: Un grupo de tres o mas expertos médicos necesitan clasificar y diagnosticar de forma correcta la enfermedad de un paciente, cada uno de los expertos necesita acceso detallado a la información del paciente, adicionalmente imágenes digitales del paciente son usadas para colaborativamente marcar y anotar secciones de la imagen y así todos los expertos puedan compartir sus conocimientos y aprender unos de otros, para poder realizar el diagnostico correctamente.

2) Desarrollo del requerimiento : Consulta Externa

Consulta Externa: En una atención planificada, el paciente y la enfermera puede asistir a una consulta externa del hospital "Virtualmente", siendo capaz de administrar los pacientes planificados con el acceso a historias clínicas y de imágenes adecuadas, también puede tener acceso a una monitorización de pacientes a distancia que podrían incluir una lectura de varios indicadores recogidos de forma remota y en donde la enfermera puede realizar su interpretación. de esta forma puede existir un dialogo paciente - enfermero ya sea que el paciente quiera resolver alguna duda que tenga respecto a su estado de salud o que el enfermero quiera enviar algunas recomendaciones acerca de su tratamiento, eliminando el inconveniente con el tiempo del viaje.

\section{a) Situación Colaborativa de Awareness}

TABLA LI. Plantilla de Situación Colaborativa - CONSUlta EXTERNA

\begin{tabular}{|c|c|}
\hline \multicolumn{2}{|r|}{ Plantilla de Situación Colaborativa } \\
\hline Id & 1 \\
\hline Actor (Quien) & Paciente, Enfermera \\
\hline Tarea (Donde) & $\begin{array}{l}\text { - Consulta información ( historia clínica, imágenes, } \\
\text { indicadores). } \\
\text { - Realiza preguntas } \\
\text { - Responde preguntas. } \\
\text { - Envía indicaciones. }\end{array}$ \\
\hline Información (Que) & - Información del paciente \\
\hline Aplicabilidad (Cuándo) & Mostrar siempre \\
\hline Interacción (Cómo) & $\begin{array}{l}\text { El enfermero consulta la información del paciente y envía } \\
\text { indicaciones, o el paciente realiza alguna pregunta al } \\
\text { enfermero con respecto a su estado de salud }\end{array}$ \\
\hline
\end{tabular}

\section{b) Identificación de los tipos de Awareness}

TABLA LII. IDENTIFICACIÓN DE TIPOS DE AWARENESS - CONSULTA EXTERNA

\begin{tabular}{|l|l|}
\hline Definición & Categoría \\
\hline "acceso a historias clínicas y de imágenes & Acción : Que esta pasando con \\
adecuadas, también puede tener acceso a una & el paciente. \\
monitorización de pacientes a distancia que & Cambios : Que ha cambiado en \\
\hline
\end{tabular}


podrían incluir una lectura de varios indicadores recogidos de forma remota y en donde la enfermera puede realizar su interpretación"

\section{c) Tabla de decisión de topologías}

VI. DECISIÓN DE TOPOLOGIAS -CONSULTA EXTERNA

\begin{tabular}{|l|l|c|}
\hline \multirow{4}{*}{ Condiciones } & Cantidad de actores & 2 \\
\cline { 2 - 3 } & Existe un actor central (Líder) & no \\
\cline { 2 - 3 } & Hay liderazgos intermedios & no \\
\cline { 2 - 3 } & $\begin{array}{l}\text { Existe una comunicación únicamente con el actor } \\
\text { central (líder) }\end{array}$ & no \\
\hline
\end{tabular}

La interacción que se realiza en la consulta externa involucra a dos actores (enfermero, paciente), de acuerdo a la descripción de las no hay un actor centrar, no se menciona de otros rangos intermedios y tampoco se menciona que la comunicación pase únicamente por el líder. De acuerdo a los resultados de la tabla anterior podemos decir que la topología que corresponde en este tipo de interacción es la de Punto a punto.

\section{a) Plantilla de los elementos de Awareness}

TABLA LIII. Plantilla DE ELEMENTOS DE AWARENESS -CONSUlta EXTERNA

\begin{tabular}{|l|l|}
\hline \multicolumn{2}{|c|}{ Plantilla de Awareness } \\
\hline Id & 1 \\
\hline Modalidad de interacción & Punto a punto \\
\hline Objeto & Ninguno. \\
\hline Niveles de interacción & $\begin{array}{l}\text { Consultar, Realizar/Responder preguntas y enviar : } \\
\text { Nivel de interacción 1 }\end{array}$ \\
\hline Roles Generales & Rol General A \\
\hline Mensaje de Awareness & Información del paciente. \\
\hline Reglas de Awareness & Reglas 1,2 y 5. \\
\hline Tipos de Awareness & Awareness Acción \\
\hline
\end{tabular}

\section{2) Desarrollo del requerimiento : Tele Consulta}

Tele Consulta: Es posible la tele consulta gracias a un software que permite a los proveedores de la atención de salud en zonas remotas y carentes de servicios médicos cargar un formulario de consulta de caso incluyendo imágenes digitales, el software envía las consultas a residentes de medicina de acuerdo a la especialidad solicitada, el software permite a los residentes responder los casos con consejos clínicos a través de las herramientas de comunicación que provee el software, si el residente necesita consultar sobre algún caso o tiene alguna pregunta sobre una enfermedad, puede preguntar a algún medico experto a distancia. el residente comparte las imágenes e información de la consulta con el experto y ellos pueden discutir de forma cara a cara por medio de una cámara web y un micrófono. El experto remoto puede dibujar o marcar en las interfaz las imágenes usando el tele puntero para recordarle al residente los segmentos de importancia. la parte que no sea clara en la comunicación oral puede ser ilustrada con mensajes instantáneos.

\section{a) Situación Colaborativa de Awareness}

TABLA LIV. Plantilla dE SITUACIÓN COLABORATIVA TELECONSULTA

\begin{tabular}{|l|l|}
\hline \multicolumn{2}{|c|}{ Plantilla de Situación Colaborativa } \\
\hline Id & 2 \\
\hline Actor (Quien) & $\begin{array}{l}\text { Proveedor de atención de salud, medico residente, medico } \\
\text { experto }\end{array}$ \\
\hline Tarea (Donde) & $\bullet$ Realiza preguntas a residente medico \\
\hline
\end{tabular}

\begin{tabular}{|l|l|}
\hline & $\begin{array}{l}\text { - Responde preguntas al proveedor. } \\
\text { - El proveedor envía consulta con imágenes } \\
\text { - El residente envía Respuesta. } \\
\text { - El residente revisa el caso medico } \\
\text { - El experto realiza observaciones / comentarios } \\
\text { - El residente apropia observaciones / comentarios. }\end{array}$ \\
\hline $\begin{array}{l}\text { Información } \\
\text { (Que) }\end{array}$ & $\begin{array}{l}\text { - Información del caso del paciente, imágenes medicas, } \\
\text { ubicación del medico experto en la interfaz }\end{array}$ \\
\hline $\begin{array}{l}\text { Aplicabilidad } \\
\text { (Cuándo) }\end{array}$ & $\begin{array}{l}\text { Información del caso se debe mostrar siempre, la ubicación del } \\
\text { experto cuando el realiza alguna acción en la interfaz. }\end{array}$ \\
\hline $\begin{array}{l}\text { Interacción } \\
\text { (Cómo) }\end{array}$ & $\begin{array}{l}\text { El proveedor realiza preguntas y envía el caso con imágenes, el } \\
\text { residente puede responder ó realizar alguna consulta a un } \\
\text { experto, y este ultimo realiza las observaciones necesarias , } \\
\text { responde al residente apropiando las observaciones hechas y } \\
\text { finalmente se le puede enviar al proveedor de salud una } \\
\text { respuesta. }\end{array}$ \\
\hline
\end{tabular}

\section{b) Identificación de los tipos de Awareness}

TABLA LV. IDENTIFICACIÓN DE TIPOS DE AWARENESS - TELECONSULTA

\begin{tabular}{|c|c|}
\hline Definición & Categoría \\
\hline $\begin{array}{l}\text { "si el residente necesita consultar } \\
\text { sobre algún caso o tiene alguna } \\
\text { pregunta sobre una enfermedad, } \\
\text { puede preguntar a algún medico } \\
\text { experto a distancia" }\end{array}$ & $\begin{array}{l}\text { Conocimiento : Que mas necesito } \\
\text { saber el residente acerca de este } \\
\text { caso } \\
\text { Acciones : Se necesita revisar alguna } \\
\text { de las ideas actuales en base a } \\
\text { nueva información. }\end{array}$ \\
\hline $\begin{array}{l}\text { "El experto remoto puede dibujar o } \\
\text { marcar en las interfaz las imágenes } \\
\text { usando el tele puntero para recordarle } \\
\text { al residente los segmentos de } \\
\text { importancia" }\end{array}$ & $\begin{array}{l}\text { Acciones : Que esta haciendo el } \\
\text { experto. } \\
\text { Ubicación : Donde esta el experto. }\end{array}$ \\
\hline
\end{tabular}

c) Tabla de decisión de topologías

La interacción que se realiza en la consulta externa involucra a tres actores (Proveedor de atención de salud, medico residente, medico experto), de acuerdo a la descripción de las tareas hay un actor central por el que pasa la comunicación, y existen otros liderazgos.

TABLA LVI. DECISIÓN DE TOPOLOGIAS -TELECONSULTA

\begin{tabular}{|l|l|l|}
\hline \multirow{4}{*}{ Condiciones } & Cantidad de actores & 3 \\
\cline { 2 - 3 } & Existe un actor central (Líder) & $\mathrm{Si}$ \\
\cline { 2 - 3 } & Hay liderazgos intermedios & $\mathrm{Si}$ \\
\cline { 2 - 3 } & $\begin{array}{l}\text { Existe una comunicación únicamente con el actor central } \\
\text { (líder) }\end{array}$ & $\mathrm{Si}$ \\
\hline
\end{tabular}

De acuerdo a los resultados de la tabla anterior podemos decir que la topología que corresponde en este tipo de interacción es la de Lineal.

\section{d) Plantilla de los elementos de Awareness}

TABLA LVII. Plantilla de ELEMENTOS DE AWARENESS TELECONSULTA

\begin{tabular}{|l|l|}
\hline \multicolumn{2}{|c|}{ Plantilla de Awareness } \\
\hline Id & 2 \\
\hline Modalidad de interacción & Lineal \\
\hline Objeto & Información de la consulta, imágenes medicas. \\
\hline Niveles de interacción & $\begin{array}{l}\text { Consultar, Realizar/Responder preguntas, enviar, } \\
\text { revisa, realiza observaciones y apropia : Nivel de } \\
\text { interacción 1 }\end{array}$ \\
\hline Roles Generales & Rol General B \\
\hline Mensaje de Awareness & $\begin{array}{l}\text { Información de la consulta, segmentos marcados de las } \\
\text { imágenes por el experto . }\end{array}$ \\
\hline Reglas de Awareness & Reglas 1,2 y 5. \\
\hline Tipos de Awareness & Awareness de Conceptos, y de espacios de trabajo \\
\hline
\end{tabular}


3) Desarrollo del requerimiento : Diagnostico

Colaborativo de Imágenes

Diagnostico colaborativo de imágenes: Un grupo de tres o mas expertos médicos necesitan clasificar y diagnosticar de forma correcta la enfermedad de un paciente, cada uno de los expertos necesita acceso detallado a la información del paciente, adicionalmente imágenes digitales del paciente son usadas para colaborativamente marcar y anotar secciones de la imagen y así todos los expertos puedan compartir sus conocimientos, expresar sus preguntas o responder a las de los demás colegas a través de herramientas de comunicación y aprender unos de otros, para poder realizar el diagnostico correctamente.

\section{a) Situación Colaborativa de Awareness}

TABLA LVIII. PlantILla DE SITUACIÓN COLABORATIVADIAGNOSTICO COLABORATIVO DE IMAGENES

\begin{tabular}{|l|l|}
\hline \multicolumn{2}{|c|}{ Plantilla de Situación Colaborativa } \\
\hline Id & 3 \\
\hline Actor (Quien) & Expertos médicos \\
\hline Tarea (Donde) & $\begin{array}{l}\text { • Consulta información del paciente } \\
\text { - Realiza preguntas } \\
\text { - Responde preguntas. } \\
\text { - Realiza anotaciones. }\end{array}$ \\
\hline Información (Que) & $\begin{array}{l}\text { • Información de las acciones que los otros expertos } \\
\text { realizan sobre las imágenes digitales }\end{array}$ \\
\hline Aplicabilidad (Cuándo) & Mostrar siempre \\
\hline Interacción (Cómo) & $\begin{array}{l}\text { Los expertos se reunión y realizan anotaciones sobre la } \\
\text { imagen, pueden dialogar en cualquier momento a través } \\
\text { de las herramientas de comunicación. }\end{array}$ \\
\hline
\end{tabular}

\section{b) Identificación de los tipo de Awareness}

TABLA LIX. IDENTIFICACIÓN DE TIPOS DE AWARENESS - DIAGNOSTICO COLABORATIVO DE IMAGENES

\begin{tabular}{|l|l|}
\hline Definición & Categoría \\
\hline "colaborativamente marcar y anotar & Acción : Que están haciendo los \\
secciones de la imagen y asi todos los & otros expertos. \\
expertos puedan compartir sus & Ubicación : Donde están los otros \\
conocimientos" & expertos. \\
\hline
\end{tabular}

\section{c) Tabla de decisión de topologías}

La interacción que se realiza en el diagnostico colaborativo de imágenes involucra 3 o mas médicos expertos, de acuerdo a la descripción de las no hay un actor centrar, no se menciona de otros rangos intermedios y tampoco se menciona que la comunicación pase únicamente por el líder.

TABLA LX. DECISIÓN DE TOPOLOGIAS -DIAGNOSTICO COLABORATIVO DE IMAGENES

\begin{tabular}{|l|l|c|}
\hline \multirow{4}{*}{ Condiciones } & Cantidad de actores & $3+$ \\
\cline { 2 - 3 } & Existe un actor central (Líder) & no \\
\cline { 2 - 3 } & Hay liderazgos intermedios & no \\
\cline { 2 - 3 } & $\begin{array}{l}\text { Existe una comunicación únicamente con el actor } \\
\text { central (líder) }\end{array}$ & no \\
\hline
\end{tabular}

De acuerdo a los resultados de la tabla anterior podemos decir que la topología que corresponde en este tipo de interacción es la de Malla.

\section{d) Plantilla de los elementos de Awareness}

TABLA LXI. Plantilla de ElEmentos de AWARENess -Diagnostico COLABORATIVO DE IMAGENES

\begin{tabular}{|l|l|}
\hline \multicolumn{2}{|l|}{ Plantilla de Awareness } \\
\hline Id & 3 \\
\hline Modalidad de interacción & Malla \\
\hline Objeto & Imágenes medicas. \\
\hline Niveles de interacción & Consultar, Realizar/Responder preguntas y realiza \\
\hline
\end{tabular}

\begin{tabular}{|l|l|}
\hline & anotaciones : Nivel de interacción 1 y 3 \\
\hline Roles Generales & Rol General C \\
\hline Mensaje de Awareness & Información de las acciones de los médicos expertos. \\
\hline Reglas de Awareness & Reglas 1,2,3,4 y 5. \\
\hline Tipos de Awareness & Awareness Espacios de trabajo \\
\hline
\end{tabular}

\section{CONCLUSIONES}

En este Apartado se presentan las aportaciones de este trabajo (sección $A$ ) y se destacan las futuras líneas de investigación que se consideran de interés en base al problema abordado que se presenta en este trabajo de investigación (sección $B)$.

\section{A. Aportaciones de la Investigación}

En este trabajo de investigación se profundizo en el tema de la conciencia del otro en un espacio virtual o Awareness y su relación con los sistemas de trabajo colaborativo. Awareness es un concepto analizado y soportado desde puntos de vista muy diversos. En este trabajo se ha realizado un proceso de análisis que ha permitido a sentar las bases para identificar sus componentes principales, su utilización y la relación que guarda con procesos, como son: la interacción, la comunicación y la colaboración.

Al reafirmar que el Awareness es un aspecto de importancia para los sistemas de trabajo colaborativo, también se ha podido constatar que el soporte del Awareness en el proceso de desarrollo del software está en sus primeras etapas y sólo disponible de forma parcial en algunas metodologías especializadas.

En este contexto, esta investigación ha realizado las siguientes aportaciones:

I. Se han analizado las aportaciones existentes sobre la aplicación, importancia y soporte del Awareness donde se incluye una amplia revisión de distintas definiciones del término awareness desde distintas perspectivas y entornos de uso, también se incluye una recopilación y descripción de varios tipos de awareness encontrados en la literatura técnica. A partir de esto se ha realizado un proceso de síntesis del cual emerge la propuesta que en esta investigación se formula sobre las características de los mecanismos de awareness : Arquitectura Auxiliar, Modo de Awareness, Propagación del Mensaje, Tipos de Aplicación, Tipos de Presentación, Métodos de Presentación. Con base a las características propuestas se formula una taxonomía centrándose en su definición y describiendo que "busca caracterizar" y que "trata de responder" cada tipo de awareness encontrado.

II. Varios modelos (topologías) de interacciones grupales los cuales representan las posibles interacciones básicas que pueden ocurrir dentro de una interacción colaborativa, los siguientes son los modelos propuestos : Punto a punto, Estrella , Malla, Lineal. También se ha propuesto un modelo de interacción compuesto Estrella-Malla, que representa interacciones entre varios grupos de actores. A partir de estos modelos y del análisis de los mecanismos de awareness en distintos entornos de uso encontrados en la literatura técnica, se ha realizado una generalización de los posibles roles relacionados en las diferentes modalidades y a partir de esta generalización se ha propuesto una agrupación de estos en cinco diferentes niveles de interacción, construyendo una relación entre nivel - rol.

III. Propuesta de elementos básicos que son de importancia en el flujo de información de tipo awareness, estos elementos son : objeto, acciones, niveles de interacción, 
rol, actores, mensaje de awareness, grupo. En base a estos elementos se definen cinco reglas de awareness las cuales ayudan a brindar la información de awareness necesaria. Además de esto se realiza una relación entre cada topología propuesta y las reglas de awareness, las cuales indican que tipo de regla aplica en cada una de las topologías.

$I V$. Descripción de una fase de análisis, la cual es aplicable en las situaciones colaborativas que se pueden encontrar en los sistemas de trabajo colaborativo, se han propuesto los siguiente pasos:

a. Describir los elementos de una situación colaborativa de awareness los cuales deben expresar todo lo necesario para saber que información requieren los actores involucrados.

b. Identificar el tipo de awareness, de acuerdo a las características que se encuentren en la descripción colaborativa y se corresponden con las características de los diferentes tipos de awareness.

c. Realizar una tabla de decisión para encontrar la topología que se corresponde a la situación colaborativa, la cual depende de los siguientes criterios: cantidad de actores, la existencia de un actor central, la existencia de liderazgos intermedios y si existe una comunicación únicamente con el actor central.

d. Describir los diferentes elementos que intervienen en la generación de la información de awareness apropiada de acuerdo a cada situación colaborativa.

\section{B. Futuras Líneas de Investigación}

Durante el desarrollo de esta investigación han surgido cuestiones que si bien no son centrales al tema abordado en la misma, han abierto varias posibilidades de trabajo (en opinión del investigador) en lo que respecta al papel del Awareness en los sistemas de trabajo colaborativo, dando lugar a las siguientes líneas de investigación:

- En esta investigación se ha realizado un análisis de los roles encontrados en la literatura revisada, esto ha dado como resultado un conjunto de roles generales que aplican a las topologías de interacción propuestas. En este contexto, se plantea el interés de explorar posibles roles adicionales que se pueden corresponder a estas topologías.

- Si bien en este trabajo de investigación se ha propuesto un topología de interacción compuesta Estrella-Malla la cual se compone de dos topologías básicas Estrella y malla, realizando esa combinación cabe preguntarse:

- ¿Es posible realizar una combinación de todas las topologías básicas, formando nuevas topologías compuestas?

- ¿Es posible validar la combinación de estas nuevas topologías compuestas, existen casos que se correspondan?

- ¿Existen una mayor cantidad de topologías básicas?

- La implementación de awareness en las topologías compuestas se realiza combinando las reglas de las topologías básicas de las cuales se compone, y estas reglas pueden ser aplicables pero tal vez no son optimas para este tipo de topologías compuestas, es por esto que surge el interés de profundizar la investigación en la combinación de estas reglas.

\section{REFERENCIAS}

[1] Palfreyman, K.A., Rodden, T. 1996 .A Protocol for User Awareness on the World Wide Web. In Proc. of the ACM Conference on Computer Supported Cooperative Work CSCW'96. ACM Press, New York, NY, pp. 130- 139.

[2] Gallardo, J., Molina, A. I., Bravo, C., Redondo, M. A. \& Collazos, C. A. 2011. An ontological conceptualization approach for awareness in domain-independent collaborative modeling systems: Application to a model-driven development method. Expert Syst. Appl., 38, 1099-1118.

[3] Gutwin, C. and Greenberg, S. 2004. The importance of Awareness for team cognition in distributed Collaboration. Team cognition Understanding the factors that drive process and performance, 201(2001-696-19):1-33.

[4] Rodríguez, D., García Martínez, R. 2012. Modeling the Interactions in Virtual Spaces Oriented to Collaborative Work. Capítulo 10 en Software Engineering: Methods, Modeling, and Teaching, Volume 2. Pág. 79-84. Sello Editorial de la Pontificia Universidad Católica del Perú. ISBN 978-612-4057-84-7.

[5] Rodriguez, D., Garcia-Martinez, R. 2014. A Proposal of Interaction Modelling Formalisms in Virtual Collaborative Work Spaces. Lecture Notes on Software Engineering, 2(1): 7680. ISSN-2301-3559.

[6] Gutwin, C., Stark, G., \& Greenberg, S. 1995. Support for Workspace Awareness in Educational Groupware. Proceedings Conference on CSCL, pp. 147-156. LEA Press.

[7] Fuchs, L., Pankoke-Babatz, U., Prinz, W. 1995. Supporting Cooperative Awareness with Local Event Mechanisms: The GroupDesk System. Proceedings of the Fourth European Conference on Computer-Supported Cooperative Work, ECSCW'95, pp. 247-262.

[8] Gutwin, C.; Greenberg, S. 2002. A Desriptive Framework of Workspace Awareness for Real- Time Groupware. Computer Supported Cooperative Work: The Journal of Collaborative Computing, 411-446.

[9] Collazos, C., Guerrero, L., Pino, J., Ochoa, S. 2002. Introducing Shared-Knowledge Awareness. International Conference: Information and Knowledge Sharing, pp. 13-18.

[10] Carroll, J., Neale, D., Isenhour, P., Rosson, M., \& McCrickard, S. 2002. Notification and awareness: synchronizing taskoriented collaborative activity. Human-Computer Studies, 605632.

[11] Collazos, C., Builes, J., \& Carranza, D. 2006. Model for supporting awareness in the CSCL ALLEGRO environment through a blackboard architecture. Revista de Ingeniería e Investigación, pp. 67-77.

[12] Ellis, C., Gibbs, S., Rein, G. 1991. Groupware: Some Issues and Experiences. Communication of the ACM, Vol. 34 No. 1.

[13] Endsley, M. R. 1995. Toward a theory of situation awareness in dynamic systems. Human Factors: The Journal of the Human Factors and Ergonomics Society, 37:32-64(33).

[14] Carroll, J. M., Rosson, M. B., Convertino, G., and Ganoe, C. H. 2006. Awareness and teamwork in computer-supported collaborations. Interacting with Computers, 18(1):21-46.

[15] Goodrich, K., Schutte, P., Flemisch, F., and Williams, R. 2006. Application of the h-mode, a design and interaction concept for highly automated vehicles, to aircraft. In 25th Digital Avionics Systems Conference, 2006 IEEE/AIAA, pages 1-13.

[16] Drury, J. L., Riek, L., and Rackliffe, N. 2006. A decomposition of uav-related situation awareness. In Proceedings of the 1st ACM SIG- CHI/SIGART conference on Human-robot interaction, HRI '06, pages 88-94, New York, NY, USA. ACM.

[17] Endsley, M. R., Bolstad, C. A., Jones, D. G., and Riley, J. M. 2003. Situation awareness oriented design: From user's cognitive requirements to creating effective supporting technologies. In Proceedings of the Human Factors and 
Ergonomics Society Annual Meeting, volume 47, pages 268272.

[18] Matheus, C., Kokar, M., and Baclawski, K. 2003. A core ontology for situation awareness. In Information Fusion, 2003. Proceedings of the Sixth International Conference of, volume 1, pages $545-552$.

[19] Baumgartner, N., Gottesheim, W., Mitsch, S., Rets-chitzegger, W., and Schwinger, W. 2010. Beaware situation awareness, the ontology-driven way. Data \& Knowledge Engineering, 69(11): 1181-1193.

[20] Dourish, P. and Bellotti, V. 1992. Awareness and coordination in shared workspaces. In Proceedings of the 1992 ACM conference on Computer-supported cooperative work, CSCW '92, pages 107-114, New York, NY, USA. ACM.

[21] Dourish, P. and Bly, S. 1992. Portholes: supporting awareness in a distributed work group. In Proceedings of the SIGCHI conference on Human factors in computing systems, CHI '92, pages 541-547, New York, NY, USA. ACM.

[22] Roseman, M. and Greenberg, S. 1996. Building real-time groupware with groupkit, a groupware toolkit. ACM Trans. Comput.-Hum. Interact., 3(1):66-106.

[23] Hill, J. and Gutwin, C. 2004. The maui toolkit: Groupware widgets for group awareness. Computer Supported Cooperative Work (CSCW), 13:539-571. 10.1007/s10606-004-5063-7.

[24] Gutwin, C., Greenberg, S., Blum, R., Dyck, J., Tee, K., and Mcewan, G. 2008. Supporting informal collaboration in sharedworkspace groupware. Journal of Universal Computer Science, 14(9):1411-1434.

[25] Dourish, P., Adler, A., Bellotti, V., Henderson, A., 1996. Your place or mine? learning from long- term use of audio-video communication. Computer-Supported Cooperative Work 5 (1), 33-62.

[26] Viegas, F.B., Donath, J.S., 1999. Chat circles. Proceedings of the CHI '99 Conference on Human Factors in Computing Systems. ACM, New York, pp. 9-16.

[27] Erickson, T., Smith, D.N., Kellogg, W.A., Laff, M.R., Richards, J.T., Bradner, E., 1999. Socially translucent systems: social proxies, persistent conversation, and the design of Babble. In: Proceedings of CHI'99, Pittsburgh, PA.

[28] Greenberg, S., 1996. Peepholes: low cost awareness of one's community. Conference Companion of CHI 1996, pp. 206-207.

[29] Cadiz, J.J., Venolia, G.D., Jancke, G., Gupta, A., 2001. Sideshow: providing peripheral awareness of important information. Microsoft Research Technical Report MSR-TR2001-83, September 2001.

[30] Tang, J., Yankelovich, N., Begole, J., Van Kleek, M., Li, F., Bhalodia, J., 2001. ConNexus to awarenex: extending awareness to mobile users. Proceedings of the CHI 2001, Seattle, WA, March 31-April 5, 2001.

[31] Buxton, W.A.S., Sellen, A.J., Sheasby, M.C., 1997. Interfaces for multiparty video conferences. In: Finn, K.E., Sellen, A.J., Wilbur, S.B. (Eds.), Video-Mediated Communication. Lawrence Erlbaum Associates, Mahwah, NJ, pp. 385-400.

[32] Neuwirth, C.M., Morris, J.H., Regli, S.H., Chandhok, R., Wenger, G.C. 1998. Envisioning communication: task-tailorable representations of communication in asynchronous work. In: Proceedings of the ACM CSCW' 98 Conference on Computer Supported Cooperative Work. Association for Computing Machinery, New York, pp. 265-274.

[33] Begole, J., Rosson, M.B., Shaffer, C.A., 1999. Flexible collaboration transparency: supporting worker independence in replicated application-sharing systems. ACM Transactions on Computer-Human Interaction 6 (2), 95-132.

[34] Ogata, H., Matsuura, K., and Yano, Y. 1996. Knowledge awareness: Bridging between shared knowledge and collaboration in sharlok. In Proc. Of Ed-Media 1996.
[35] Collazos, C., Guerrero, L., and Pino, J. 2003. Knowledge construction awareness. Journal of Student Centered Learning, 1(2):76-86.

[36] Yang, S.J.H. 2006. Context aware ubiquitous learning environments for peer to peer collaborative learning. Journal of Educational Technology \& Society, 9(1):188-201.

[37] Yong, L. T. 2009. Collaborative awareness for translation groupware. In Procs. Of the International Conference on Information and Multi- media Technology, ICIMT 2009, pages 47-51.

[38] Yamamoto, Y., Kashihara, A., Kawagishi, K., and Tsu- kamoto, N. 1989. A tool for construction of personal database: Trias. In The Trans. of IPSJ, volume 30, pages 733-742.

[39] Farooq, U., Carroll, J. M., and Ganoe, C. H. 2007. Supporting creativity with awareness in distributed collaboration. In Proceedings of the 2007 international ACM conference on Supporting group work, GROUP '07, pages 31-40, New York, NY, USA. ACM.

[40] Garrido, J. L., Gea, M., Padilla, N., Cañas, J. J., and Waern, Y. 2002. Amenities: Modelado de entornos cooperativos. In Actas del III Congreso Internacional de Interacción PersonaOrdenador 2002, pages 97-104, Madrid, España, Mayo 2002.

[41] Penichet, V. M., Lozano, M. D., Gallud, J. A., and Tesoriero, R. 2010. Requirement-based approach for groupware environments design. Journal of Systems and Software, 83(8):1478 - 1488.

[42] Molina, A. I., Redondo, M. A., and Ortega, M. 2009. A methodological approach for user interface development of collaborative applications: A case study. Science of Computer Programming, 74(9): 754 - 776.

[43] Group, O. M. 2001. Unified modelling language specification.

[44] Jensen, K. 1996. Coloured Petri Nets - Basic Concepts, Analysis Methods and Practical Use. Springer, 2nd edition.

[45] Penichet, V. M., Lozano, M. D., Gallud, J. A., and Tesoriero, R. 2009. User interface analysis for groupware applications in the touche process model. Advances in Engineering Software, 40(12):1212 - 1222. Designing, modelling and implementing interactive systems.

[46] Dillenbourg, P., Baker, M., Blaye, A., and O’ Malley, C. 1996. The evolution of research on collaborative learning. In Spada, E. and Reiman, P., editors, Learning in Humans and Machine: Towards an interdisciplinary learning science., pages 189-211. Oxford: Elsevier.

[47] Molina, A. I., Redondo, M. A., Ortega, M., and Hoppe, U. 2008. Ciam: A methodology for the development of groupware user interfaces. Journal of Universal Computer Science, 14(9):14351446.

[48] Rodríguez, D., Bertone, R., García-Martínez, R. 2010. Collaborative Research Training Based on Virtual Spaces. En Key Competencies in the Knowledge Society (Eds. Reynolds, N. \& Turcsányi-Szabó, M.). IFIP Advances in Information and Communication Technology, 324: 344-353. ISBN 978-3-64215377-8.

[49] Herrera, A., Rodríguez, D., García-Martínez, R. 2013. Taxonomía de Mecanismos de Awareness. Actas del XI Workshop de Tecnología Informática Aplicada en Educación. Proceedings XIX Congreso Argentino de Ciencias de la Computación. Pag. 651-660. ISBN 978-987-23963-1-2.

[50] Marcos-García, J. 2012. Análisis de interacciones para la detección dinámica y el soporte de roles participativos en entornos CSCL aplicando técnicas basadas en SNA. Tesis Doctoral en Ingeniería Informática. Escuela Técnica Superior de Ingeniería Informática. Universidad de Valladolid.

[51] Rodríguez, D., Charczuk, N., García-Martínez, R. 2013. Investigación en Progreso: Espacios Virtuales para Trabajo Colaborativo. Revista Latinoamericana de Ingeniería de Software, 1: 28-33, ISSN 2314-2642. 
[52] Rodríguez, D., García-Martínez, R. 2013. Elementos de Análisis y Diseño para Espacios Virtuales para la Formación de Investigadores. Revista Latinoamericana de Ingeniería de Software, 1(2): 45-56, ISSN 2314-2642.

[53] Aronson, E., \& Patnoe, S. 1997. The jigsaw classroom: Building cooperation in the classroom (2nd ed.). New York: Addison Wesley Longman.

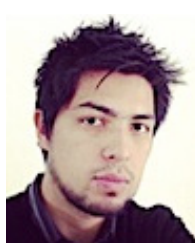

Alexander Herrera. Ingeniero de Sistemas por la Universidad San Martin, Bogotá - Colombia. Es Candidato del Programa de Magister en Ingeniería de Sistemas de Información de UTN-FRBA. Es Investigador Tesista del Laboratorio de Investigación y Desarrollo en Espacios Virtuales de Trabajo del Grupo de Investigación en Sistemas de Información de la Universidad Nacional de Lanus. 